\title{
The Readability and Usability of Building User Guides
}

Michael Anderson, BBSc

March, 2013 



\section{Acknowledgements}

I would like to thank my Supervisor, Prof. George Baird for his continued support, feedback, guidance and patience.

I would like to thank BRANZ who provided financial assistance for this project.

Finally I would like to thank my friends and family for helping make this research possible. A special thanks to Yasmin Merwood, Nicola Anderson, Philippa Anderson and my parents Kevin and Sue Anderson for the constant support and encouragement

Anderson and my parents Kevin and Sue Anderson for the constant support and encouragement. 
The Readability and Usability of Building User Guides

Acknowledgements 


\section{Preface}

This thesis was submitted as part of the requirements for a Master of Building Science degree at the School of Architecture, Victoria University Wellington

Author: Michael Anderson

School of Architecture

Victoria University of Wellington

Email: andersmich3@gmail.com
Supervisor: George Baird

Professor of Building Science

Victoria University of Wellington

Email: George.Baird@vuw.ac.nz 
The Readability and Usability of Building User Guides

Preface 
Abstract

\section{Abstract}

Building user guides are intended to inform building occupants about the building systems within their workplace. They are created to describe and document all the necessary information pertaining to the buildings operation, maintenance, management and basic trouble shooting procedures. They have been found to be useful, as building systems are becoming increasingly complex. There is evidence to suggest that the Building User Guides are designed at a level that is too technical and too difficult to use for the average building user and that they are therefore not doing their job.

This research evaluates how easily building occupants are able to read and use building user guides, that have been designed for use in green buildings (where they can contribute to the building's New Zealand Green Building Council's sustainability rating).

Twenty-three Building User Guides by a range of firms and writers were sampled from all over the country. The building user guides were assessed for their readability and how easy they are to use. Their readability level was assessed using the Simple Measure of Gobbledegook (SMOG) as a basic measure of readability, while a second measure, a word frequency profiler was used to assess the vocabulary needed to read current building user guides. A usability study was completed through a user survey. This was completed by 47 respondents. The survey used both a Performance Test and a Text Evaluation Questionnaire to assess the building user guide's usability.

The readability study found that the building user guides were written at a level that meant the majority of New Zealanders would struggle to comprehend. The constant use of technical language and jargon present in the building user guides detracted from the overall readability of the document that. A consequence of these results would be the users failing to understand aspects of a building user guides. Furthermore, this could lead to the incorrect use of a building's services, 
Abstract

which in turn could affect the efficient use of GreenStar rated buildings and their performance in practice.

The usability study found that users were capable of finding some set information within the building user guide. Of the tested aspects in the usability survey it was found that the contents page had the biggest impact on the participant's perception of usability. Other key aspects found that would increase the usability include: bolder headings, a clearer layout, the addition of a frequently asked question section as well as the ability for the building user guide to be searched for key words.

A set of guidelines were developed from the findings of this research, for future building user guides to follow. 
The Readability and Usability of Building User Guides

Abstract 


\section{Table of Contents}

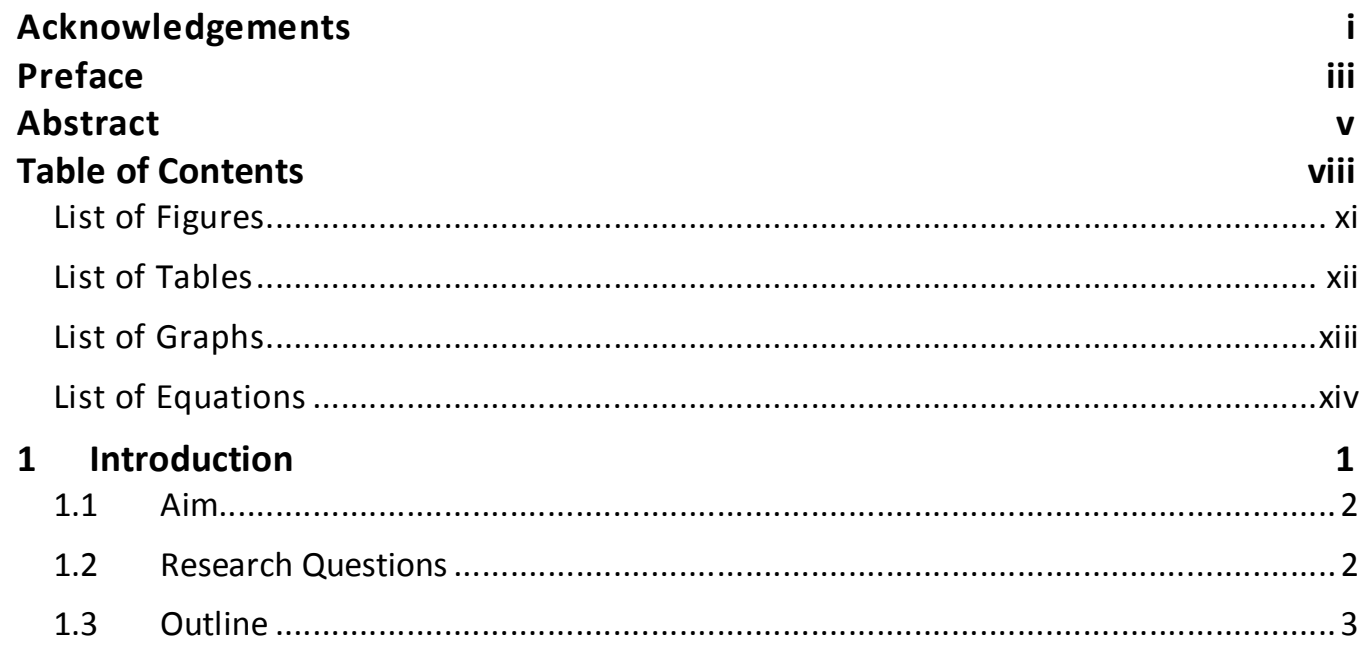

2 Literature Review 4

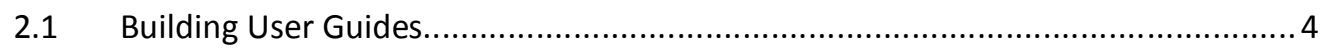

2.1.1 Definition of Building User Guides..........................................................

2.1.2 Why Building User Guides are Important ................................................6

2.1.3 Studies of Building User Guides ............................................................

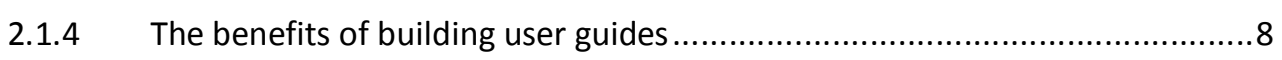

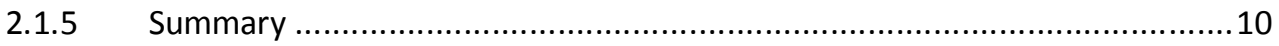

$2.2 \quad$ NZGBC requirements of a building user guide ................................................ 11

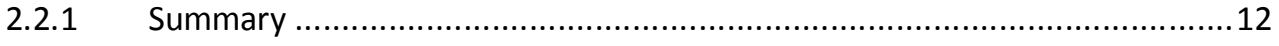

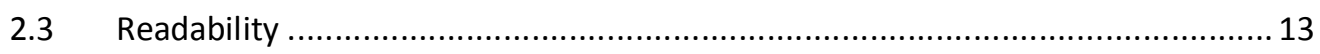

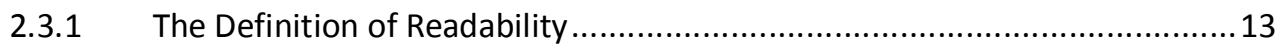

2.3.2 History of Readability ........................................................................ 14

2.3.3 The History of Quantifying Readability ....................................................14

2.3.4 Readability Formulae - Applicability and Limitations................................17

2.3.5 The use of Readability Formulae ..............................................................19

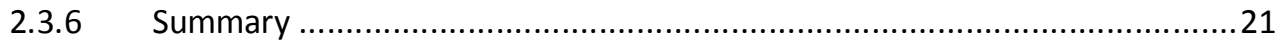

2.4 Current Standard of New Zealand Adult Literacy Levels ................................... 22

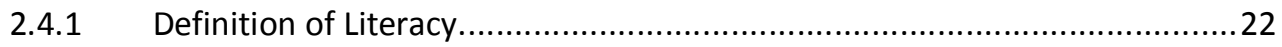

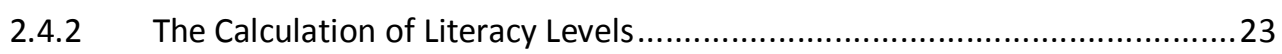

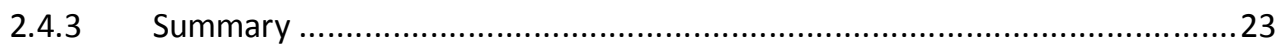

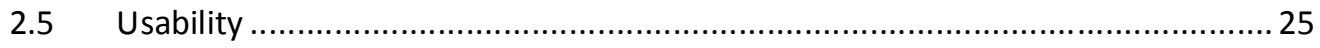

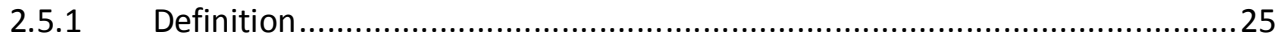

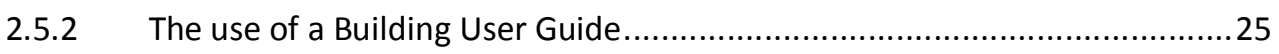

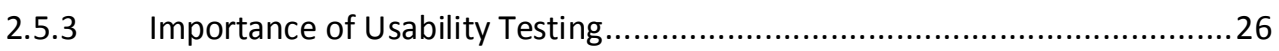




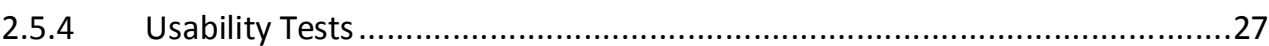

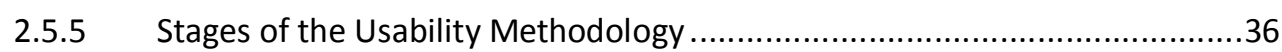

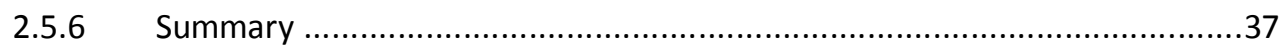

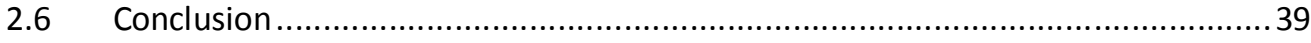

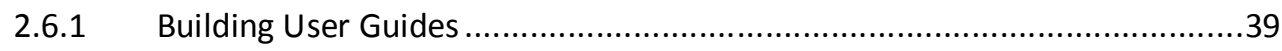

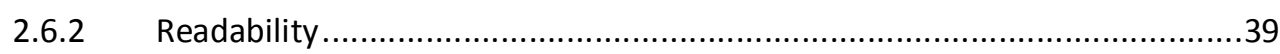

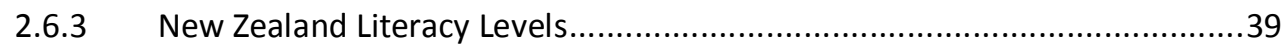

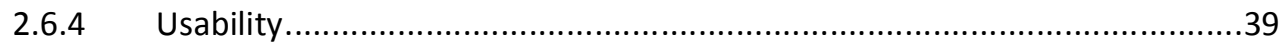

3 Readability Analysis $\quad \mathbf{4 0}$

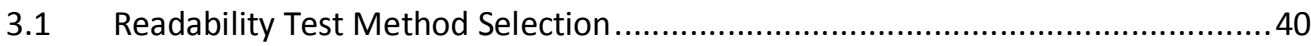

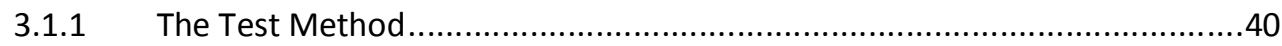

3.1.2 Sherman's type of Readability Assessment................................................40

3.1.3 Thorndike's type of Readability Assessment ...............................................48

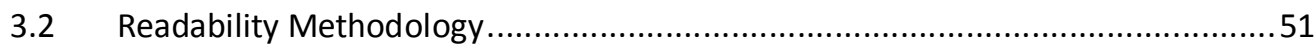

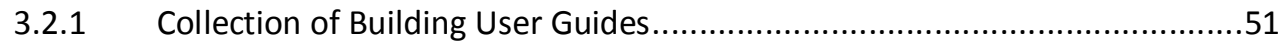

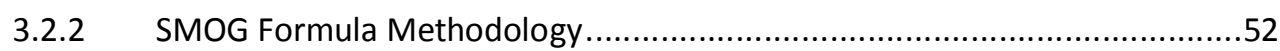

3.2.3 Assessing the Text Using the Word Frequency Profiler ...............................58

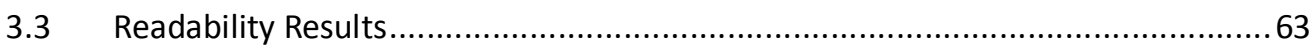

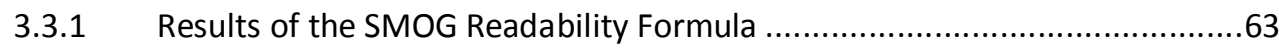

3.3.2 Results of the Word Frequency Profiler ....................................................67

3.3.3 Comparison Between the two Assessments ............................................68

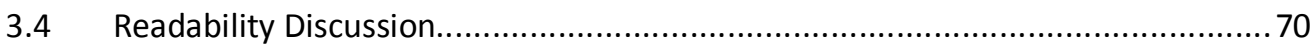

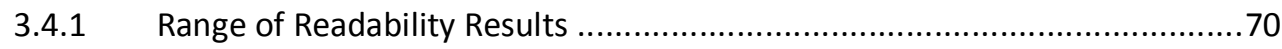

3.4.2 Comparison with New Zealand Literacy levels ...........................................71

3.4.3 Comparison of the SMOG results and the Word Frequency Profiler results .72

3.4.4 Aspects affecting the results of the Assessments.......................................73

3.4.5 Best Readability Assessment Method ..................................................74

4 Usability Analysis $\quad \mathbf{7 6}$

4.1 Usability Assessment Method Selection ........................................................... 76

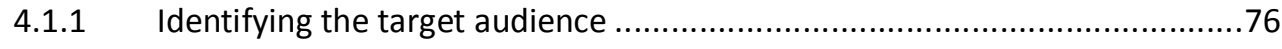

4.1.2 The use of Building User Guides by the target audience .............................77

4.1.3 de Jong and Schellens Overview of Methods ............................................77

4.1.4 Results of de Jong and Schellens' Methodology.........................................82

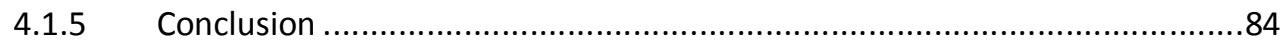

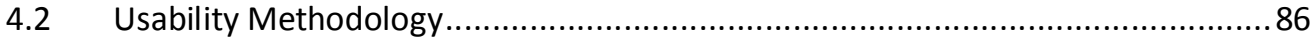

4.2.1 The Building User Guides that will be assessed .........................................86

4.2.2 Assessing the Building User Guides using a survey....................................87 


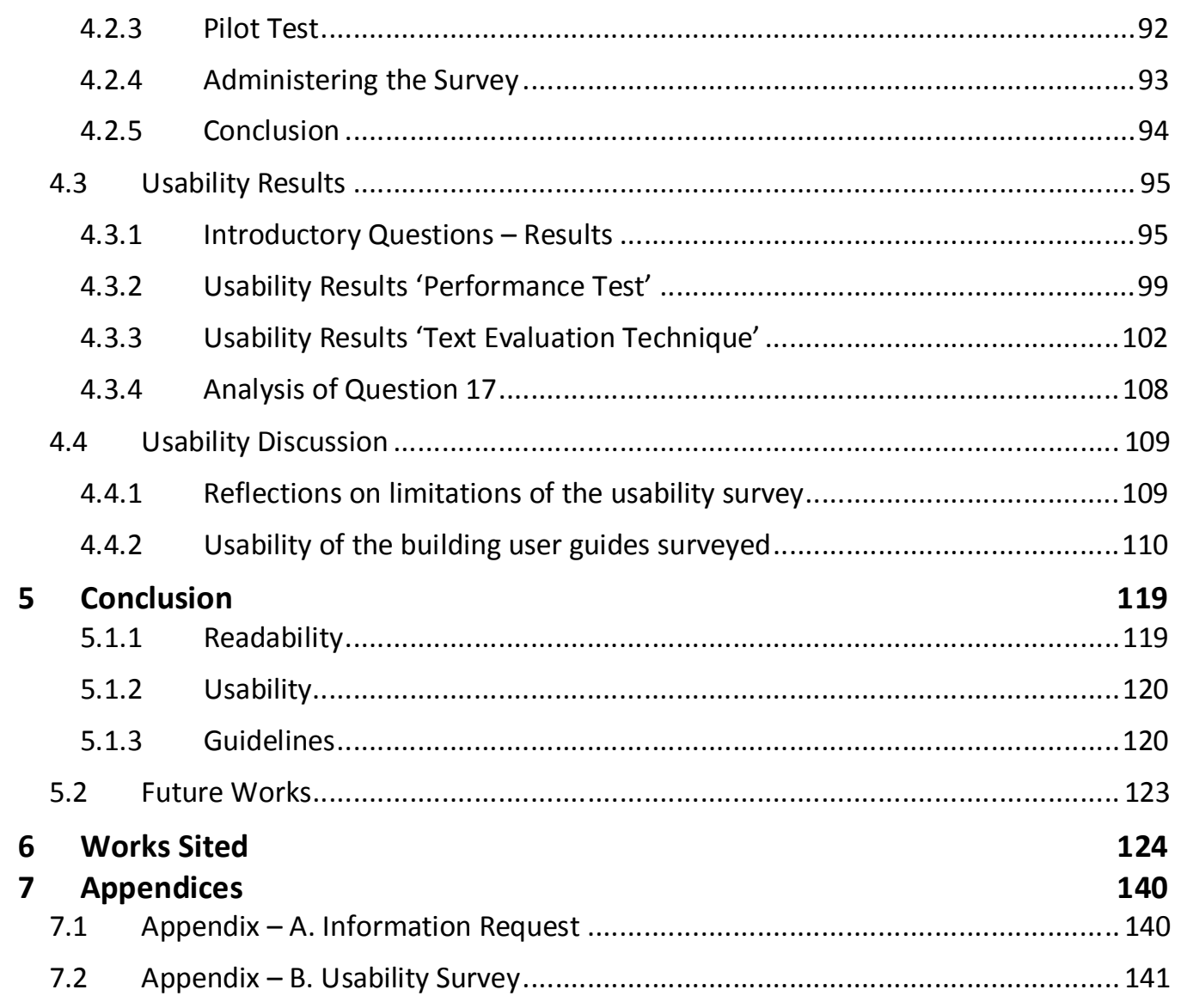




\section{List of Figures}

Figure 1 Relational structure of building documents (J. Harris et al., 2011) ..........................5

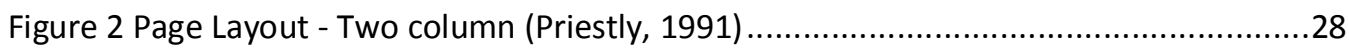

Figure 3 Usability Framework (figure directly copied)(ISO, 1998, p. 3) .............................32

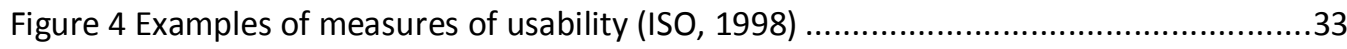

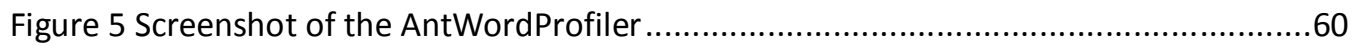

Figure 6 Example of results from AntWordProfiler .......................................................61

Figure 7 Example of the table of contents in BUG 1....................................................111

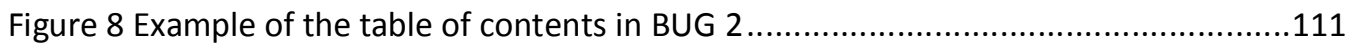

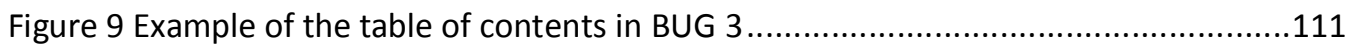

Figure 10 the example of the FAQ section in BUG 1..................................................117

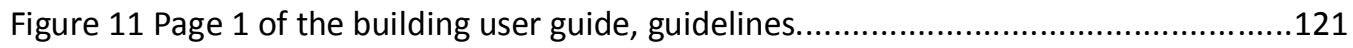

Figure 12 Page 2 of the building user guide, guidelines.................................................122 


\section{List of Tables}

\section{List of Tables}

Table 1 Information required for a Building User Guide (taken from the Green Star Technical

Manual) (New Zealand Green Building Council, 2009) .....................................................12

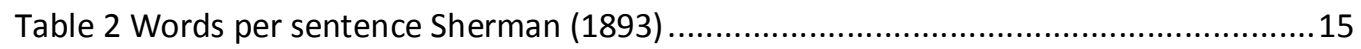

Table 3 Variables that affect readability - taken from (McLaughlin, 1968) ..........................18

Table 4 Overview of Methods in Relation to Functions and Topics ......................................36

Table 5 Range of results of the SMOG Assessment ...........................................................63

Table 6 Explanation of scores given in the usability evaluation method...............................78

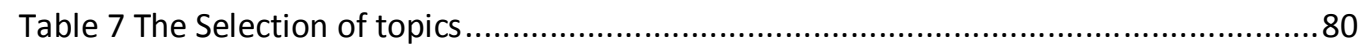

Table 8 the topic's required to be evaluated by the usability assessment ........................... 81

Table 9 Proposed evaluation method compared to the usability evaluation methods .........83

Table 10 Questions and answers for question set one - January to April.............................89

Table 11 Questions and answers for question set two - May to August ..............................89

Table 12 Questions and answers for question set three - September to December .............90

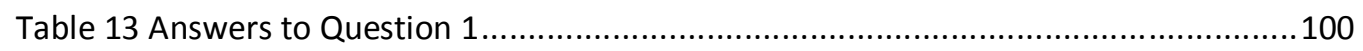

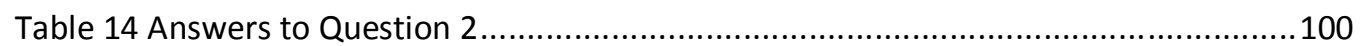

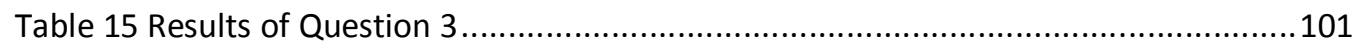


List of Graphs

\section{List of Graphs}

Graph 1 Number of Readability Formulae found in the collected Journal Articles ...............42

Graph 2 Fry's Readability Graph (ReadabilityFormulas.com, 2013) .....................................47

Graph 3 shows the total number of words used and total number of pages of each of the 23

collected Building User Guides (Sorted by total amount of words) ...................................52

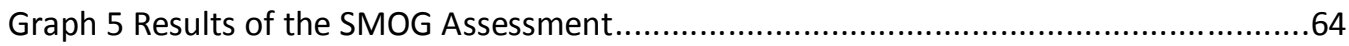

Graph 4 Average SMOG assessment scores across all BUGs ...........................................64

Graph 6 SMOG equation compared to NZ Adult Literacy..............................................65

Graph 7 Percentage of times Sentence Group 1 appears, as first, in the top 5 and in the top

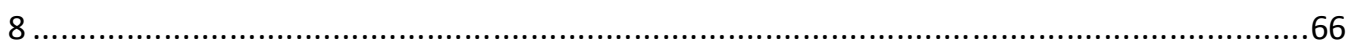

Graph 8 Vocabulary size needed to comprehend $98 \%$ of the words in the text...................67

Graph 9 Percentage of words in each of Nation's 25, $1 \mathrm{~K}$ lists across all building user guides.

Graph 10 SMOG Grade Level compared with Vocabulary Size .......................................69

Graph 11 Percentage of Male and Female Survey Respondents, overall and across the three

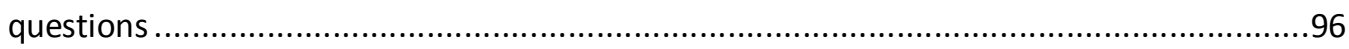

Graph 12 Percentage of the different age groups, overall and across the three questions..96

Graph 13 Percentage of participants that have used a building user guide, overall ............96

Graph 14 Percentage of participants who answered either question 1, 2 or 3 ...................97

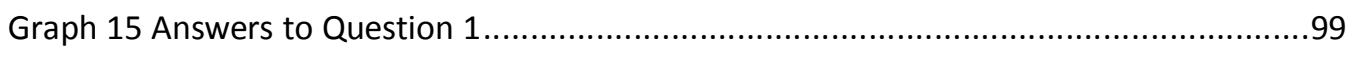

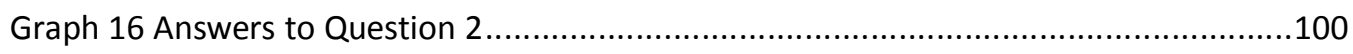

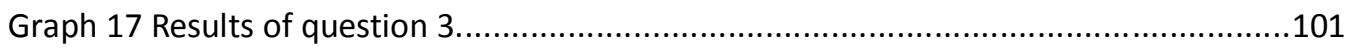

Graph 18 Percentage Ranking of the BUG's based on the different Questions, and Overall

Graph 19 Percentage of Aspects chosen as being Helpful in terms of usability by Respondents 108 


\section{List of Equations}

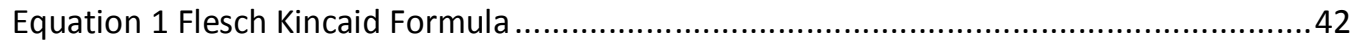

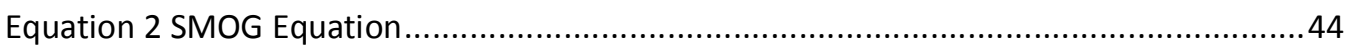

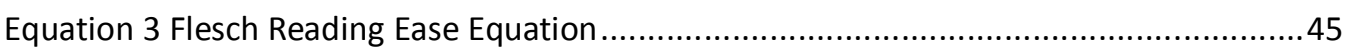

Equation 4 SMOG formula using a selection of 30 sentences...........................................55

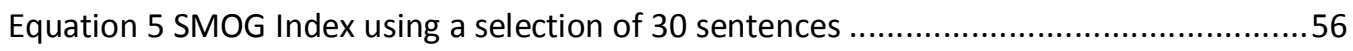

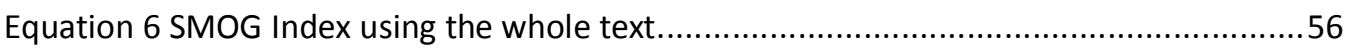

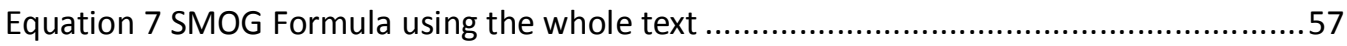


Introduction

\section{Introduction}

With the introduction of sustainable services, green buildings are becoming too technical and complex (Bond, 2010). Building user guides are created to inform building occupants how to use these green features to ensure a building is operating at its full potential (Department of the Environment and Water Resources, 2007). They are created to describe and document all the necessary information pertaining to a building, including its operation, maintenance, management and basic troubleshooting procedures (Baharuddin et al., 2011).

A building user guide is aimed at management personnel, building occupants and tenant representatives, and is expected to provide details regarding the everyday operation of a building and its systems (New Zealand Green Building Council, 2008). However, despite a building user guide being required to achieve points in the New Zealand GreenStar rating scheme, there is limited literature on how to present and write an appropriate guide. Research has found that building user guides may be "too technical and too difficult" (Monfared \& Sharples, 2011, p. 350) for users to read and use.

A number of studies have found aspects of user guides such as; readability, usability, content and distribution, can affect their success (Allwood \& Kalén, 1997; Bevan \& Macloud, 1994; Cuomo \& Bowen, 1994; Haneef, 1998). This study focuses on two aspects, readability and usability. Studies have found that user guides often exceed the reading capacity of the target population resulting in poor comprehension of the services and sustainability features of buildings (Schriver, 2000; Shaw, 1989; Wegner \& Girasek, 2003). A number of studies have also addressed the need for usability testing within user guides. However, information regarding usability problems within the building service sector is scattered (Karjalainen \& Koistinen, 2007; Molich \& Dumas, 2008). 
Introduction

\subsection{Aim}

This research will focus specifically on building user guides created for the New Zealand Green Building Council (NZGBC) GreenStar rating scheme, and will assess their readability and usability. Where readability is the ease in which a reader can comprehend the text of a document and usability is the ease in which the user can operate the manual. The aim of this research is to investigate if current building user guides are able to be read and understood by building occupants and the results will recommend guidelines for improving a building user guide's readability and usability.

The readability assessment will compare the building user guides to the literacy level of the occupants in a building. It will also investigate the most appropriate readability assessment tool to use.

The usability assessment will assess the building user guides against building occupants requirements and investigate whether the building occupants can effectively use building user guides. Furthermore the specific aspects of a building user guide that influence their use will be explored.

The conclusion of this thesis will be a set of guidelines for new building user guides to follow.

\subsection{Research Questions}

To answer the two main research questions, they have been split up into several sub-questions.

What is the readability level of building user guides?

- What is the range of readability scores of the current building user guides created for buildings that are a part of the New Zealand Green Building Council's GreenStar Accreditation scheme?

- How do the scores compare to the literacy levels of New Zealand's general public?

- What readability assessment method is the best to use with building user guides? 
Introduction

- Why do some building user's guides score better than others?

What is the usability level of building user guides?

- Are the building user guides able to be used by building occupants?

- What made the building user guides easy to use?

- What made the building user guides harder to use?

\subsection{Outline}

This thesis begins with an overview and definition of building user guides, readability, literacy and usability. Various methods of assessing both the readability and usability of building user guides are documented (see Chapter 2).

A selection of readability assessment tools was explored, a suitable test method is established, and its process documented (see Section 3.1 and 3.2).

The readability assessment was completed and the results were used to evaluate the building user guides readability level (see Section 3.3).

The readability results were then analysed (see Section 3.4).

The most appropriate usability assessment tool is selected and a suitable test method was established (see Section 4.1 and 4.2).

A usability appropriate survey has been created and distributed among building occupants. The results have been used to evaluate the usability of building user guides (see Section 4.3).

The usability results were then analysed (see Section 4.4)

Finally both the readability and usability conclusions were stated and a set of guidelines were created (see Chapter 5). 


\section{Literature Review}

This literature review will provide insights into all the major aspects of this thesis. The literature review will be split into five different sections. This will provide the basis for the assessment of both the readability and usability of building user guides.

1. Building User Guides - this section will investigate why a building user guide is important to have in a building

2. Requirements of a GreenStar Building User Guide - this section will describe the required aspects of a building user guide to gain the credits available under the New Zealand Green Building Council's GreenStar Programme

3. Readability - this section will provide a definition of readability and how the readability of text can be calculated

4. New Zealand Literacy Levels - this section will investigate the literacy level of the average New Zealander, which is important as it will determine what the readability level of building user guides should be

5. Usability - this section will provide a definition of usability and the process of selecting and using a usability test to assess a document

\subsection{Building User Guides}

This section of the literature review will introduce the building user guide; give its definition and outline where a building user guide fits into building documents. Furthermore, it will state why building user guides are important and how they can affect the occupants within a building.

\subsubsection{Definition of Building User Guides}

Harris, Wilson and Deramchi $(2011$, p. 6) state that "A building user guide will support efforts to operate a building efficiently by ensuring the building design intent is understood and helping the occupants use the building in the most efficient way". They also propose as part of the relational structure of building documents, building user guide sit at the bottom of the hierarchy (see Figure 1). This does not mean it is the least important of building documents, but demonstrates that it is the first port of call for any problems or information pertaining to a building's operation. The location of the building user guide in the 
hierarchy illustrates that it is for everyday use and for any problems found in a building.

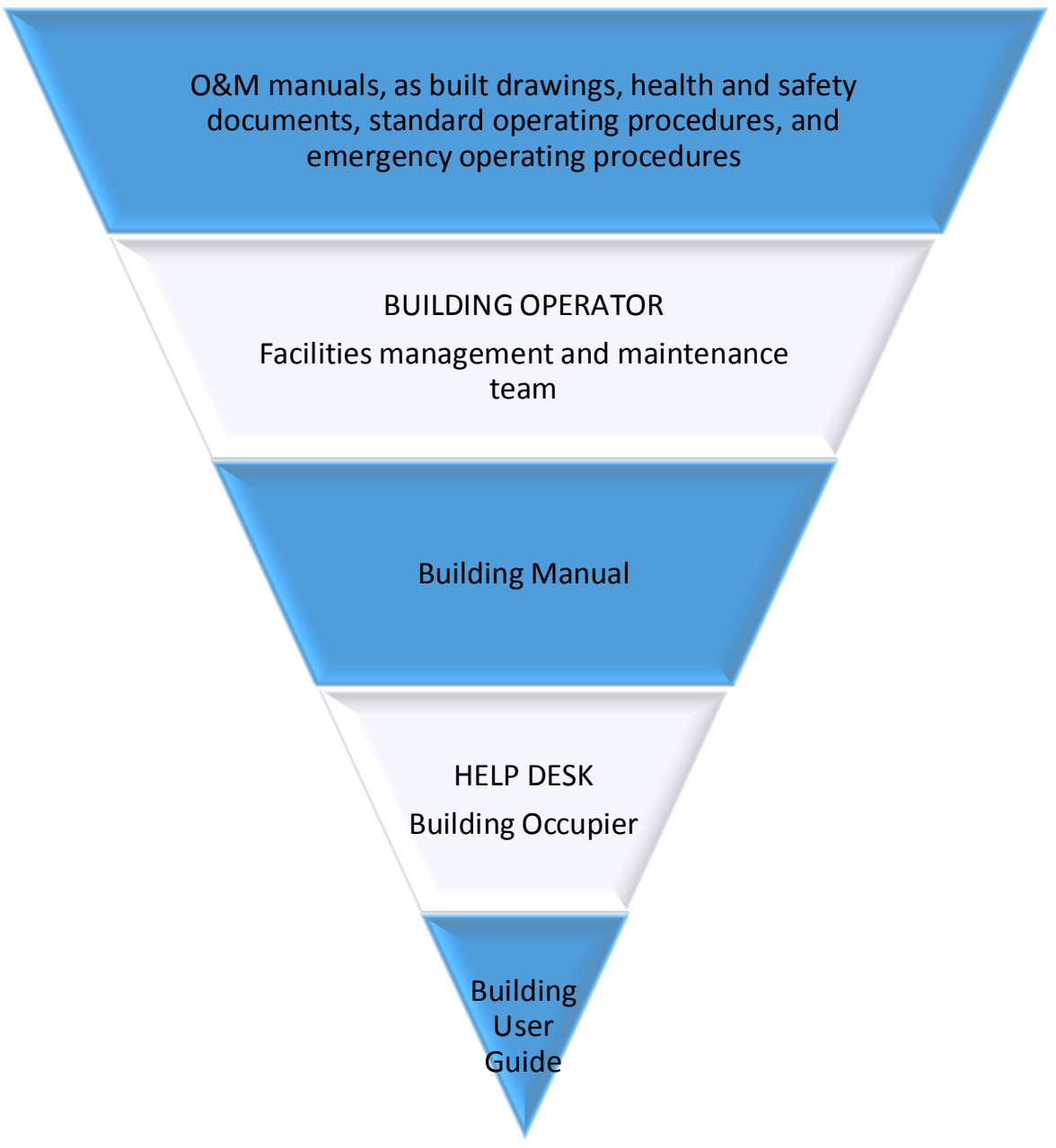

Figure 1 Relational structure of building documents (J. Harris et al., 2011)

The definition of a building user guide will be taken from the New Zealand Green Building Council's (NZGBC) technical documentation. This thesis will be specifically investigating GreenStar Building User Guides, so the NZGBC's definition of a building user guide from their technical documentation may be used. The definition incorporates both J. Harris's et al., (2011):

Building User Guide: provides details regarding the everyday operation of the building and the systems that building occupants encounter, making it easier for all occupants within the building to understand (New Zealand Green Building Council, 2008). 


\subsubsection{Why Building User Guides are Important}

The NZGBC expects that the building user guide should provide details regarding the everyday operation of the building and the systems that building occupants encounter, making it easier for all occupants within that building to understand (New Zealand Green Building Council, 2008). The creation of a building user guide gains 1 credit towards a GreenStar rating (New Zealand Green Building Council, 2008). The aim of the credit is to ensure that design features are used efficiently and that changes to office space are managed in the most environmentally appropriate manner.

A report that reviewed the inclusion of a Building User Manual (identical to the building user guide) within the Malaysian Green Building Index, explained that the building user manual document is the most important aspect in the development process by the consultant. The building user guide ensures that the building will operate efficiently, without any breakdowns due to technical problems that may arise during the occupancy period (Baharuddin et al., 2011). The Building Research Establishment states that when a building user guide was not part of the handover process, the result was an inefficient approach that was not economic in terms of achieving a good life cycle cost (Graves, Jaggs, \& Watson, 2003).

The GreenStar Building System is also used in Australia and South Africa. The Building Research Establishment Environmental Assessment Method (BREEAM), that is the equivalent to GreenStar, is used in countries such as United Kingdom and the Netherlands, to reward the inclusion of a building user guide within their assessment method. The inclusion of a building user guide in the two green building rating tools illustrates the demand for building user guides in newer green buildings. The problem is, there has been little research into how readable and usable a building user guide is. 


\subsubsection{Studies of Building User Guides}

A study of 22 green rated buildings was completed in Australia (Bond, 2010). This study was completed by conducting interviews with both the managers and users of buildings. It found that green buildings are becoming too technical and complex (Bond, 2010). In the same study, a building user guide was identified by interviewees as a successful or necessary approach to challenges faced within green buildings (Bond, 2010).

Holmes, Hudson and MacDonald (2012) undertook a smaller study of the users of five green rated buildings (rated under BREEAM) to identify the value of each credit in the system. The credit for a building user guide was valued by two of the respondents. In one case, it was used as an effective tool to introduce new tenants to the operation of the building (Holmes et al., 2012). In another case they found it helpful as a contact list for consultants and suppliers (Holmes et al., 2012). In two of the other buildings a building user guide was not produced, however interviewees did state they would have found one helpful when the purpose of the guide was described to them (Holmes et al., 2012). In the last case it was reported that a simple building user guide was in existence but it had been given to the outsourced Facilities Manager (FM) contractor (Holmes et al., 2012).

Another study of two recently constructed government department buildings was completed in the United Kingdom. The buildings were not connected to one another, but they had both won many awards and were the first office buildings to be awarded "BREEAM Excellent" status in their region (Monfared \& Sharples, 2011). The study involved a three stage data collection methodology. In the second stage, 20 members of staff were interviewed about their attitudes towards the concept of sustainability and their experiences in their building. During this stage it was revealed that the occupants found the building user guides "too technical and too difficult" (Monfared \& Sharples, 2011, p. 350).

As well as studies completed in finished buildings, studies have also been completed on the content within building user guides. The main content of a building user guide is the data that will aid the building occupants to freely manage and 
Literature Review

effectively use their indoor environment (Baharuddin et al., 2011). This may or may not include the following attributes.

- Incorporate green maintenance practices as well as control policies (Osso, Walsh, Gottfried, \& Simon, 1996)

- A clear design intent so that the users and building managers know how systems should operate (Leaman, Thomas, \& Vandenberg, 2007)

- What useable controls are there, what building users control, what they are supposed to do and give feedback on whether the controls have worked properly (Leaman et al., 2007)

- What the consequences are if the controls are not used correctly (Too \& Too, 2011)

- Be created depending on the different classes of users, for example, a facilities manager would have a more in-depth version compared to the average office user (Bordass \& Leaman, 1996)

\subsubsection{The benefits of building user guides}

The benefits of the use of building user guides within a building have yet to be covered in published literature. However, Armitage, Murugan and Kato (2011) completed a study of green certified buildings in Australia and found that the most common way of educating employees of the buildings services was via the distribution of a user guide (Armitage et al., 2011). The following section will discuss the perceived benefits of building user guides for building occupants.

Green buildings, like the ones designed under GreenStar are often more complex than buildings built without green principles (Lamborn, Luther, \& Fuller, 2013). This results in building services being difficult to manage and to understand adequately (Brown \& Cole, 2009; Leaman et al., 2007), for example, complex electronic controls (Bordass, Leaman, \& Bunn, 2007).

Karjalainen and Koistinen (2007) state that in regards to green building services, controls are not often not used correctly as users do not know how they work. Part of the purpose of a building user guide is to provide an overview of the services in a 
Literature Review

building as well as explain how to control them (Baharuddin et al., 2011). The use of a building user guide within a GreenStar rated building may result in users knowing how best to use the controls.

As occupants continue to understand how things work within a building they are more tolerant and become more satisfied with their environment (Too \& Too, 2011). Armitage et.al state that "when comparing the satisfaction levels of users based on the level of education they had received about the building's green features, their level of satisfaction was greater" (2011, p. 176). In particular people who have greater control over their indoor environment are more tolerant of wider ranges of temperature (Heerwagen, 2000; Leaman \& Bordass, 1999).

It has been found that when occupants have perceived control of a building their productivity increases. Baird and Lechat state that "buildings with high scores for personal control of temperature, ventilation and lighting had productivity improvements of the order of $8 \%, 4 \%$ and $2 \%$ respectively" $(2009$, p. 108). Brown and Cole state "a user's lack of awareness or understanding of the building's environmental systems and features, and action strategies can be taken to influence comfort conditions" (2009, p. 230).

Furthermore, Baird and Lechat (2009) found if a building manger took a larger role in educating the tenant, rather than just solely relying on a user guide, their level of understanding was greatly increased.

A building user guide can also provide an indication of how a building is performing. Monitoring and targeting is required to be addressed within building user guides (New Zealand Green Building Council, 2008). Too \& Too (2011) and Leaman \& Bordass (1999) both express the need to provide feedback on whether the building has been properly utilised and whether or not the systems are actually working.

The information collected in the monitoring and targeting section of the building user guide can then be used to express energy consumption. This has been found to change the behaviour of occupants within a building as it increases their interaction with the building (Healey, 2011). Subsequently, as shown in studies of both 
residential buildings (Darby, 2006; Petersen, Shunturov, Janda, Platt, \& Weinberger, 2007) and commercial buildings(Bordass, Leaman, \& Ruyssevelt, 2001; Lockton, Harrison, \& Stanton, 2008), it has been shown to increase energy savings.

In research completed by Lockton et al. (2008), persuasive principles encourage building users to reduce their energy use. For example, when monitored energy use can be compared to that of their peers. "If users are made aware that they are using more energy or creating more waste than other 'similar' users, this may cause them to alter their behaviour" (Lockton et al., 2008). However the authors also say that this can have adverse effects if, when compared, their actual use is lower than that of their peers, a reason to not attempt to further reduce electricity usage has been found.

\subsubsection{Summary}

Studies have shown that building user guides do have a place, not only in the GreenStar building system, but also GreenStar rated buildings themselves. Building user guides have been found to be a valued and successful approach to the complex nature of buildings. There are also further benefits to be had, as more studies focus on the actual use of building user guides within a building. However, building user guides have been found to be "too technical and too difficult" (Monfared \& Sharples, 2011, p. 350). This indicates the need to complete a study to find out why users may perceive building user guides as being too technical and too difficult to read and understand. 


\subsection{NZGBC requirements of a building user guide}

A building user guide is a document that is being produced more and more in New Zealand with the introduction of the GreenStar building process as seen by the amount of GreenStar buildings being constructed (New Zealand Green Building Council, 2012). The credit Management-5 under the GreenStar Office V2 Built Rating (New Zealand Green Building Council, 2008) sees the inclusion of a building user guide to obtain 1 credit towards a GreenStar rating. Under the Man-5 Building User Guide page from the GreenStar Technical Manual, the following is required of a building user guide.

"The aim of the credit is to encourage and recognise the provision of guidance material to enable building users to achieve the environmental performance envisaged by the design team and to manage future changes that promote efficiency and environmental quality. One point is awarded where it can be demonstrated that there is provision of a Building Users' Guide that is appropriate to the building (whether electronic or hardcopy), which includes information relevant to the building users, occupants and tenants' representatives."(New Zealand Green Building Council, 2008)

The Building Users' Guide must include the following:

\section{$\underline{\text { Topics }} \quad \underline{\text { Description }}$}

Energy and Environmental Strategy

Monitoring and Targeting

Information on energy-efficient features
and strategies in relation to the building,
including an overview of the potential
savings - stated for economic and
environmental impact - to building users
and occupants
Energy targets and benchmarks for the
building and tenancy as well as a
metering and sub-metering strategy with
details on how to read, record and
present meter readings.
A description of the basic function and
operation of the following, with
simplified system diagrams and
explanation of energy saving features:
Ventilation, heating system, cooling

Building Services 
$\underline{\text { Topics }}$

\begin{tabular}{|c|c|}
\hline & $\begin{array}{l}\text { system, electrical system, lighting, and } \\
\text { domestic hot water. }\end{array}$ \\
\hline Transport Facilities & $\begin{array}{l}\text { Car-parking requirements including } \\
\text { details of the provision of cyclist } \\
\text { facilities, conditions of access and } \\
\text { appropriate use. Also provide, if } \\
\text { applicable, local public transport } \\
\text { information, maps and timetables and } \\
\text { information or links on alternative } \\
\text { methods of transport to the workplace } \\
\text { (e.g. carpooling) }\end{array}$ \\
\hline Materials and Waste Policy & $\begin{array}{l}\text { Information on recycling including what } \\
\text { can be recycled, where the recycling } \\
\text { storage areas are, and schedules for } \\
\text { waste/recycling removal. Include } \\
\text { instructions on proper use for less } \\
\text { common practices such as composting }\end{array}$ \\
\hline Expansion/Re-fit Considerations & $\begin{array}{l}\text { A list of environmental } \\
\text { recommendations for consideration, } \\
\text { highlighting in particular the areas } \\
\text { covered in the Building Users' Guide and } \\
\text { Green Star NZ (e.g. use of } \\
\text { environmentally friendly materials, } \\
\text { exhausts for printing/photocopying } \\
\text { rooms etc.). }\end{array}$ \\
\hline References and Further Information & $\begin{array}{l}\text { Links to relevant information including } \\
\text { websites, publication and organisations } \\
\text { pertaining to energy and water } \\
\text { conservation, efficient building } \\
\text { operation, indoor air quality/sick building } \\
\text { syndrome, environmentally friendly } \\
\text { design features, etc. }\end{array}$ \\
\hline
\end{tabular}

Table 1 Information required for a Building User Guide (taken from the Green Star Technical Manual) (New Zealand Green Building Council, 2009)

\subsubsection{Summary}

For a building user guide to pass the New Zealand GreenStar requirements the guide must contain the information in Table 1. As this is a requirement, the content of the building user guide will not be specifically investigated, rather how the language and layout affect readability and usability. 
Literature Review

\subsection{Readability}

This section will give a definition of readability, a brief history of readability studies and an in-depth history of two important texts relating to the quantification of readability. This section is finished with both the limitations and applicability of readability formulae as well as where they have been used.

\subsubsection{The Definition of Readability}

There are various descriptions of readability found in literature. Klare gives the term readability the following three descriptors:

- To indicate legibility of either handwriting or typography,

- To indicate ease of reading due to either the interest-value or the pleasantness or writing,

- To indicate ease of understanding or comprehension due to the style of writing

(1963, p. 1).

Other useful definitions include:

- "The degree to which a given class of people find a certain reading matter compelling and comprehensible (McLaughlin, 1969, p. 187),

- "Ease of reading words and sentences" (Hargis et al., 2004, p. 6)

- "The ease of reading created by a literary style that fits the reading level of the audience" (DuBay, 2007, p. 6).

For the purposes of this thesis, the following definition from The Literacy Dictionary will be used, "the ease of comprehension because of style of writing" (T. L. Harris \& Hodges, 1995, p. 203). This definition takes into account the need for building occupants to understand the operation of the building and the systems that they may encounter. 
Literature Review

\subsubsection{History of Readability}

Evidence can be found of concerns around the readability of text in publications in various studies throughout history. The first evidence found of what we now coin 'Readability' was in 900 A.D when Talmudist made counts of words and ideas of the Talmud which was a body of laws (Lorge, 1944). Klare (1963) more recently identifies the next serious interest among educators "appeared about 1940, for example, when the ease of understanding was considered in terms of vocabulary in the McGuffey Readers"(p.30)

It has been noted that "after World War I, reading formulae emerged as the major approach to ascertaining readability" (Kingston \& Weaver, 1967, p. 45). Even though the identification of the first readability formula can be debated (Klare, 1963), many in current use have developed from the work of Kitson (1921, pp. 5863) and Lively and Pressey (1923) . "Despite the use of somewhat different methods and criteria, the typical readability formula involves the systematic sampling of running words, which are then analysed according to frequency, complexity and sentence length (Kingston \& Weaver, 1967, p. 45)".

\subsubsection{The History of Quantifying Readability}

There are two important texts as stated by Dubay (2004) that led to the development of the first readability formulae. These two texts are Sherman (1893) and Thorndike (1921).

Sherman (1893) first found an indication that literature could be measured. He compared texts that had been written throughout time starting with the preElizabethan through to his current time. He found that sentence length averages shortened over time, see Table 2 as quoted in Dubay (2004, p. 10). 
Time Period

Pre-Elizabethan Times (<1550)

Elizabethan Times (1550-1603)

Victorian Times (1837-1893)

Sherman's Time (>1893)

Table 2 Words per sentence Sherman (1893)

\section{Words per Sentence}

50 Words per sentence

45 Words per sentence

29 Words per sentence

23 Words per sentence

Other important findings were the consistency of the average length of sentence by individual authors. This became the basis for the validity of using samples of texts rather than the entire text for readability prediction. This is because a sample would be a good representation of the whole text.

Sherman's work set the agenda for a century of research in reading (Dubay, 2004, p. 11). It proposed the following;

- Literature is a subject for statistical analysis

- Shorter sentences and concrete terms increase readability

- Spoken language is more efficient than written language

- Over time, written language becomes more efficient by becoming more like spoken language

The Teacher's Word Book by Thorndike (1921) is the second most important text as it is the first English Language based research that indicates word frequency as a predictor of readability. Thorndike found "teachers of languages in Germany and Russia were using word counts to match texts with students. The more frequent a word is used, they found, the more familiar it is and the easier it is to use" (Dubay, 2004, p. 12). The use of a greater amount of common (higher frequency) words in texts results in a greater understanding of the text, as we are able to learn these words more readily (Klare, 1968). This is the principle behind why word frequency is used to calculate readability. Thorndike's book listed 10,000 words by their frequency of use and was the first extensive listing of words in English by frequency. 
Johnson (1946) and Fry, Kress and Fountoukidis (2000) have also indicated the importance of the frequency of words used in text. Fry et al., concluded that the 100 most frequent words make up almost half of all written material and the first 300 words make up about 65\% (2000). Klare (1968) concluded "not only do humans tend to use some words much more often than others, they recognise more frequently used words more rapidly, prefer them, and understand and learn them more readily". In a similar vein, Chall and Dale (1995) wrote that "it is no accident that vocabulary is also a strong predictor of text difficulty".

There have been many formulae derived since the texts from (1) Sherman's and (2) Thorndike's first published works.

1. Readability Formulae are often created with the analysis in some form of a texts syllable and sentence length count, as these have been found to have a statistical correlation with the comprehension of passages (Bormuth, 1969).

a. The Flesch-Kincaid method (Flesch, 1948) which assesses readability on the basis of the average number of syllables per word and the average number of words per sentence (Doak, Doak, \& Root, 1995);

b. The Simple Measure of Gobbledygook or SMOG (McLaughlin, 1969), which counts the number of polysyllabic words in a 10-sentence passage;

c. The Fry Readability Graph (Fry, 1977) which measures the number of sentences and total number of syllables in three 100 word passages against the "Working Readability Graph" (Fry, 1977, p. 249)

2. The following are word lists that identify the frequency of words in given text;

a. The Dale List of 769 words (Dale, 1931);

b. Words on the Dale List of 3,000 Familiar Words (Dale \& Chall, 1948);

c. The 251,000 word family lists made from the British National Corpus (Nation, 2006). 
Literature Review

Thorndike's research has also resulted in lists of 10,000 words (Thorndike, 1921), 20,000 words (Thorndike, 1942) and finally 30,000 words (Lorge \& Thorndike, 1963).

Readability formulae often return an estimate of a text's difficulty in terms of school grade levels, that is the years of schooling needed to be able to comprehend the text (Chapman, Tunmer, \& Allen, 2003). Klare, states that the scale "compares reader's ability levels to the difficulty of written material"(Barr, Kamil, Mosenthal, \& Pearson, 1984, p. 718).

\subsubsection{Readability Formulae - Applicability and Limitations}

This section is split into two sections, the first shows the aspects that are not included when specifically investigating the readability of text, followed by documented limitations and the applicability of readability formulae.

\subsubsection{Aspects that are not included in Readability Formulae}

Readability should not be confused with legibility. Legibility is defined by the Merriam Webster dictionary as "capable of being read or deciphered: PLAIN <legible handwriting>" (Merriam-Webster, 2005). The legibility of a document is how easy the physical words are to read, due to font, size and type. Readability is how easy the words are to comprehend.

Readability can be affected by many variables. McLaughlin reports the following variables that affect readability; visibility, legibility, individual differences and logical determinants (McLaughlin, 1968). Table 3 briefly describes these aspects.

$\underline{\text { Aspects }}$

Visibility

\section{Descriptions}

The visibility of the actual text. Reading is impossible unless the letters are visible. For example, visibility is reduces by glossy paper because this reflects so much light is produces glare, other 
Legibility

Individual Differences

Logical Determinants examples are tinted paper and size of type.

The efficiency with which graphemes (a letter or combinations of letters representing a single sound) and combinations of graphemes in a text can be recognized at speed is termed the texts legibility - for which visibility is a prerequisite.

These are motivational variables such as interestingness and aesthetic appeal. For example, the quality of the illustrations and aesthetic preference, as well as how interested the reader is on the particular topic.

These determinants are how the text is organised on the page. This includes the order of ideas that has been brought up as well as the orderliness of

presentation.

Table 3 Variables that affect readability - taken from (McLaughlin, 1968)

However, these variables were not considered in the majority of the early readability formulae as they were hard to quantify. Rush states that "formulae cannot assess a reader's interests, experience, knowledge and motivation" (1985, p. 274). Readability formulae only take into account the objective factors and do not usually "account for more subjective factors such as illustrations present, types of punctuation used, or font size used" (Drake, 2008, p. 27).

\subsubsection{Limitations and Applicability}

There are many studies that outline the limitations of readability formulae, Bruce, Rubin, \& Starr, (1981), Gilliland (1975), Klare (1976), McCall \& Schroeder (1960) and Redish (2000). Anagnostou and Weir, report the limitations into four main points (2006):

- They cannot measure conceptual difficulty - no formula takes into account the content of the document being evaluated.

- They cannot check incomprehensibility of expression - readability scores remain the same even if the text is scrambled. For example "Mary had a 
Literature Review

little lamb" would have the exact score with the phrase "Lamb a Mary little had". It is clear that the second phrase is incomprehensible but readability formulae are unable to detect that.

- There is discrepancy in the results of readability formulae for the same text - for example the scores of the opening paragraph of 'What is wrong with readability formulae', score the following results:

- Flesch Kincaid Grade Level: 15.8

○ The SMOG Index:12.3

○ Gunning Fog: 17.1

- They assume all readers are alike - Readability formulae make no distinctions based on reader's characteristics. Redish (2000, p. 134) notes "they take no account of differing purposes, maturity and ability of readers"

Bruce, Rubin and Starr (1981) also states that validity is a problem. This view is also shared by Duffy and Kabance (1982), Redish (2000), Schriver (2000) and Spache, (1978). "A formula validated with one group of students and one type of text is found to be invalid for the same types of students and texts as conditions change over a 25 year period" (Bruce et al., 1981). Spache (1978), the creator of the Spache Readability Formula, concludes that if a readability formula is to continue to reflect accurate estimates of the difficulty of today's books, it too, must change.

With all the limitations addressed above, many researchers still see the applicability for readability formulae. Grundner (1981) states that testing for readability is such an easy process that it hardly seems ethically defensible not to do it. Burke and Greenberg (2010), suggest that readability formulae are a good place to start as they are quick and objective, by no means do they state that there are not limitations with the formula, but conclude that they are a good place to start for the assessment of text.

\subsubsection{The use of Readability Formulae}

The first readability formulae were used specifically, and often exclusively, for school readers. However, the continual development of the formulae (illustrated by the now 200+ formulae available (Benjamin, 2012)), meant that they are now being 
used for almost any type of document. Fry (1986) illustrates this by pointing out that readability formulae are among the most frequently cited articles of all types of educational research. While Dubay (2004), states that the applications give researchers an objective means of controlling the difficulty of passages in their experiments

The following documents have had research into their readability completed:

- Patient Education Materials (Aleligay, Worrall, \& Rose, 2008; K. Johansson, Salanterä, Katajisto, \& Leino-Kilpi, 2004; Krass, Svarstad, \& Bultman, 2002; Kusec, Mastilica, Pavlekovic, \& Kovacic, 2002; Luk \& Aslani, 2011),

- School Books (Gunning, 2003; Kistulentz, 1975; Parker, Hasbrouck, \& Weaver, 2001),

- Library Websites (Lim, 2010),

- Clinical Reports (Zeng-Treitler et al., 2007),

- Educational Print (Vallance, Taylor, \& Lavallee, 2008),

- Consent Forms (Grundner, 1981; Hochhauser, 1997, 2008; Lawson \& Adamson, 1995; Waggoner, 1996),

- Risk Disclosures (Linsley \& Lawrence, 2007),

- Financial Reporting (Loughran \& McDonald, 2010; Smith \& Smith, 1971),

- Military Documents (Booher, 1971; Caylor, Sticht, Fox, \& Ford, 1973),

- Adult Literacy Materials (Burke \& Greenberg, 2010),

- Written Computer Materials (Liu, Kemper, \& Bovaird, 2009)

\subsubsection{Readability Formulae used with User Manuals}

Throughout the literature there has been minimal research into the assessment of building user guides in terms of their readability. Technical documents, which building user guides fall under, as a category of text, have also not been widely assessed. Booher, who in 1971 released a paper for the Naval Air Systems Command, states that even though research on readability is vast "only a very small portion has any direct relation to technical publications" $(1971$, p. 7$)$. In the 
Literature Review

aforementioned publication, Booher goes on to state that "methods of testing manuals and guides for preparing them are in great demand" (1971, p. 9).

Lemos (1983) investigated the measurement of the readability of the COBOL manuals published by the major mainframe data processing companies ( $\mathrm{COBOL}$ being a computer programming language, Common Business-Orientated Language). His research used the Flesch Reading Ease Index; this was used as it was found to be easy, modifiable and highly reliable when coupled with standardized text input procedures. The COBOL manual was assessed as it had been widely criticised, "One should not be forced to refer to a textbook in order to figure out a manual [...] Wouldn't it be more cost effective to produce, once, a readable manual..?" (Lemos, 1983, p. 377). The results showed that the manuals fell within the 30-50 scoring range using the Flesch Reading Ease. This range is described by Flesch as being of a "difficult" reading level, the level you would expect in academic journals (Lemos, 1983). "In conclusion, it is proposed that readability indices can be of practical importance for both users and publishers of technical material" (Lemos, 1983, p. 388).

\subsubsection{Summary}

Over the last 100 or so years, readability formulae have been used in a large spectrum of situations. Across these situations many formulae have been produced, the majority of these formulae have either derived from Sherman's early works or Thorndike's identification of word frequency effecting readability. However, with the large amount of attention readability formulae have gained, their limitations have been realised. It has been found that readability formulae are an effective starting point in investigating text. However, they should be used in conjunction with other assessment techniques. 


\subsection{Current Standard of New Zealand Adult Literacy}

\section{Levels}

This section will outline the literacy level that a building user guide should aim to gain, to accommodate the majority of New Zealanders literacy ability. This will be done by first understanding what is meant by a 'literacy level'. Followed by how the use of the Adult Literacy and Life Skills Survey, along with census data, can estimate the literacy level of the average New Zealander.

\subsubsection{Definition of Literacy}

It is important for anyone to have the ability to read documents that they use every day. This is why the Organisation for Economic Co-operation and Development (OECD) defines literacy as follows:

"The ability to understand and employ printed information on daily activities, at home, at work and in the community to achieve one's goals and to develop one's knowledge and potential" (Statistics Canada, 1997)

"Higher levels of literacy are needed now more than any time in the past. And the demand for literacy in the future can only increase" (Statistics Canada, 1997, p. 11). A janitor noted the importance of being able to read the label (including warnings) on chemicals she uses; a manual labourer who unpacks delivery trucks needs to accurately count and read the number of items he unpacks each day (Cain \& Benseman, 2005); just like an office worker may need to read a building user guide to know how to make his or her work place more comfortable

Readability formulae often give a level of required readability in terms of how many school years it takes to be able to read the assessed text. For example the Simple Measure of Gobbledegook test, results in a score called the 'SMOG Grade'. This is the American Schooling Grade that a person must have completed to fully understand the text assessed (McLaughlin, 1969). This is the reason why it is important to establish a literacy level that the majority of New Zealanders are able to comprehend. 
Literature Review

The average literacy rate of New Zealanders has not been published as a grade level. To gain an understanding of the literacy of the users of the building user guides a snapshot of the recent Adult Literacy and Life Skills Survey (ALL) 2006 (Ministry Of Education, 2012) as well as information reported by Statistics New Zealand (2002) were reviewed. The average literacy rate was estimated by finding the literacy level that relates to reading a building user guide, followed by the average level of education.

\subsubsection{The Calculation of Literacy Levels}

The Adult Literacy and Life Skills Survey was conducted in 2006 is an investigation of the distribution of certain skills among people aged 16 to 65 in New Zealand (Satherley, Lawes, Sok, \& Sok, 2008).

The study, a bid to accomplish these goals, this study assessed the survey participants on the following three parts of literacy:

1. Prose Literacy - the ability to understand and use information from texts such as fiction and newspapers

2. Document Literacy - the ability to locate and use information from timetables, graphs, charts and forms

3. Quantitative Literacy - the ability to use numbers in context, such as balancing a chequebook or calculating a tip

The survey found that the majority of people $(84 \%)$ who had obtained a 'Higher Secondary' education had an ALL document literacy score of Level 2 or above, as well as half scoring at a Level 3 or above. A score at the Level 2 mark means a person has the ability to search a document and filter out some simple distracting information and make low level inferences (Satherley et al., 2008). A score of Level 3 means a person is able to perform more complex information-filtering (Satherley et al., 2008).

\subsubsection{Summary}

The average level of education can be found from information published by Statistics New Zealand (2002) which states “Over three-quarters (76\%) of New 
Literature Review

Zealanders aged 25-64 years have achieved secondary or tertiary educational qualifications".

From this information, the level of readability based on school years that building user guides should aim for is a New Zealand school grade of year 10, which relates to approximately 10 years of schooling. The majority of readability formulae are based on the American schooling system, a New Zealand grade of year 10 is equivalent to an American grade between 8 and 9 . 
Literature Review

\subsection{Usability}

This section of literature review will first address the definition of Usability, followed by the identification of usability aspects of manuals and finally ways to assess usability of manuals.

\subsubsection{Definition}

There are a variety of ways 'usability' is defined. Heaton (1992), states usability should be defined "in a manner that can incorporate users, tasks and environments to set explicit performance goals relating to the effectiveness, training time and subjective opinions of sample users" (p. 147). Similarly, Guillemette (1989) writes "usability refers to the degree in which documentation can be effectively used by target readers in the performance of tasks under environmental requirements and constraints" (p. 218). Guillemette (1989) goes on to state that the 'effectiveness', refers to the level of efficiency and accuracy of use, while performing certain tasks. The reader is the primary source for reporting perceptions of tiredness, comfort, boredom, frustration or excessive personal efforts in using documentation (Guillemette, 1989, p. 218).

As most of the definitions are given in respect to particular products, for example Guillemette's definition stems from his work with software documentation. A more succinct definition is needed to provide a broader definition to encapsulate building user guides. For this reason, the definition given as part of ISO 9241-11:1998 Guidance on Usability (1998) will be used in this thesis: "the extent to which a product can be used by specified users to achieve specified goals with effectiveness, efficiency and satisfaction in a specified context of use"(p. 2).

\subsubsection{The use of a Building User Guide}

Building user guides are classified under the broad term of "Technical Documentation" (Rude, 1988). As a technical document building user guides are further classified under the term "Reference Material” (S. Rosenbaum \& Walters, 1988). Reference material is used when specific information is needed. "People use reference documentation to look up answers to specific questions" (S. Rosenbaum 
$\&$ Walters, 1988, p. 152). A building user guide should be designed and written to maximise the procedural knowledge; which requires a document layout that is different to conventional documents (De Mul \& Van Oostendorp, 1996). “An expository text (e.g. giving a description of system capabilities) may be easily understood when written in conventional prose style. This is not the case for a text which explains how to carry out certain procedures" (Wright, 1983, p. 13). According to Wright (1977), headings, tables, illustrations and summaries all need to be tailored towards the user of technical documentation for the text to be effective.

\subsubsection{Importance of Usability Testing}

In the field of technical documentation, it has become apparent that usability evaluation research can be a positive way of monitoring, improving and maybe even guaranteeing the user-friendliness and effectiveness of documents (Lentz \& De Jong, 1997). Using a usability test or evaluation on a document can reveal what may cause problems for users of the final product.

When designing any form of manual, whether it be for a computer program, electronic appliance or for a whole building, it is important to consider usability (ISO, 1998). In contrast to readability, usability cannot be calculated by using a derived algorithm. "Readability is a necessary but insufficient basis for assessing the usability of documentation (Guillemette, 1989, p. 14)".

When assessing documents for usability, you will often find different users will assess a document in different ways. Therefore, results gained from the tests will not always reveal the same problems (Rosenbaum, 1989). The number of usability issues is close to infinite, it is not possible or at least infeasible to find all usability issues (Molich, 2010). "Usability evaluation has become a very important part of developing documents, and its importance will continue to grow as more and more people come to rely on technical documents to carry out everyday tasks on the job and at home (Grice \& Ridgway, 1989, p. 230)". 
Literature Review

Not only is it important to assess a document like a building user guide for usability, it is important to investigate the right method to do so. The following sections will analyse how to choose the most relevant usability test to use for building user guides.

\subsubsection{Usability Tests}

There are two viewpoints on usability in the design process or the creation of a document:

- Improving usability during the design by applying all relevant knowledge

- Improving usability by evaluation with users

(Van Welie, Van Der Veer, \& Eliëns, 1999)

The first school of thought relates to the specific aspects of a document, like, the layout, the use of images and the colours used in the document. The second focuses on using usability evaluation tests to indicate and/or solve problems that users have with the specific documentation. User focussed methods are generally preferred because they give direct information about how the audience may respond to the different aspects of documents (Schriver, 1997).

The following two sections of the literature review will investigate methods of assessing usability by uncovering design aspects of user guides or technical documents that have been found to increase the overall usability.

\subsubsection{Improving usability by applying all relevant knowledge}

The usability of technical documentation has been investigated previously (Jonassen, 1980; Priestly, 1991; Rude, 1988; Wheildon, 1986; Wogalter et al., 1987). From this literature factors like, layout, text, illustrations and colour have been found to have an effect on the usability of documents.

Readers often struggle to access the information found in an instruction manual (Rude, 1988). Often when readers can't find the information they want in a document they abandon it (Rude, 1988). Rude (1988), goes on to say that as a 
characteristic of text, format joins with organisation, style and completeness of information in affecting the ease and accuracy of reading (p. 64). The following section will go through the principles of layout, use of images, font and use of colour in technical documentation.

\subsection{Layout}

Hartley (1981, 1985, 2004), Hedberg (1987), Jonassen (1980) and Priestly (1991) have suggested that to increase the ease in which a document is used it should incorporate the page layout illustrated in Figure 2. "The left hand column would be for headings, major points, prompts or icons, if used. While the right hand column would be for body text, graphics and tables which should be left aligned" (Priestly, 1991). When the two column layout has been used in a document, users can scan down the left hand column for quick reference of all the major headings. Users that need specific information can then easily identify headings and choose the most relevant for their search (Hedberg, 1987). This is important as it reduces the time needed to find information that users require.

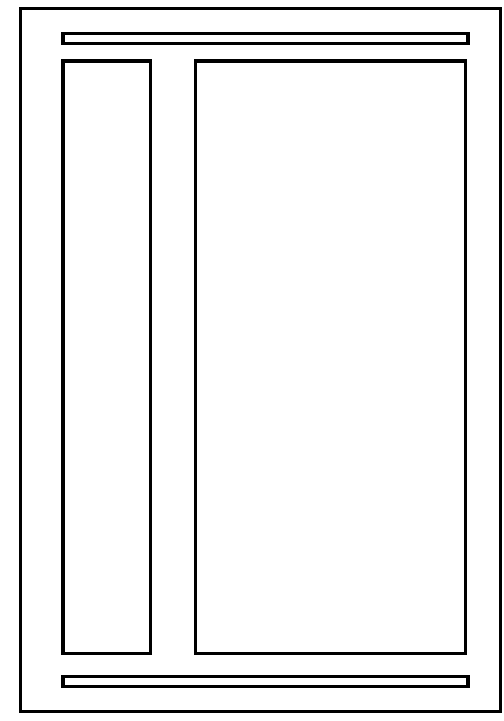

Figure 2 Page Layout - Two column (Priestly, 1991)

\subsection{Text}

Type should be chosen to reflect and complement the information being presented (Mackiewicz, 2004). It is important to not use too many different fonts (Hedberg, 
Literature Review

1987; Tracy, 1995). When choosing a font you need to consider two factors; legibility and readability (not the readability discussed in section 2.3 , but the physical readability of a font) (Mackiewicz, 2004). This has been illustrated by a study completed by Tracy (1995), which found that if you set a novel in 'newspaper' type, the book would become so uninviting that the success of the work would be jeopardised. On the other hand, if you set a newspaper in a 'book' type the newspaper would not be taken seriously (Tracy, 1995, p. 171). Hedberg (1987) suggests the following guidelines around typefaces;

- Make headlines all one size (for example 24 point); section headings one size (for example 18 point); subheadings one size (for example 14 point); and the remaining text all one size (for example 10 point)

- Put more space above a heading than below it

- Text set unjustified is more interesting, easier to read, and gets the reader back to the start of a new line quickly

- Use capital letters sparingly as readers read shapes, not individual letters

It is important to consider the type of text used in building user guides. The text should be in a typeface that is easily read and the correct size. Hedberg's listed points provide a good starter for considering the correct typeface to include in a building user guide.

\subsection{Illustrating Warnings}

In the case of representing warnings in manuals, if a warning is not noticed or seen it will not be remembered (Young \& Wogalter, 1990, p. 905). An example of a warning in a building user guide maybe to highlight the importance of using the correct technicians when services need work. The majority of published guidelines on warnings emphasise the characteristics of getting the users attention (Cunitz, 1981; Peters, 1984; Wogalter et al., 1987). Young and Wogalter's (1990) research found conspicuous print (print that had been highlighted orange) and Icons Present (an icon that represented the risk) enhanced memory of their content. Manuals should be designed in a way readers will notice and attend to their warnings. If warnings need to be highly visible in building user guides it would be useful to 
consider the works of Cunitz (1981), Peters (1984) and Wogalter et al. (1987). Other parts of the building user guide that need to be noticed and not forgotten could use the same principles.

\subsection{Colour}

The use of colour can affect the way a reader will read certain text (Priestly, 1991). Using colour to emphasise text on a page can be an appropriate way of guiding a reader through text. As noted in section 2.5.4.1.3, Young and Wogalter (1990) highlighted warning text with orange to grab the reader's attention.

However, the use of colour can have a negative effect on documentation. Wheildon (1986), makes comment from his research and produces evidence to indicate that colour plays an important part in document design. His research compares how users perceive both black and blue text. In the research it was noted that 8 out of 10 people found the blue more aesthetically pleasing and that 9 out of 10 found the black text boring. However, when readers attempted to read the blue text, only 1 out of 10 displayed good comprehension (Wheildon, 1986). Wheildon's (1986), findings illustrates that even though aesthetics may be important, ease of use should remain front of mind for any writer of building user guides. Proper use of colour to emphasise important information, warnings, major headings or important diagrams is effective, but too much colour may negatively impact comprehension by readers. This must be considered when designing building user guides.

\subsection{Other important aspects}

When designing instructional text it is also important to consider the use of:

- A detailed contents page,

- A glossary of terms,

- An index might be appropriate if the document is long enough

(Hartley, 1981) 


\subsubsection{Improving Usability by evaluation with users}

In the case of building user guides, evaluation using users or readers is a good method for obtaining data about actual usage (Van Welie et al., 1999). This view is shared by de Jong and Schellens (1997), who state that "although text-focused and expert-focused methods may provide valuable feedback on documents, in our view they can't replace reader-focused evaluations".

The following section will focus on two texts: ISO 9241-11 1998 (ISO, 1998) and Reader-Focused Text Evaluation - An Overview of Goals and Methods (de Jong \& Schellens, 1997). The international standard is being used as it identifies the main components needed for any usability test, whether it be for building user guides or computer monitors. The broad scope of the standard is a good starting point for any usability evaluation method (Bevan \& Curson, 1999; Jokela, livari, Matero, \& Karukka, 2003; Jokela et al., 2003). The second paper by de Jong \& Schellens (1997) has been referenced by other authors to select the most appropriate usability method (de Jong \& Schellens, 2000; Sienot, 1997; Van Velsen, Van Der Geest, Klaassen \& Steehouder, 2008; Van Waes, 2000). The first text will look at the individual parts of a usability evaluation that need to be considered before completing a test. The second reviews the different focusses of usability tests and provides guidance on what usability test should be considered.

\subsection{Outline of ISO 9241-11:1998 Guidance on Usability}

Before choosing a usability test it is important to understand the users, goals of the document, goals of the study and the document itself (ISO, 1998). ISO 9241-11:1998 states when specifying or measuring usability, the following information is needed:

- A description of the intended goals

- A description of the components of the context of use including users, task, equipment and environments

- Target or actual values of effectiveness, efficiency and satisfaction for the intended contexts

(ISO, 1998, p. 4) 
Literature Review

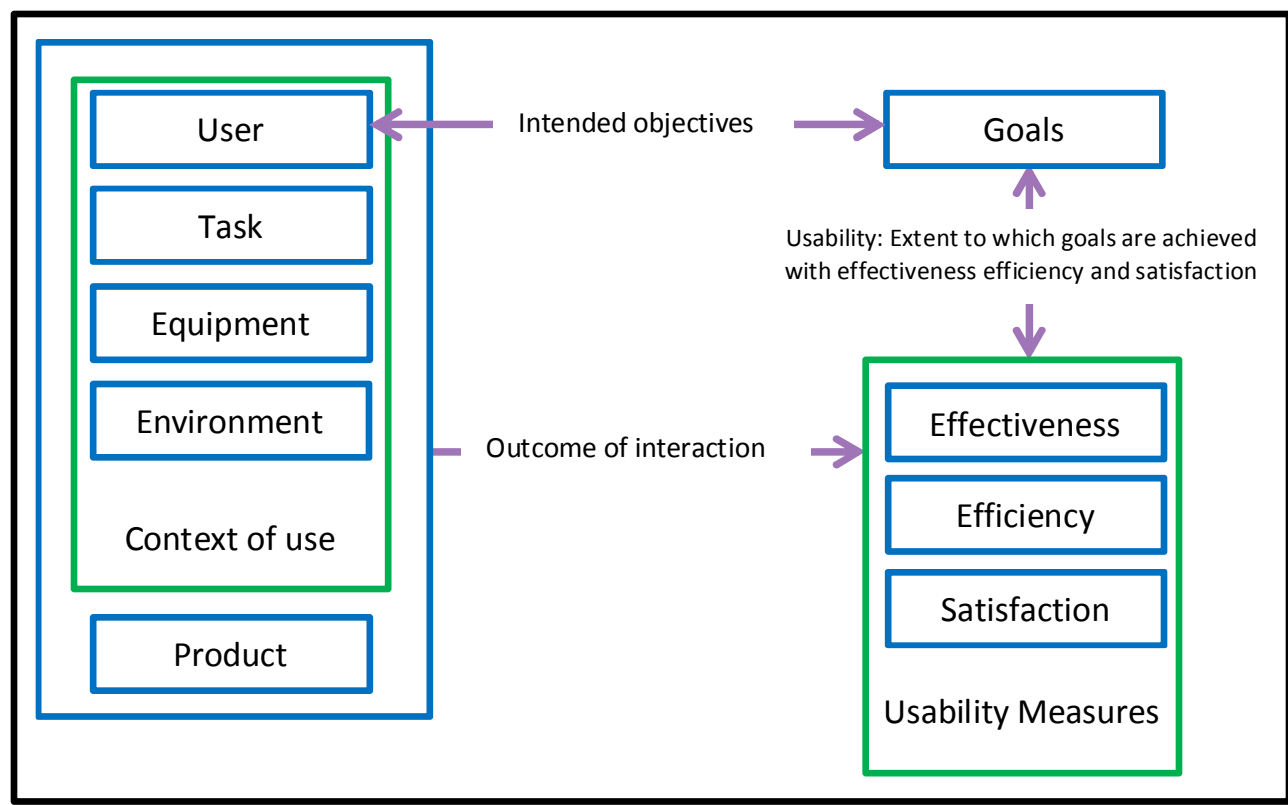

Figure 3 Usability Framework (figure directly copied)(ISO, 1998, p. 3)

Figure 3 illustrates the components needed when specifying usability tests. User, task, equipment and environment are aspects of the product that the test will be used on; in this case, it will be building user guide. It also demonstrates the different components that can form a cohesive analysis of the variables affecting usability. The figure illustrated forms the basis of many usability evaluation methods (Jokela et al., 2003). The following sections will briefly outline the different components in Figure 3.

As per Figure 3, there are four key components for identifying the context of use of a user guide. Describing the users will illustrate who your target audience is and their relevant characteristics (for example, experience, education and age). Tasks illustrate specifically what the user completes with the product. Describing the equipment and environment will illustrate what is being used (equipment) and where (environment).

The usability objective or goal is then measured under three separate categories effectiveness, efficiency and satisfaction. These three measures have been widely used to assess the usability of products (Bevan \& Macloud, 1994; Bevan, 1995; Jeng, 2005). 
The effectiveness of a product is described by ISO 9241-11:1998 as "the accuracy and completeness with which users achieve specified goals" (ISO, 1998). Efficiency is "measured by relating the level of effectiveness achieved to the resources used" (ISO, 1998). Finally satisfaction is measured by the response of the user either subjectively or objectively. Measuring subjectively would mean quantifying the strength of the user's satisfaction in terms of reactions, attitudes or opinions (ISO, 1998). Measuring objectively would mean observing the behaviour of the users (ISO, 1998). These can be best illustrated by an example seen in Figure 4.
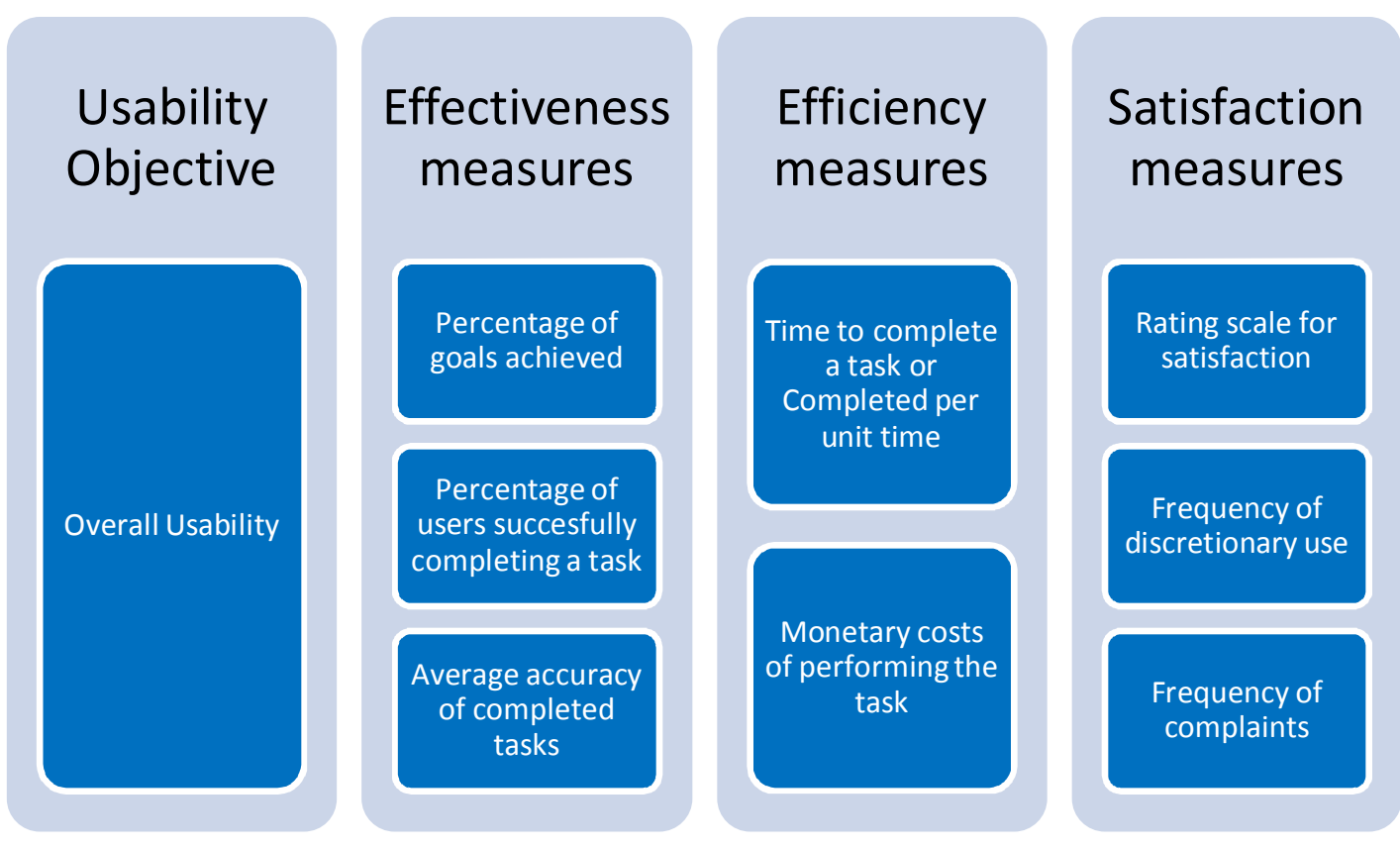

Figure 4 Examples of measures of usability (ISO, 1998)

\subsection{Overview of Reader-Focused Text Evaluation}

In their paper, de Jong and Schellens (1997) compile a table of conditions that reflect the type of usability method that should be undertaken. They first do this by breaking down the term 'effectiveness' mentioned in Figure 4.

They split this measure into six different categories (summarised from de Jong and Schellens (1997, pp. 404-405));

1. Selection: The target group of readers must be able to easily locate the information they require in the document. 
2. Comprehension: Readers must correctly understand the information given and once located; understand what the document is conveying.

3. Application: In the case of instructional documents, such as user manuals, comprehension alone is insufficient. Readers must also be able to apply the information in a productive way and realistic setting.

4. Acceptance: The intended readers should find statements in the text as acceptable and credible as possible:

- Behavioural advice must be seen to be relevant and realistic,

- Factual statements must be considered true,

- Company policy must come across as fair and reasonable,

- Value judgments in the text must be endorsed.

5. Appreciation: The readers must appreciate the way the information is presented. This covers tone of voice, writer-reader relationship and the familiarity or aesthetic quality of the text. It also includes readers' assessment of figures, illustrations and layout.

6. Relevance and completeness: The text must contain the right information for its intended readers. The information that is given must be complete and readers should not be left with any important question on the topic.

The next step suggested is to choose what the overall function of the test will be. The three functions will address how the evaluation contributes to the quality of the final document. The three functions include verifying the document, troubleshooting and improving the document and facilitating a choice between alternatives.

The following definitions have been summarised from (De Jong \& Schellens, 1997, pp. 406-408);

1. Verification: The primary aim is to give a general indication of whether anything is wrong with the text. The tests often used for this function result in a quantitative score, for example the number of questions answered correctly by tested readers. This function assesses the document as a whole, in part, or its characteristics and is often completed at the end of the design 
Literature Review

process to conclude whether it should be put into circulation or not. For example, if the total number of wrong answers outweighs the number of correct answers the document should be revised.

2. Troubleshooting: This function is aimed at locating and diagnosing the problems that readers have with the text. This is different from the first function because it investigates the actual problems not just finding out if there are any. The data gained in this section is qualitative data. Trouble shooting evaluations may be carried out throughout the document design process, from exploring options in the early stages to optimising the final text.

3. Choice Supporting: This function is aimed at identifying the advantages and disadvantages of alternative forms of presentation. This function is only useful if a choice has to be made between two or more ways of presenting information. A choice supporting evaluation is often quantitative research, but a qualitative evaluation may also be useful to find out what makes one option superior to another.

de Jong and Schellens (1997) have compiled Table 4 to help choose the correct method to use.

\section{Overview of Methods in Relation to Functions ${ }^{a}$ and Topics}

\begin{tabular}{|c|c|c|c|c|c|c|c|}
\hline Methods & 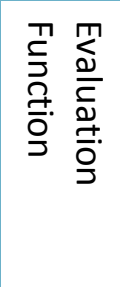 & $\begin{array}{l}\frac{\mathscr{D}}{D} \\
\stackrel{D}{+} \\
\frac{0}{3}\end{array}$ & $\begin{array}{l}\frac{0}{0} \\
\frac{3}{3} \\
\frac{0}{0} \\
\frac{1}{\sigma} \\
\frac{0}{9} \\
\frac{\omega}{0} \\
\frac{0}{2}\end{array}$ & 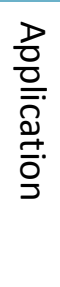 & 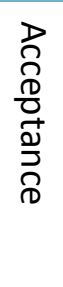 & $\begin{array}{l}\frac{D}{0} \\
\frac{0}{0} \\
\frac{0}{D} \\
\frac{1}{0} \\
\frac{1}{0} \\
\frac{0}{3}\end{array}$ & 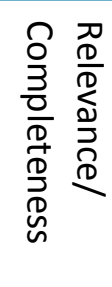 \\
\hline Portfolio method & $\mathrm{V} / \mathrm{T}$ & $x x$ & & & & & \\
\hline Target-plan method & $\mathrm{V} / \mathrm{T}$ & $x x$ & $\mathrm{x}$ & & & & \\
\hline $\begin{array}{l}\text { Reading behaviour } \\
\text { registration }\end{array}$ & $\mathrm{V} / \mathrm{T}$ & $x x$ & & & & & \\
\hline Cloze test & V & & $x x$ & & & & \\
\hline Comprehension test & $\mathrm{V} / \mathrm{T}$ & & $x x$ & & & & \\
\hline
\end{tabular}


Literature Review

Stage 1 - Determine if the documents are being distributed: If the documents themselves aren't being distributed to the right people, it does not matter how usable they are. Distribution should be based on user input. If it is not, the distribution system may need revamping.

Stage 2 - Identify the target audience: As described in ISO 9241-11:1998, it is important to know who the users of the document are. Kostur also suggests it is important to know how and where the document is being used. Overall this establishes the 'context of use' shown in Figure 3 (page 32).

$\underline{\text { Stage } 3}$ - Select a group of participants: The test participants should be the users. For a usability test to be successful it is important to get 'real users' from the target audience who understand your research goals and have permission to complete the test.

Stage 4 - Gathering usability criteria: Choosing the test that will collect the right information is important. Section 4.1.3 is useful in this respect. Using the information again from stage 2 to feed into Table 4 would be one way to indicate the type of usability test needed.

Stage 5 - Compiling the usability criteria: Once usability information is gathered, it must be transcribed it and reviewed it. The aim is to look for items most users have identified as top priority and for recurring actions or comments.

Stages 6 through to 9 These stages are all outside the scope of this project as they revolve around the writing of the document, reviewing the new document and testing it again.

\subsubsection{Summary}

This section of the literature review has outlined the aspects (layout, text, illustrating warnings and colour) that can affect the overall usability of a document. It is important to use these aspects correctly if a building user guide is to be usable. The actual assessment of the usability of building user guides can be completed with different methods. Both ISO 9241-11:1998 (1998) and de Jong and Schellens 
Literature Review

(1997) illustrate the aspects needed to both complete and choose the correct usability method. While Kostur (1990) outlines an appropriate plan of how to complete a usability assessment. 
Literature Review

\subsection{Conclusion}

\subsubsection{Building User Guides}

Studies have shown that building user guides do have a place in not only the GreenStar building system, but also GreenStar rated buildings themselves. However, building user guides have been found to be "too technical and too difficult" (Monfared \& Sharples, 2011, p. 350). This indicates the need to complete a study to find out why users may perceive building user guides as being too technical and too difficult to read and understand.

\subsubsection{Readability}

It was found that there are two different types of readability assessment tools. Readability equations derived from Sherman's early work and Word Assessment Tools created from Thorndike's early work. It has been found that readability formulae are a good starting point in investigating text; however they should also be used in conjunction with other assessment techniques.

\subsubsection{New Zealand Literacy Levels}

Using information from both the ALL study and Statistics New Zealand, the average literacy level of New Zealanders was Year 10 or 10 years of schooling which corresponds to American Grade Level 8-9.

\subsubsection{Usability}

Particular aspects of technical documents have been found to affect the usability (layout, text, illustrating warnings and colour). However, to assess the usability of a document, actual users need to be used as part of a usability assessment method. Both ISO 9241-11:1998 (1998) and de Jong and Schellens (1997) illustrate the aspects needed to both complete and choose the correct usability method. While Kostur (1990), outlines an appropriate plan of how to complete a usability assessment. 


\section{Readability Analysis}

The readability analysis chapter will investigate the overall readability of building user guides. The first section has investigated the most appropriate assessment method to ascertain a readability level. Section 3.2 has detailed the methodology of the readability assessment, followed by the results in Section 3.3. Finally an analysis of the results has been completed in Section 3.4.

\subsection{Readability Test Method Selection}

\subsubsection{The Test Method}

This section identifies the most appropriate readability assessment to use for this research and discusses why the selected test was chosen.

As stated in the literature review (Section 2.3.3), readability tests can be categorised into two groups: equations derived from Sherman's early works and adaptations of Thorndike's wordbooks. Equations derived from Sherman's work revolve around the statistical analysis of the text. The statistical analysis uses an equation with variables such as; sentence length, word count, syllable count etc. The adaptions of Thorndike's work establish a readability level based on the frequency of 'harder' words in a text (origins discussed in Section 2.3.3).

The subsequent sections investigate a rand of readability tests, resulting in the selection of one readability assessment from each of Sherman's work and Thorndike's for use in the methodology.

\subsubsection{Sherman's type of Readability Assessment}

There are a large number of readability formulae (Section 2.3.4), so a cluster sample was used to identify the most popular tests. Cluster sampling is a sampling technique used when it is difficult to identify every object in the sample(Babbie, 2012). A cluster sample was used to find journal articles that used readability formulae as part of their assessment or methodology. Once collected, 143 uses of readability formulae were found. The four most popular were identified, and finally 
one was selected based on the ease of use, how fast it could be used and how well it correlated to other formulae.

\subsubsection{Readability Formula Methodology}

The aim of this methodology is to identify the four most commonly used readability formulae from a selection of journal articles. To find enough journals a cluster sample was used. Three linguistic databases (MLA International, Linguistics and Language Behaviour Abstracts and ERIC via Proquest) were chosen at random and used to find the journal articles. To find the articles in each of the three publications the search term used was "readability formulae", the articles found were restricted by the date published and only articles produced after 2000 were used. Restricting the journals by date decreased the amount of journals found and it meant that only recent studies that used readability formulae were a part of the study. The restriction by date published, only relates to the journal articles not the readability formulae, for example, you may find a study published in 2005 using a formula created in 1948.

A total of 73 journal articles were found, six from MLA International, thirty from Linguistics and Language Behaviour Abstracts and 37 from ERIC via Proquest. Each article found was reviewed for the readability formula used. A total of 16 unique readability formulae were found with 157 uses of readability formulae found in total (see Graph 1).

The four most used formulae were the Flesch Kincaid Formula, the SMOG equation, Flesch Reading Ease and Fry's Readability Graph. 


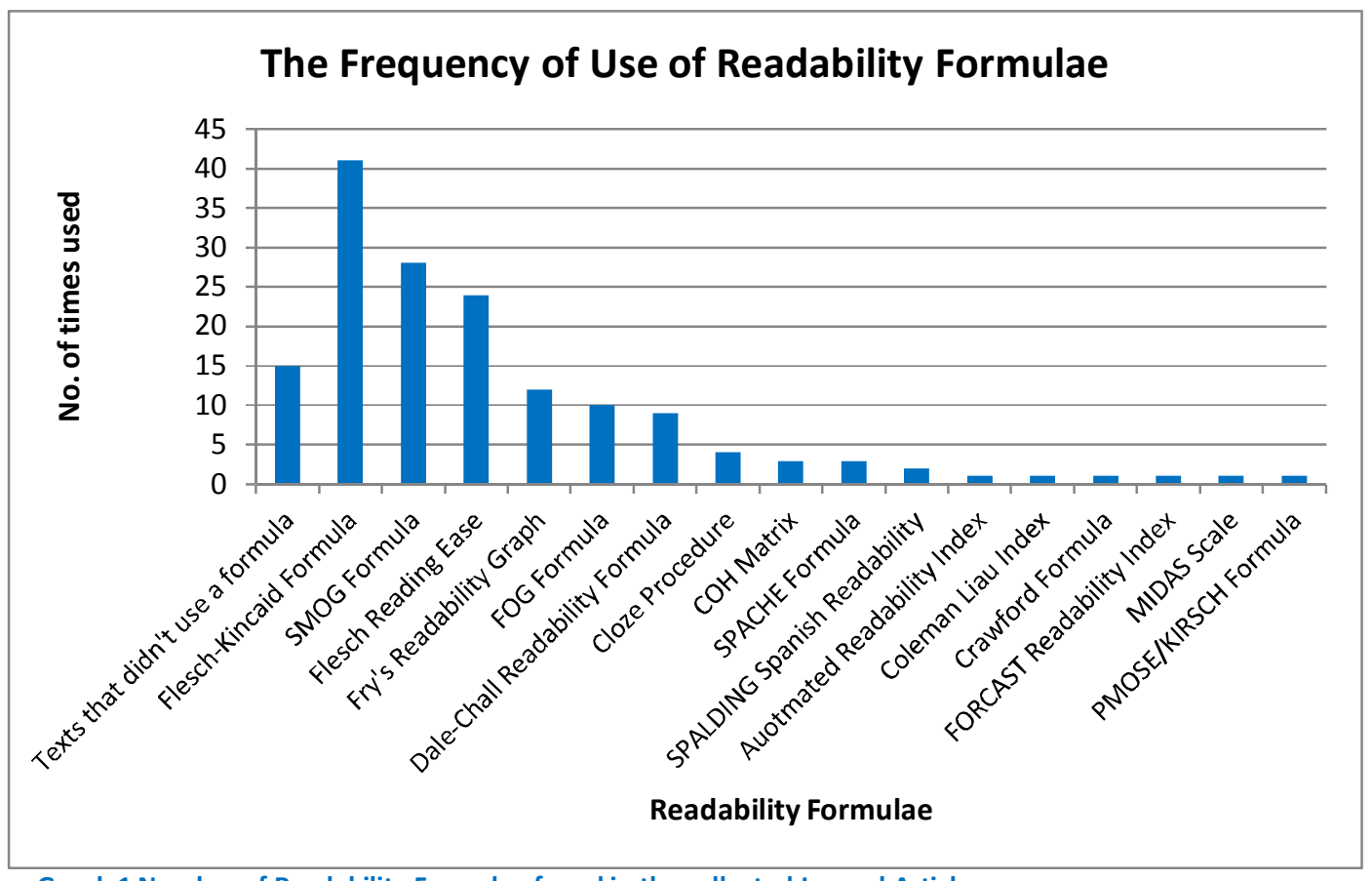

Graph 1 Number of Readability Formulae found in the collected Journal Articles

\subsubsection{Four most popular Readability formulae}

This section outlines an explanation of the Flesch Kincaid Formula, the SMOG equation, Flesch Reading Ease and Fry's Readability Graph. Followed by an explanation of how each equation is calculated and its advantages and disadvantages.

\subsection{Flesch Kincaid Formula}

The Flesch Kincaid Formula is an adaptation of the Flesch Reading Ease. The formula was created for Navy Use in 1951 (Dubay, 2004). As part of the adaptation, the 'score' result used in the Flesch Reading Ease formula was converted into a grade level. In 1978 the formula was authorised by the U.S. Department of Defence as a way of validating the readability of technical manuals (Dubay, 2004).

The Flesch Kincaid Formula is calculated by choosing a segment of continuing text, 100 words or more and then applying Equation 1 to the selection.

$$
G L=(.39 \times A S L)+(11.8 \times A S W)-15.59
$$


- $\mathrm{GL}=$ Grade Level

- $\mathrm{ASL}=$ average sentence length (the number of words divided by the number of sentences)

- $\mathrm{ASW}=$ average number of syllables per word (the total number of syllables in the sample divided by the number of words)

\subsection{Advantages and Disadvantages}

\section{Advantages:}

- This formula is readily available for use at it is incorporated into the Microsoft Word computer program (by selecting File $>$ Options $>$ Proofing $>$ select "Show readability statistics" - every time spellcheck is run the readability statistics will be shown) (Burke \& Greenberg, 2010)

- This formula is appropriate for all reading levels from early primary school through to college (based on USA's schooling system) (Burke \& Greenberg, 2010)

- The final score is easily relatable to a USA school grade (Dubay, 2004)

\section{Disadvantages}

- This formula tends to underestimate the difficulty of text by approximately two grade levels (Burke \& Greenberg, 2010)

\subsection{Simple Measurement of Gobbledegook (SMOG)}

The SMOG equation was created by McLaughlin (1969). The formula is based on $100 \%$ comprehension of the McCall Crabbs Standard Lessons in Reading, standardised graded readings, and validated on college students (Heyneman, 2006).

To calculate the grade level for a document with the SMOG equation select three 10 sentence sections, (one each from the beginning, middle and end of the text) (McLaughlin, 1969, p. 639). Within the three sections all the words that contain three syllables or more (polysyllabic) are counted and Equation 2 is applied. 


$$
G L=3.1291+1.0430 \times \sqrt{P S C}
$$

Equation 2 SMOG Equation

- $\mathrm{GL}=$ Grade Level

- $\quad P S C=$ Number of Polysyllabic words counted in the three sections (Polysyllabic words are defined as words that have 3 or more syllables)

\subsection{Advantages and Disadvantages}

\section{Advantages}

- The SMOG formula estimates the readability based on $100 \%$ comprehension as opposed to other formulae that use anywhere between $50-75 \%$. This provides a more meaningful standard to base the grade level results on (Burke \& Greenberg, 2010)

- Appropriate for secondary schooling through to adult materials (Burke \& Greenberg, 2010)

- The SMOG formula has both a simplified and a more complex equation based on the time available and how detailed the investigation needs to be (McLaughlin, 1969)

\section{Disadvantages}

- The SMOG formula often over-estimates the grade level by one to two grades (Burke \& Greenberg, 2010)

\subsection{Flesch Reading Ease}

The Flesch Reading Ease formula was published by Flesch in 1948 (Dubay, 2004). It was the third most commonly used readability formula found in this study, which is reflective of results of similar studies. McDonald and Loughran (2010) and Ogloff and Otto (1991) state that the Flesch Reading Ease formula is one of the most common and Cramer (1978), includes the readability formula as one of six most widely used formulae. 
The Flesch Reading Ease score is calculated by choosing a segment of text 100 words or more and then applying Equation 3.

$$
\begin{gathered}
\text { Score }=206.835-(1.015 \times A S L)-(84.6 \times A S W) \\
\text { Equation } 3 \text { Flesch Reading Ease Equation }
\end{gathered}
$$

- Score $=$ position on a scale of 0 (difficult) to 100 (easy), with $30=$ very difficult and $70=$ suitable for adult users

- $\mathrm{ASL}=$ average sentence length (the number of words divided by the number of sentences)

- $\quad \mathrm{ASW}=$ average number of syllables per word ( the number of syllables divided by the number of words)

\subsection{Advantages and Disadvantages}

\section{Advantages}

- This formula is readily available for use as it is incorporated into the Microsoft Word computer program (by selecting File > Options $>$ Proofing $>$ select "Show readability statistics" - every time spellcheck is run the readability statistics will be shown) (Burke \& Greenberg, 2010)

- This formula is appropriate for all reading levels (Burke \& Greenberg, 2010)

- Became the most widely used formula (Dubay, 2004; Klare, 1963)

- Dubay (2004) and Klare (1963) claim that it is one of the most tested and reliable readability formula

\section{Disadvantages}

- The score at the end of the calculation has a range from 0-100 and thus requires an extra step to convert the result into a school grade

\subsection{Fry Readability Graph}

The Fry readability graph was created by Edward Fry (1968). The graph was created while he was working in Uganda educating locals to teach English. Fry's graph was 
validated with comprehension scores of primary and secondary school materials and by correlations with other formulae (Dubay, 2004).

The following is the process outlined by Fry (1968) for the use of the Readability Graph:

- Select three 100 word passages from near the beginning, middle and end of the book. Skip all proper nouns,

- Count the total number of sentences in each passage (estimating to the nearest tenth of a sentence). Average the totals from the three samples,

- Count the total number of syllables in each hundred-word sample. Average the total number of syllables for the three samples,

- Plot on the graph (Graph 2) the average number of sentences per hundred words and the average number of syllables per hundred words. Most plot points fall near the heavy curved line. Perpendicular lines mark off approximate grade level areas. 


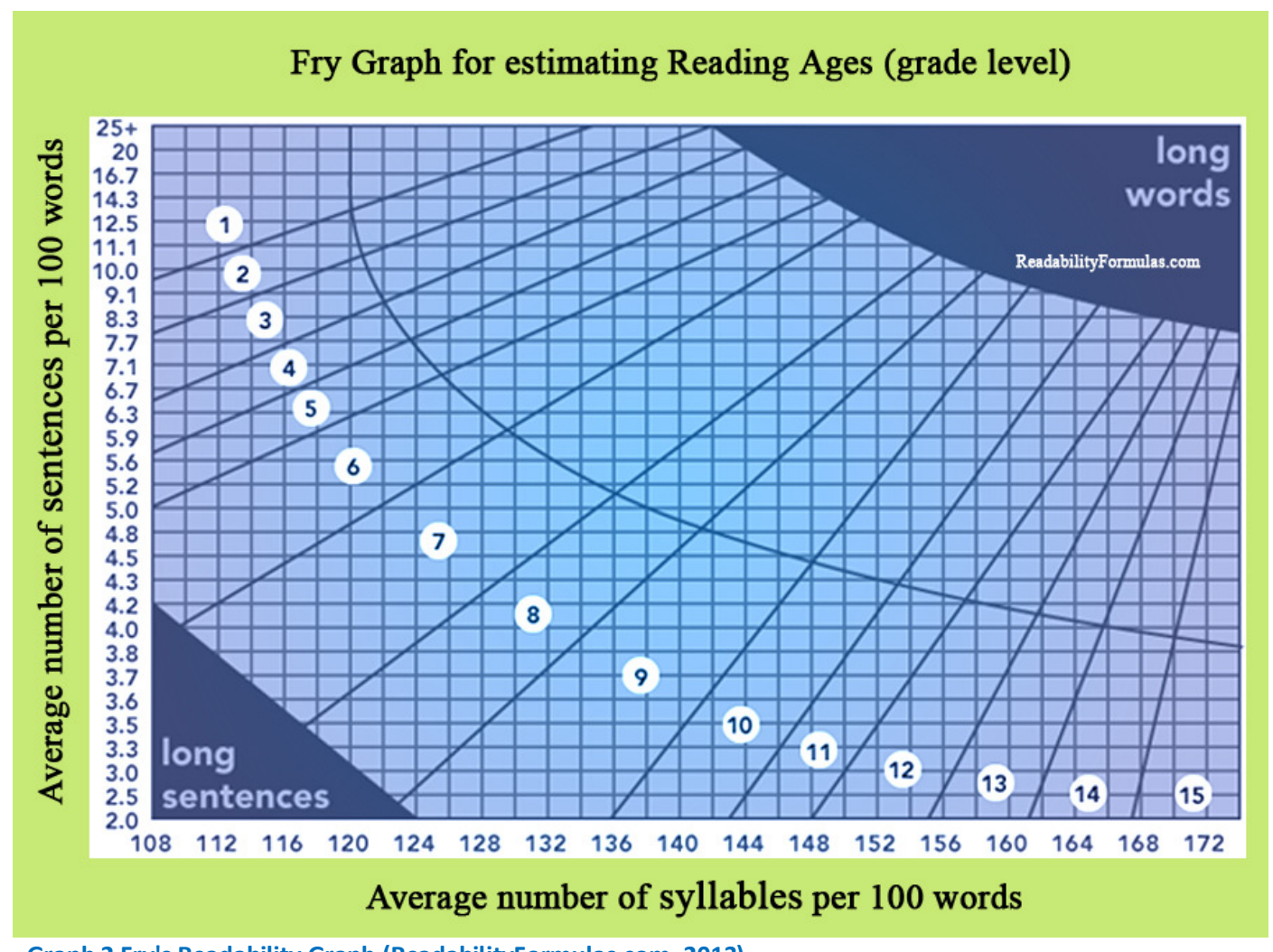

Graph 2 Fry's Readability Graph (ReadabilityFormulas.com, 2013)

\subsection{Advantages and Disadvantages}

\section{Advantages}

- Correlates well with the SMOG formula and Flesch Reading Ease (Aleligay et al., 2008)

- The graph is known for its simplicity without sacrificing the accuracy of the readability score (Fry, 1977)

\section{Disadvantages}

- Not accurate beyond the $12^{\text {th }}$ grade (American Grade) (Kahn \& Pannbacker, 2000)

- Requires more time to calculate than the SMOG equation, as you have to look up the value on a graph (Kahn \& Pannbacker, 2000) 


\subsubsection{Conclusion of Sherman's Work}

All four of the equations use the same variables as part of their formulae. This results in the four formulae correlating well with one-another (Aleligay et al., 2008). The other variable considered when choosing the readability equation is the speed it took to calculate a readability score. Both the Flesch Reading Ease and Flesch Kincaid Formula are able to be calculated using Microsoft Word, however this would not be helpful as the Building User Guides are all in PDF format. The PDF format is not easily converted into a Microsoft Word document. Maginni's (1982, p. 598) suggests that the formula that would be the fastest and simplest to use would be the SMOG formula. The SMOG equation also has the benefit of having a simpler version which is known as the SMOG index that is even faster to calculate (McLaughlin, 1969). Fry's Readability Graph is known for its simplicity - however having to find the result using a graph results in a longer calculation time. For the reasons stated above the SMOG formula is one of the two readability assessments tools that will be used in this thesis, the second readability assessment is discussed in Section 3.1.3.

\subsubsection{Thorndilke's type of Readability Assessment}

Thorndike's work uses frequency as a predictor of readability (see section 2.3.3). For this reason, he created word lists that identified the most frequently used English written words. The first studies of word frequencies started before the advent of the computer (Johansson, 1985). The majority of Thorndike's work was created before the wide spread use of computers, for this reason his work will not be considered for use as lists with larger amounts of words have been created.

The resultant availability of computers' processing power has made the creation of the words list easier and the process of storing, comparing and analysing words faster (Johansson, 1985). Furthermore it makes the ability to update these lists easier, for the convenience of time, this methodology, only word lists that have been created with the use of a computer will be analysed. 
Word profiling uses word frequency lists that analyse each word in a text based on its hardness (less frequently used word) (Mollet, Wray, Fitzpatrick, Wray \& Wright, 2010). A computer program can separate each word into its frequency of use which generates analyses based on how many less frequent words there are in a text.

The basic principles behind different word frequency profiling assessment tools is similar in that they address word frequency as an indicator of readability (DuBay, 2007). The use of a word frequency profiler has been used to calculate the readability of a large array of texts from books to movie scripts (Nation, 2006). Mollet et al. (2010) state that using a word profiler is a good way of estimating how many words are known in a text. Below are four methods of assessing text by word frequency profiling:

1. 'Nations 25K List' (Nation, 2006) Frequency and AntWordProfiler (Lawrence, 2012) is a simple program and word list combination that return basic frequency information. They break the words in a text into 25 frequency bands of 1000 word lemmas each (Mollet et al., 2010).

2. Cobbs VocabProfiler produces a lexical frequency profile according to Nations first two, thousand frequency bands (Mollet et al., 2010). It also calculates Lexical Density - the proportion of tokens (words) which are content bearing rather than functional (Ure, 1971).

3. V_Size (Meara \& Mireaplex, 2004) calculates the distribution of the words across frequency bands. By fitting a curve to the graph, V_Size estimates the total size of the productive vocabulary of the writer (Mollet et al., 2010).

4. JACET 8000 (Ishikawa et al., 2003) is based on a combined corpus of English language texts relevant to Japanese learners, organised into eight frequency bands of 1000 (Yamaguchi, 2006).

\subsubsection{Summary and Conclusion of Thorndike's Word}

The four different word lists and/or computer programs are by no means an exhaustive list, but are considered some of the most popular (Mollet et al., 2010). 'Nation's 25K' word list along with the AntWordProfiler are known to be simple to 
use and produce user friendly results (Nation, 2006). 'Nation's $25 \mathrm{~K}$ ' is also one of the longest wordlists (i.e. contains the largest number of words). Cobbs VocabProfiler is similar to Nations list but it is only a small list and it finds the Lexical Density which is not needed. V_Size is based more on finding the vocabulary ability of the writer rather than the text. JACET 8000 is more aimed at Japanese texts. For the reasons stated above, the second readability assessment tool that was used in the methodology was 'Nation's $25 \mathrm{~K}$ ' list along with the processing ability of the AntWordProfiler. 


\subsection{Readability Methodology}

This research used both the SMOG Equation and Nations 25K wordlist (coupled with AntWordProfiler) as identified in Chapter 3. These two readability assessment tools were used to assess the readability level of Building User Guides. This chapter is split into three sections, first a description of the building user guides and where they were collected from, the second outlines the process of using the SMOG equation and finally the third outlines the process of using Nation's $25 \mathrm{~K}$ wordlist.

The two analysis tools were used to answer the following research questions repeated from Section 1.2:

- What is the range of readability scores of the current building user guides created for buildings that are a part of the New Zealand Green Building Council's GreenStar Accreditation scheme?

- How do the scores reflect on the literacy levels of the New Zealand's building occupants?

- How do the scores of the two methods compare with one another?

- Why do some Building User Guides score better than others?

As per Section 0 the aim of this research is to also establish the best process in determining the readability level of a text. Therefore, the identification of the better suited readability process has been completed.

\subsubsection{Collection of Buillding User Guides}

A list of all the GreenStar projects was obtained from the New Zealand Green Building Councils website (New Zealand Green Building Council, 2012). A letter (See Appendix - A) was sent to the Environmentally Sustainable Design (ESD) consultants or the owners of the buildings to request the use of the available building user guides.

Six different companies wrote the Building User Guides documents collected. A total of 23 building user guides were collected. Just under half (11) were from buildings in Auckland, five were collected for buildings in Wellington, two each from 


\section{Readability Analysis}

Christchurch and Hamilton and one each from Northland, New Plymouth and Ohakea. The majority of the buildings were office buildings (18), four were Educational Institutions and one was industrial. The guides collected were completed between March 2008 and September 2011. The received building user guides were all obtained in PDF form.

Illustrated in Graph 3 the highest total number of words and pages out of the collected building user guides (BUG) belongs to BUG 4 with 9,754 words and 44 pages. The lowest word count belongs to BUG 20 with 1,579 words and the lowest number of pages belongs to BUG 9 with 6 pages. The average word count of the building user guides was 4,390 and the average number of pages was 22 .

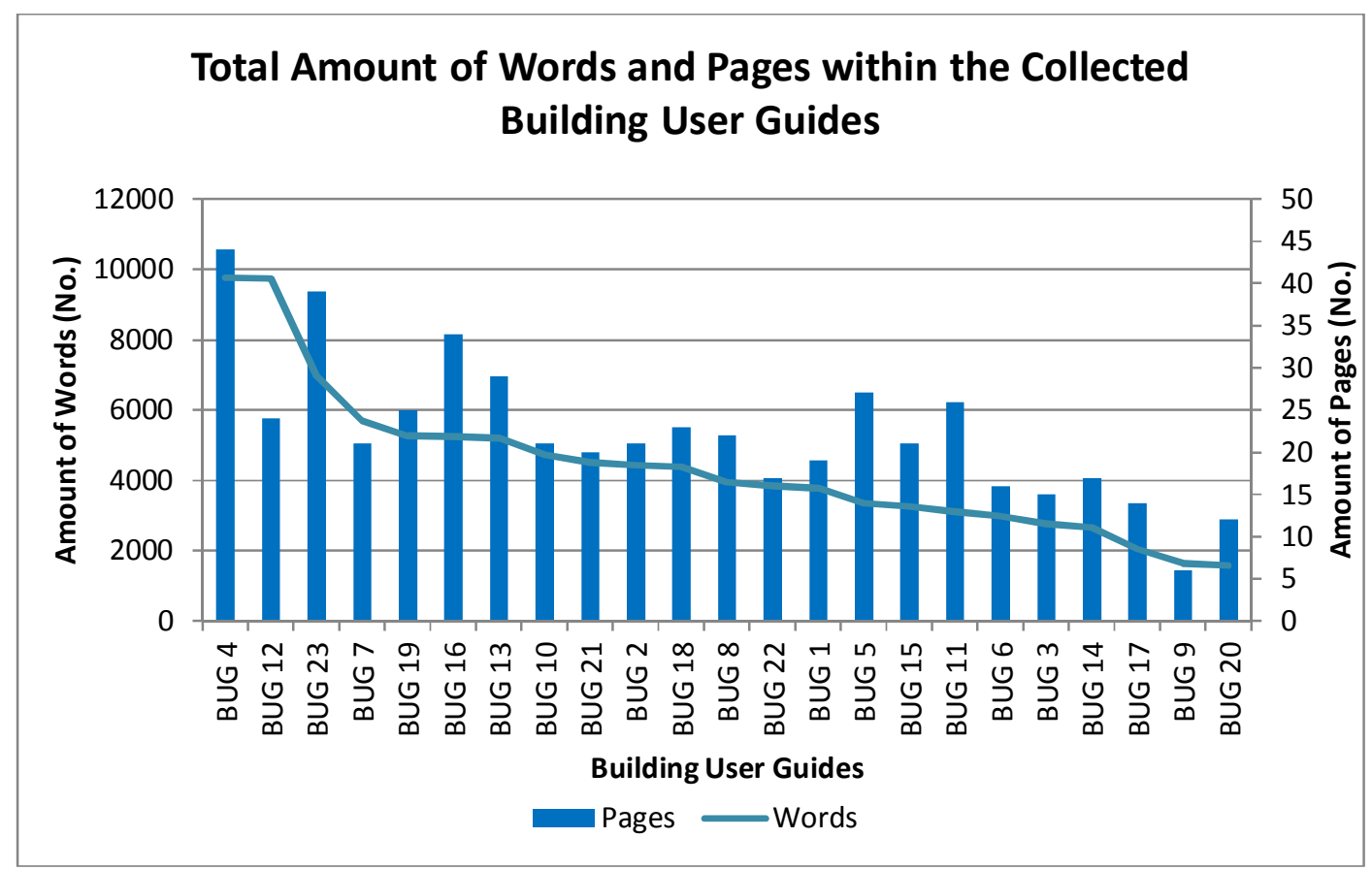

Graph 3 shows the total number of words used and total number of pages of each of the 23 collected Building User Guides (Sorted by total amount of words)

\subsubsection{SMOG Formula Methodology}

This section illustrates how the SMOG formula has been used to analyse the building user guides. The first sub-section illustrates how the selection of text was used as well as how sentences were identified and polysyllabic words were found. 
The second sub-section discusses how the formulae were applied to the text once this information was found.

\subsubsection{Guidelines of the SMOG testing procedure}

The first part of the SMOG procedure was the selection of the text used to calculate the readability score. This process is outlined by McLaughlin (1969):

"Count 10 consecutive sentences near the beginning of the text to be assessed, 10 in the middle and 10 near the end. Count as a sentence any string of words ending with a period, question mark or exclamation point"(McLaughlin, 1969, p. 639).

Research into the sampling variability of formulae has found that using samples from within a text rather than a complete text "may obscure a great deal of variability within a text" (Carrell, 1987, p. 32). With this said, the SMOG formula has used 30 sentences which McLaughlin (1969) estimates is around 600 words compared to other readability formulae which may instruct you to use samples of around 100 words.

"By sampling 30 sentences, which typically cover 600 words, you get a reliable prediction straight away, particularly if the 30 sentences are divided into three groups of ten consecutive sentences, each group being in a different part of the text"(McLaughlin, 1969, p. 641).

As there have been no studies completed that have assessed the readability of building user guides, the selection of 30 sentences will be compared with applying the formula to the whole document. This will identify if using a 30 sentence selection is sufficient enough to represent the whole document's readability level.

A string of words that end in a punctuation mark identifies a sentence. However, a common occurrence within the collected building user guides is their use of bullet points. The majority of the bullet points do not end with a punctuation mark. For the purpose of this study, a bullet point will be counted as one sentence.

The second part of the SMOG process is the counting of the polysyllabic words: 
"In the 30 selected sentences count every word of three or more syllables. Any string of letters or numerals beginning and ending with a space or punctuation mark should be counted if you can distinguish at least three syllables when you read it aloud in context. If a polysyllabic word is repeated, count each repetition" (McLaughlin, 1969, p. 639).

Other treatments for common situations:

- Numbers - to assess numbers when in numeric form, pronounce the whole number to determine if they are polysyllabic

- e.g. 11 should be counted as "eleven" returning 3 syllables

- Abbreviations - to assess abbreviations, or acronyms, pronounce them in their full form i.e. unabbreviated

- e.g. SMOG should be counted as "simple measure of gobbledygook" with the words having 2,2,1,4 syllables respectively or Prof. should be counted as Professor returning 3 syllables

- Hyphenations - to assess hyphenated words count them as if they were just one word

- e.g. middle-aged, should be counted as 3 syllables

- Websites are commonly used in building user guides to provide references for finding extra information and should not be counted as part of the formula

As stated in section 3.1.2.1, the SMOG equation has two equations; one deemed the original formula known as the 'SMOG equation' and the second deemed as the simple formula for mental maths known as the 'SMOG index'. The 'SMOG index' uses rounded numbers as variables i.e. using 3 instead of 3.1291 and using 1 instead of 1.0430, to make the calculations easier. For this study both formulae (the 'SMOG formula' and the 'SMOG index') will be used to determine if their use has any effect on the end outcome. 
Readability Analysis

\subsubsection{SMOG Readability Method}

A total of four separate tests using the SMOG formula will be completed on each building user guide. As identified in sub-section 3.2.2.1 there are two different formulae, the 'SMOG formula' and the 'SMOG Index'. Furthermore it was stated that as a result of building user guides not having been assessed for their readability, the original 30 sentence selection method may not have been appropriate. It was concluded that both a $\mathbf{3 0}$ sentence selection as well as the whole text would be used and compared. The four separate tests were:

1. The SMOG formula using a selection of 30 sentences - (Equation 4)

2. The SMOG index using a selection of 30 sentences - (Equation 5)

3. The SMOG formula using the whole text - (Equation 6)

4. The SMOG index using the whole text - (Equation 7)

\section{Test one - SMOG Formula with 30 sentences}

\section{Method:}

1. Identify the three 10 sentence passages for use

a. Count out the first 10 sentences of the document

b. Starting with the first full sentence on the middle page of the building user guide, count 10 sentences

c. Count the last 10 sentences of the building user guide, working backwards from the last punctuation mark

2. In the selected 30 sentences count every word of three or more syllables using the guidelines in section 3.2.2.1

3. Use the SMOG formula (Equation 4) to calculate the SMOG grade level of the text.

$$
\text { GIndex }=3.1291+1.0430 \times \sqrt{P S C}
$$

Equation 4 SMOG formula using a selection of $\mathbf{3 0}$ sentences

Where: GIndex = SMOG grade index and PSC $=$ Polysyllable count 


\section{Test two - SMOG index with 30 Sentences}

\section{Method:}

1. Identify the three $\mathbf{1 0}$ sentence passages for use

a. Count out the first 10 sentences of the document

b. Starting with the first full sentence on the middle page of the building user guide, count 10 sentences

c. Count the last 10 sentences of the building user guide, working backwards from the last punctuation mark

2. In the selected 30 sentences count every word of three or more syllables using section 3.2.2.1 as a guide.

3. Use the SMOG index (Equation 5) to calculate the SMOG grade level of the text.

$$
G L=3+\sqrt{P S C}
$$

Equation 5 SMOG Index using a selection of 30 sentences

Where: $\mathrm{GL}=$ Grade level and PSC = Polysyllabic Count

Test three-SMOG Formula with the whole document

\section{Method:}

1. Separate the whole text (with the exception of the appendix) into 10 sentence blocks.

2. For each section of ten sentences count every word of three or more syllables using section 3.2.2.1 as a guide (effectively counting all polysyllabic words in the document).

3. Use Equation 6 to calculate to the SMOG grade index of the text.

$$
\text { GIndex }=\sqrt{P S C \times \frac{30}{T N S}}+3
$$

Equation 6 SMOG Index using the whole text 
Where: GIndex = SMOG grade index, PSC $=$ polysyllabic count and TNS $=$ Total Number of Sentences

\section{Test four - SMOG Index with the whole document}

\section{Method:}

1. Separate the whole text (with the exception of the appendix) into 10 sentence blocks.

2. For each section of ten sentences count every word of three or more syllables using the section 3.2.2.1 as a guide (effectively counting the all polysyllabic words in the document).

3. Use Equation 7 to calculate to the SMOG grade index of the text.

$$
G L=1.043 \times \sqrt{P S C \times \frac{30}{T N S}}+3.1291
$$

Equation 7 SMOG Formula using the whole text

Where: GIndex = SMOG grade index, PSC = polysyllabic count and TNS = Total Number of Sentences

\subsubsection{How the Results were Assessed}

Each building user guide was assessed using the four formulae and the results displayed in Section 3.3. A chi square tests if there is a statistical relationship between the variables that are more than chance (Diaconis \& Efron, 1985) to indicate if there was a correlation between the four SMOG assessments. A chisquare test calculates a chi-squared value $\left(\chi^{2}\right)$ as well as a level of significance $(p)$. If a test of significance gives a $p$-value lower than or equal to the significance level $(\alpha)$, the null hypothesis is rejected (Fisher, 1926). For this research a value of $>0.05$ is used for $\alpha$, meaning a $p$-value of $>0.05$ results in an association of the two variables (Fisher \& Yates, 1963). This test was followed by a two-tailed Spearman's correlation test that was used to assess the strength of the relationship between the SMOG assessments. 


\subsubsection{Assessing the Text Using the Word Frequency Profiler}

The word frequency of the building user guides was calculated using the program AntWordProfiler (Lawrence, 2012) (Downloadable from the Laurence Anthony Laboratory web site: http://www.antlab.sci.waseda.ac.jp/). The word list used was 'Nation's 25K' list, a list developed from the British National Corpus (BNC), available from Paul Nation's, Victoria University Profile (http://www.victoria.ac.nz/lals/about/staff/paul-nation).

This chapter will first explain how the word list was created, followed by the method used to find the word frequency of the building user guides.

\subsubsection{Nation's 25K Word List}

'Nation's 25K' is a list of twenty-five 1,000 word lemmas developed from the British National Corpus (BNC). A word lemma is an auxiliary proposition used in the demonstration of another proposition (Merriam-Webster, 2005). For example, if run was a proposition, runs, ran and running are all demonstrations of other propositions. The words in the BNC are a collection of samples of written and spoken language from newspapers, periodicals, journals and books. This collection is designed to represent a wide cross section of British English with the latest version released in 2007 (Oxford University Computing Services, n.d.). The list adds frequency values to each word found in the samples of newspapers, periodicals, journals and books, using these values words are sorted into lists of 1,000 by frequency of word family or in Nations list, lemmas (Mollet et al., 2010, p. 451).

"The range, frequency, and dispersion data that were used for the division of the words into lists is thus based on lemmas and not on word-families. For example, the word family of 'abbreviate' contains the following members: abbreviate, abbreviates, abbreviated, abbreviating, abbreviation, abbreviations. This family consists of two lemmas: the abbreviate lemma with four members and the abbreviation lemma with two members." Nation (2006, p. 63) 
As the BNC is derived mainly from British English literature, many proper nouns, hyphenated words and abbreviated words are not included in the $25 \mathrm{~K}$ word list and will be treated as follows:

- Proper Nouns - proper nouns, for example Kurahaupo, Rangitoto, Helensville, Aotea etc., were added to a special list that was also imported into AntWordProfiler see (Figure 5). This means that the proper nouns are not included under the unknown words total (Nation, 2006).

- Hyphenated words - words that are hyphenated need to be split into two words and are "simply counted as separate words" (Nation, 2006, p. 66).

- Abbreviations/Acronyms - much like proper nouns, abbreviations and acronyms have their own specific list so they do not get included in the unknown words total

The AntWordProfiler compares Nations25K word list against a piece of text. The program looks word by word at the text that needs to be assessed and finds the list that each word belongs to, for example, the word 'access' is in the second 1000 word list. The program then computes the percentage of words from the chosen text found in each word list. As an example of an analysis, Nation (2006), identified it takes between 8,000 and 9,000 word lemma to read a standard newspaper.

The reader is presumed to have an understanding of the proper nouns, abbreviations and acronyms within the text. Consequently the frequency of the proper nouns, abbreviations and acronyms will not be counted within the results of the assessment.

\subsubsection{Word Frequency Profiler Method}

The same 23 building user guides that were assessed in the SMOG test will be used again. As stated in section 3.1.2.3, the building user guides were all received in PDF format which meant they all needed to be converted into .txt files in order to import them into the AntWordProfiler. 


\section{Readability Analysis}

Once converted into txt files all 23 building user guides were checked for any spelling errors and all proper nouns, abbreviations and acronyms were found and added to the corresponding lists. All hyphenated words were made into two separate words. This process took about 1.5 hours to complete per building user guide, because the whole text had to be read and checked without the aid of a computer.

After the conversion, both the building user guides .txt files and Nation's $25 \mathrm{~K}$ word lists were imported into AntWordProfiler - see screenshot of the AntWordProfiler Figure 5.

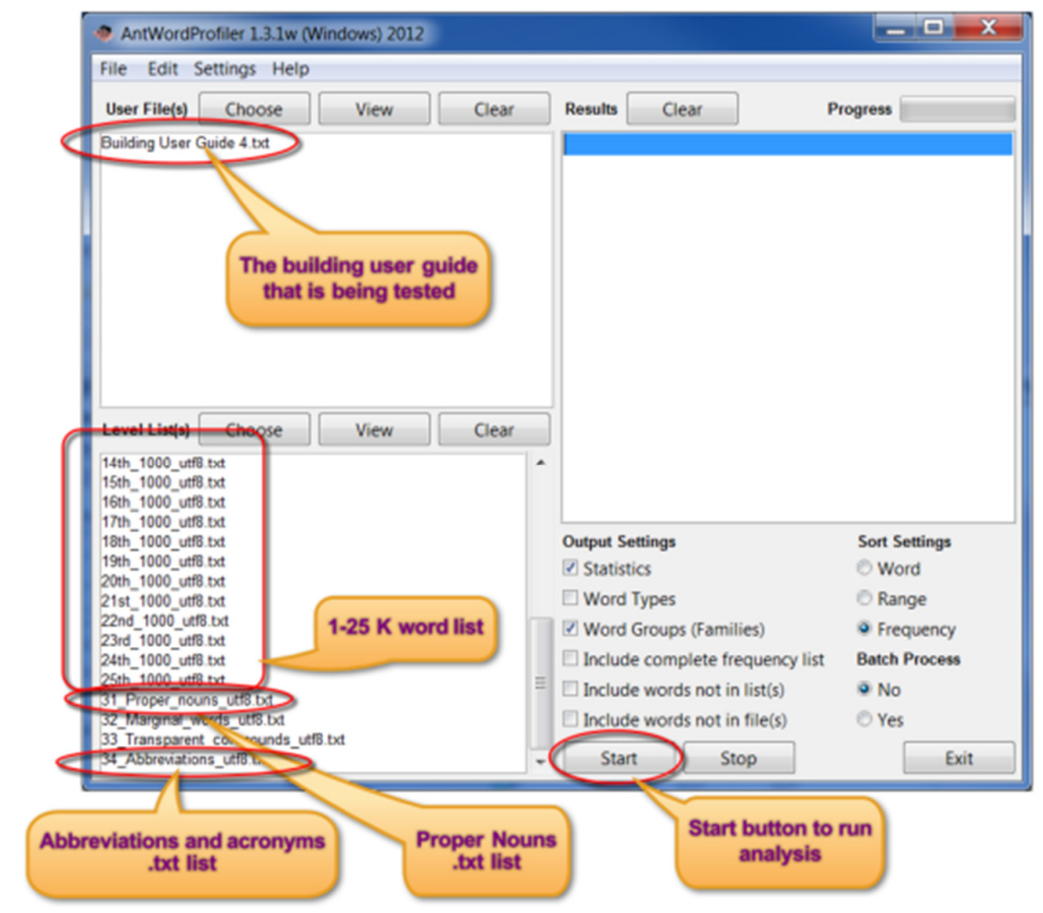

Figure 5 Screenshot of the AntWordProfiler

All 23 building user guides were run and saved individually as a 'Nations Range File' (a save-as option within the AntWordProfiler (File>Save Results in Nations 'Range' format)). These saved files once opened in Excel returned results as shown in Figure 6. As mentioned previously, the readers are presumed to have an understanding of the proper nouns, abbreviations and acronyms in the text. As a result of this presumption, an extra column in the results was added to find the cumulative 
percentage total of all the words excluding the proper nouns, abbreviations and acronyms found in the text.

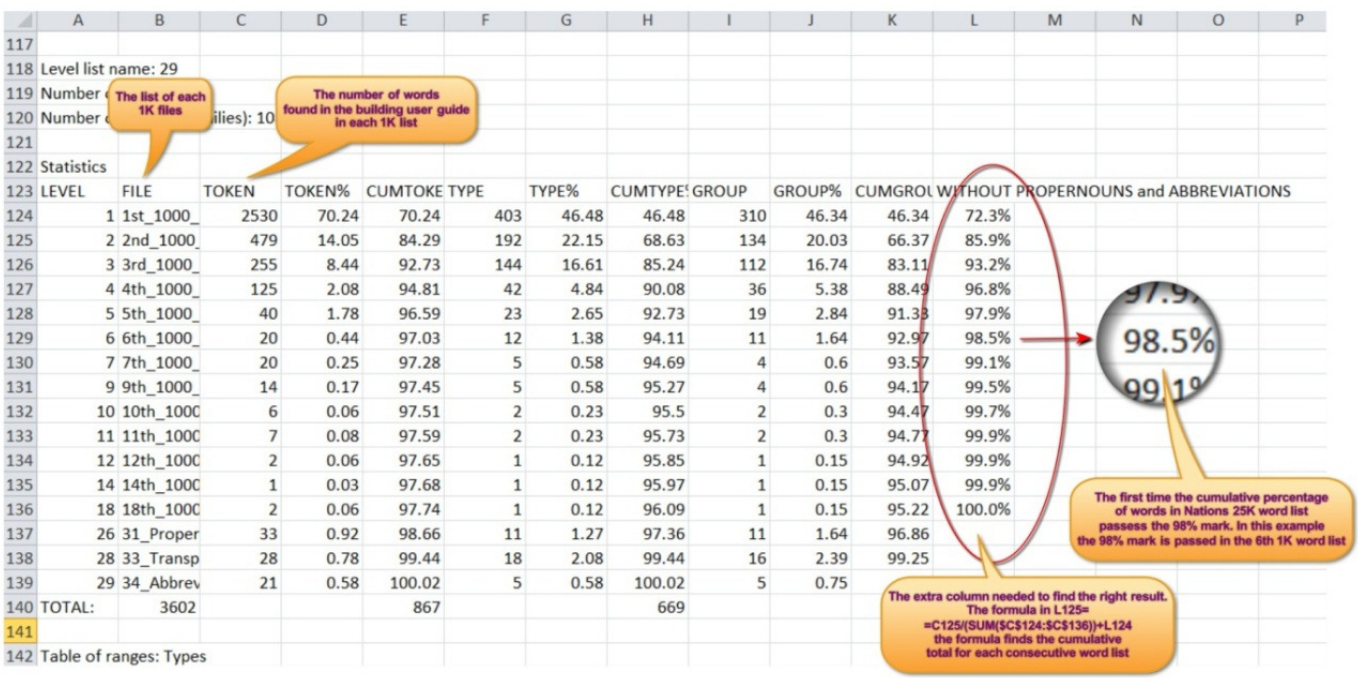

Figure 6 Example of results from AntWordProfiler

\subsubsection{Explanation of Results}

AntWordProfiler was used to assess the text at a coverage level of $98 \%$ for all 23

Building User Guides in this study. The $98 \%$ point is where the reader has the ability to understand all but 1 in 50 words (Nation, 2006). This level has been stated as the level required for most readers to gain adequate comprehension (Nation, 2006). To find the $98 \%$ mark, see Figure 6, an example of the results produced by BUG 1 .

Figure 6 demonstrates that at list level 6 , the cumulative total of words first passes the $98 \%$ mark. This result indicates that $98 \%$ of the words found in this particular building user guide were in lists 1-6 with the rest falling between 7 and 18. This also shows that the reader of this building user guide requires a total of 6,000 word lemmas to understand the text.

No studies have compared the amount of word lemmas required in grades of school like the SMOG results. As a consequence, the building user guides assessed will be compared to the amount of word lemmas needed to understand a newspaper 
(between 8,000-9,000 word lemmas (Nation, 2006)) to provide some baseline comparison. 


\subsection{Readability Results}

The following sections will review the results of the two separate tests that were outlined in the Readability Methodology (Section 3.2). The results section will display the information with a further analysis presented in the Discussion (Section 3.4).

\subsubsection{Results of the SMOG Readability Formula}

Graph 5 presents the findings on the readability score, calculated with the four equations outlined in Methodology. The 23 Building User Guides are identified by number for the purposes of anonymity.

Examining the document collection as a whole

The greatest range of scores came from the equations that used a 30 sentence sample with a difference of grade score of 4.8 and 5 respectively.

SMOG Assessment Tool

SMOG Equation with 30 sentences

SMOG Index with 30 sentences

SMOG Equation using the whole document

SMOG Index using the whole document

\section{$\underline{\text { Range of Scores }}$}

Grade Level of $12.5-17.3$

Grade Index of 12-17

Grade Level of 12.6-15.7

Grade Index of 12-15

Table 5 Range of results of the SMOG Assessment 


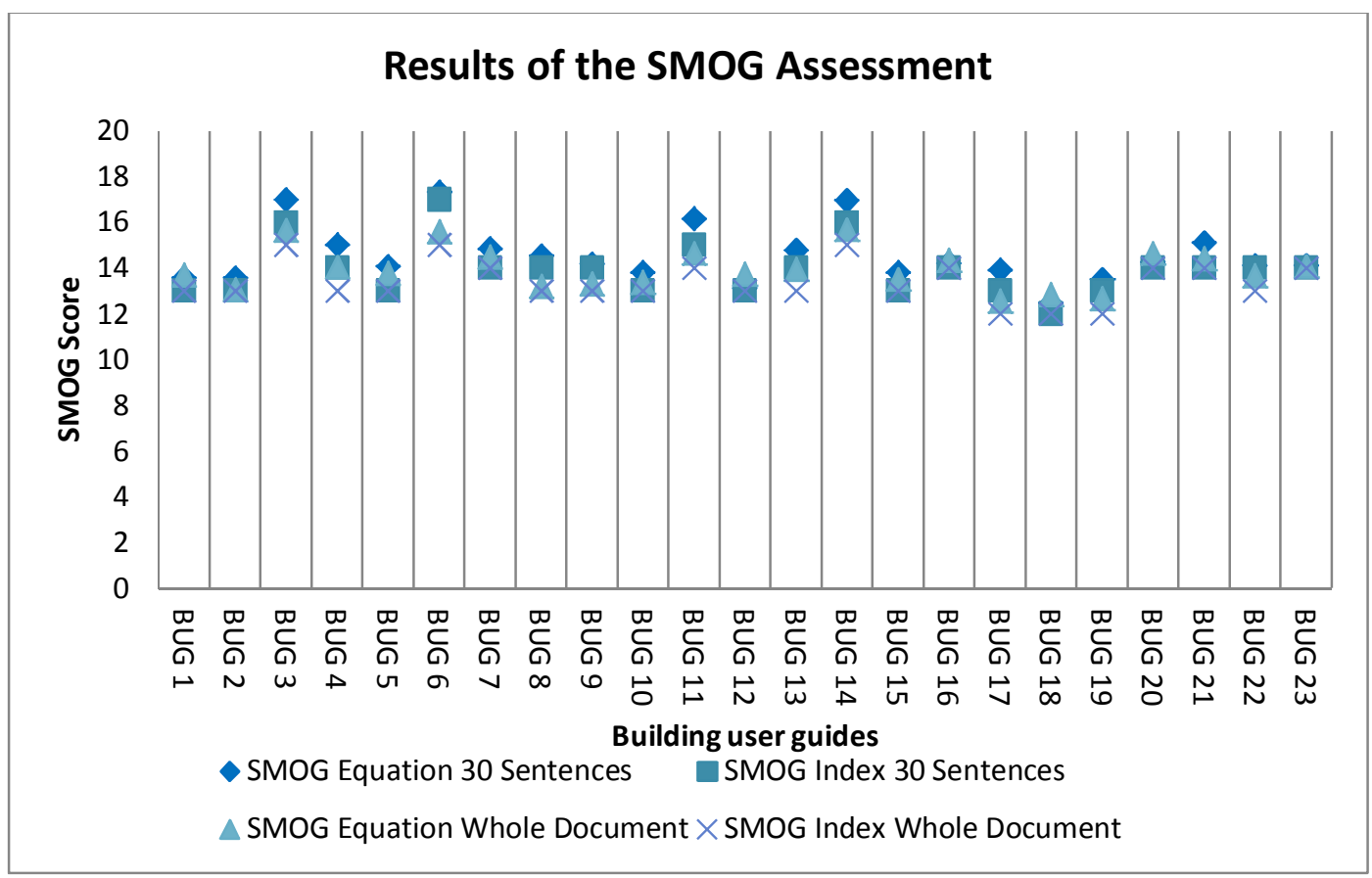

Graph 5 Results of the SMOG Assessment

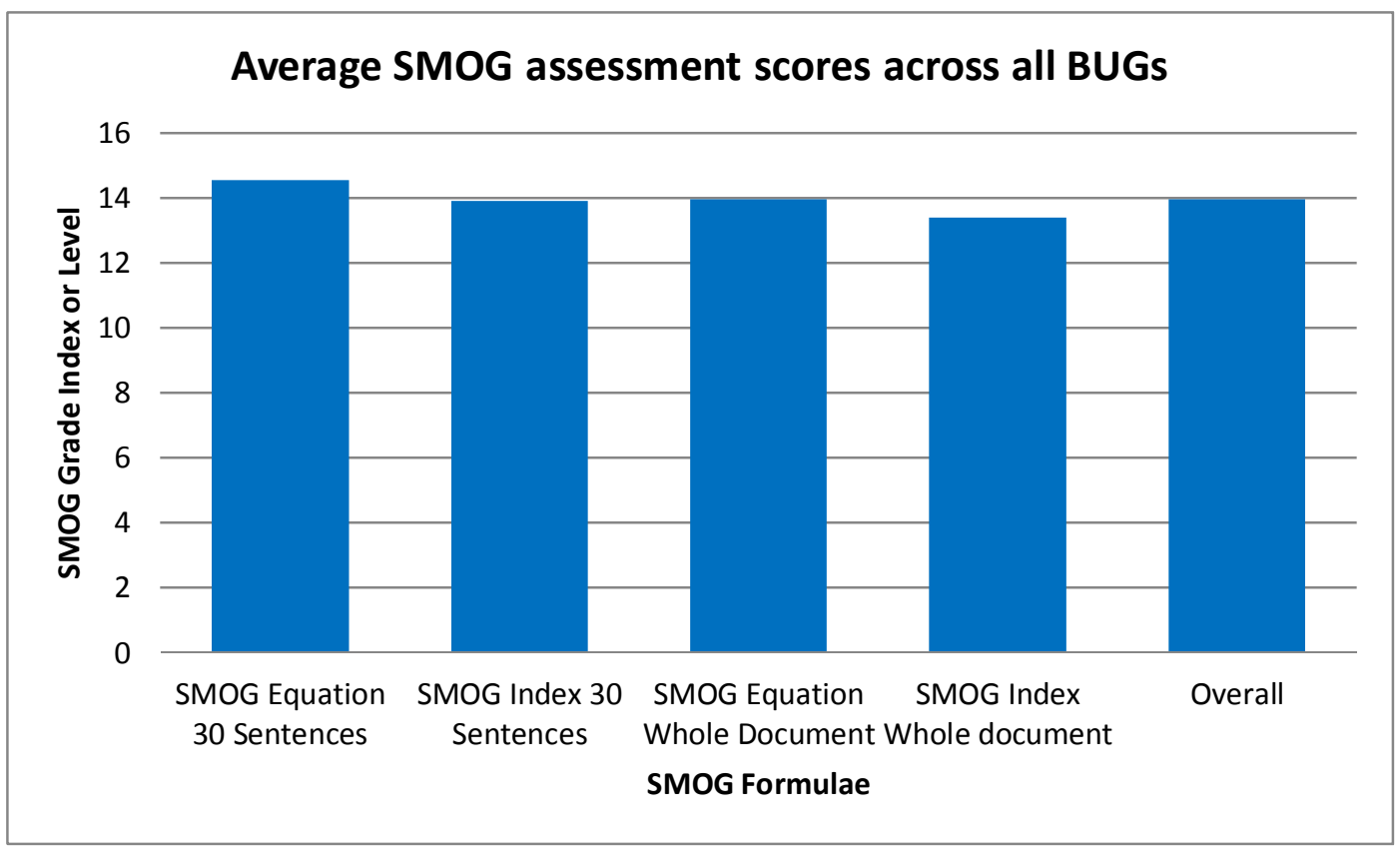

Graph 4 Average SMOG assessment scores across all BUGs 


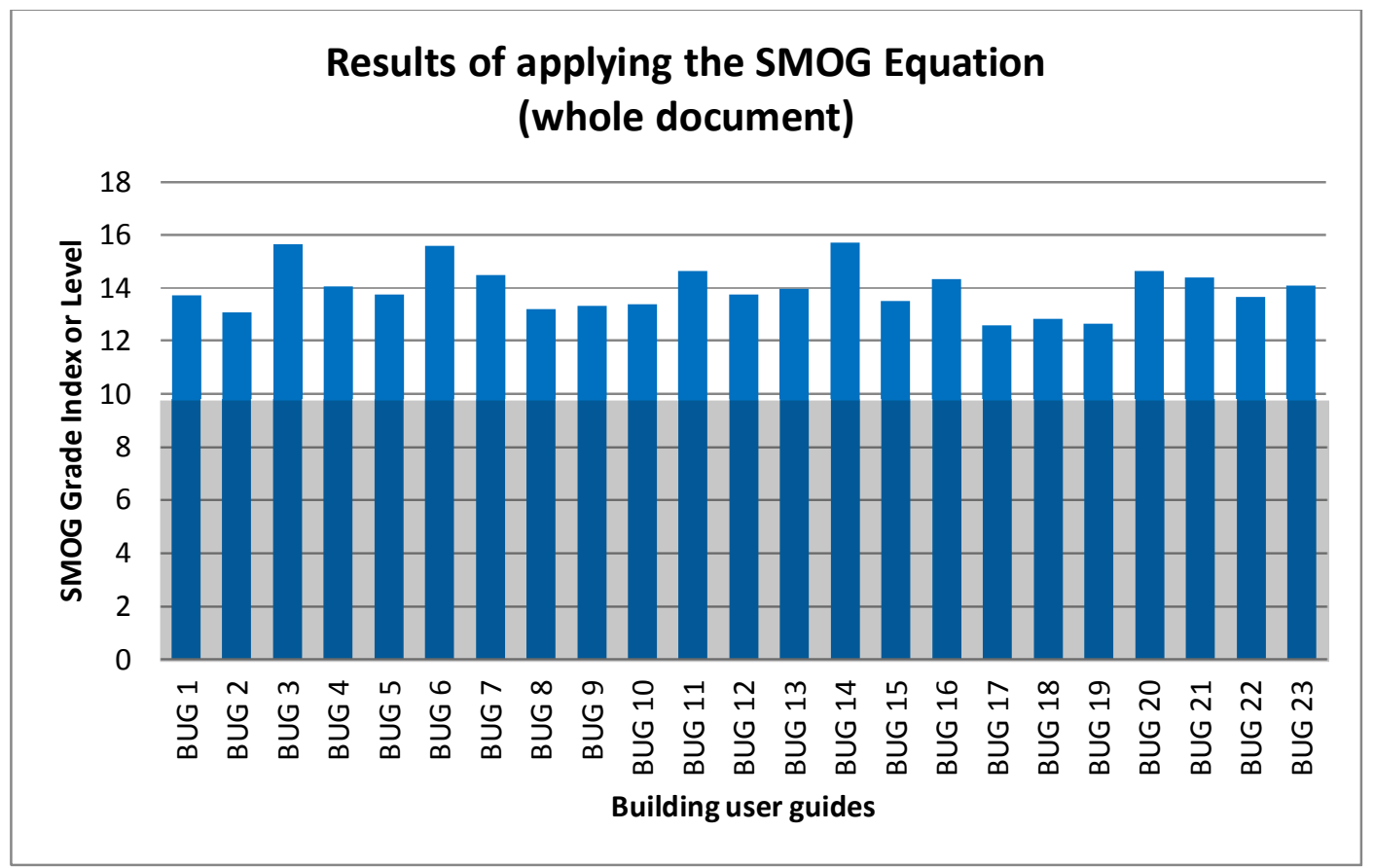

Graph 6 SMOG equation compared to NZ Adult Literacy

The SMOG equation using the whole document has been used as an overall indication of the building user guides SMOG results. This equation has been used as it calculates the most accurate results. This is because it used the equation rather than the index (simplified version) and it used the whole document rather than just the 30 sentences. This equation's average results $(13.9 \pm 0.2)$ were also the closest to the overall average of $13.9 \pm 0.4$ (see Graph 4).

Graph 6 displays the SMOG Equation results in order of building user guide. The grey box shown in Graph 6 indicates the preferred level of school grade based on the average literacy of New Zealanders. As discussed in Section 2.4, a score of American School Grade 8-9 (10 years of schooling) or below is preferred. None of the 23 building user guides is within this band, with the closest score of 12.6 recorded by BUG 17, being 3.6 grade levels above the preferred level. The worst performing building user guide, by highest grade level, was BUG 14 that recorded a SMOG score of $15.7,6.7$ grade levels above the preferred level. 
In the process of calculating the building user guides SMOG scores, the polysyllabic words of each 10 sentence sample was calculated separately. Reviewing the number of polysyllabic words in each section, it was found that the first 10 sentences of the Building User Guides commonly contained some of the highest scores (see Graph 7). 48\% of the Building User Guides showed that the first 10 sentences contained the largest number of polysyllabic words compared with the remaining 10 sentence sections. Sentence Group 1 appeared in the top five 83\% of the time and in the top eight all but in one instance at $96 \%$.

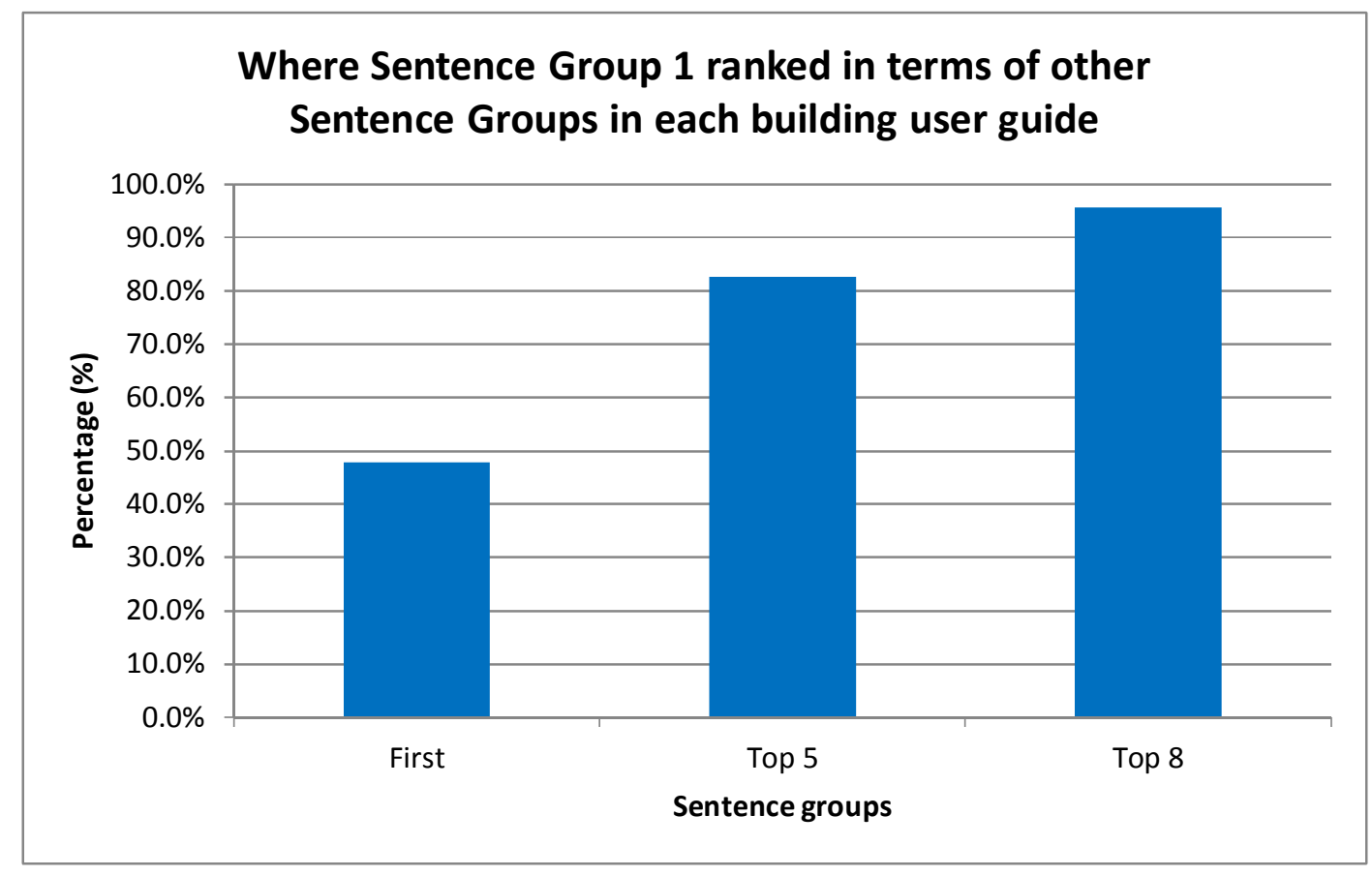

Graph 7 Percentage of times Sentence Group 1 appears, as first, in the top 5 and in the top 8

A chi square test $\left(\chi^{2}\right)$ was completed using IBM SPSS (IBM, 2012) to test the null hypothesis that there was no significant difference between the four SMOG assessments. The results show an association of $p=0.00$ indicating an association. Using IBM SPSS again a Two-Tailed Pearson Correlation test was completed and it was found, like the chi square test had, that there was a high statistical correlation of $0.863-0.960$ with a significance (2-tailed) of 0.000 (near perfect proof of association). The statistical correlation found with the four equations shows that there is a strong probability that if one Building User Guide was ranked higher in 
terms of the readability score, it would be similarly ranked with the other three equations. As there is a strong correlation between the four equations, the SMOG score results will rank the Building User Guides in a similar order; therefore it may be hypothesised that any equation could be used to indicate the grade level of a building user guide.

\subsubsection{Results of the Word Frequency Profiller}

This section will illustrate the findings of the Word Frequency Profiler assessment. First the overall results have been displayed, followed by common trends found.

Graph 8 presents the findings of the word frequency percentage analysis. Examining the document collection as a whole, the level of vocabulary needed to comprehend $98 \%$ of the text ranges from level $5-10$. The mean vocabulary level of the 23 Building User Guides is 7 with a standard deviation of 1.5 levels. This means that the reader of a Building User Guide requires the vocabulary of 7,000 word lemmas to comprehend the written text. The line shown at the vocabulary size of 8,000 indicates the number of word lemmas needed to comprehend a local newspaper (Nation, 2006). Out of the 23 building user guides only six were above this size which indicates that the majority, (74\%, of building user guides) are below or equal to the vocabulary size needed to read and comprehend a newspaper

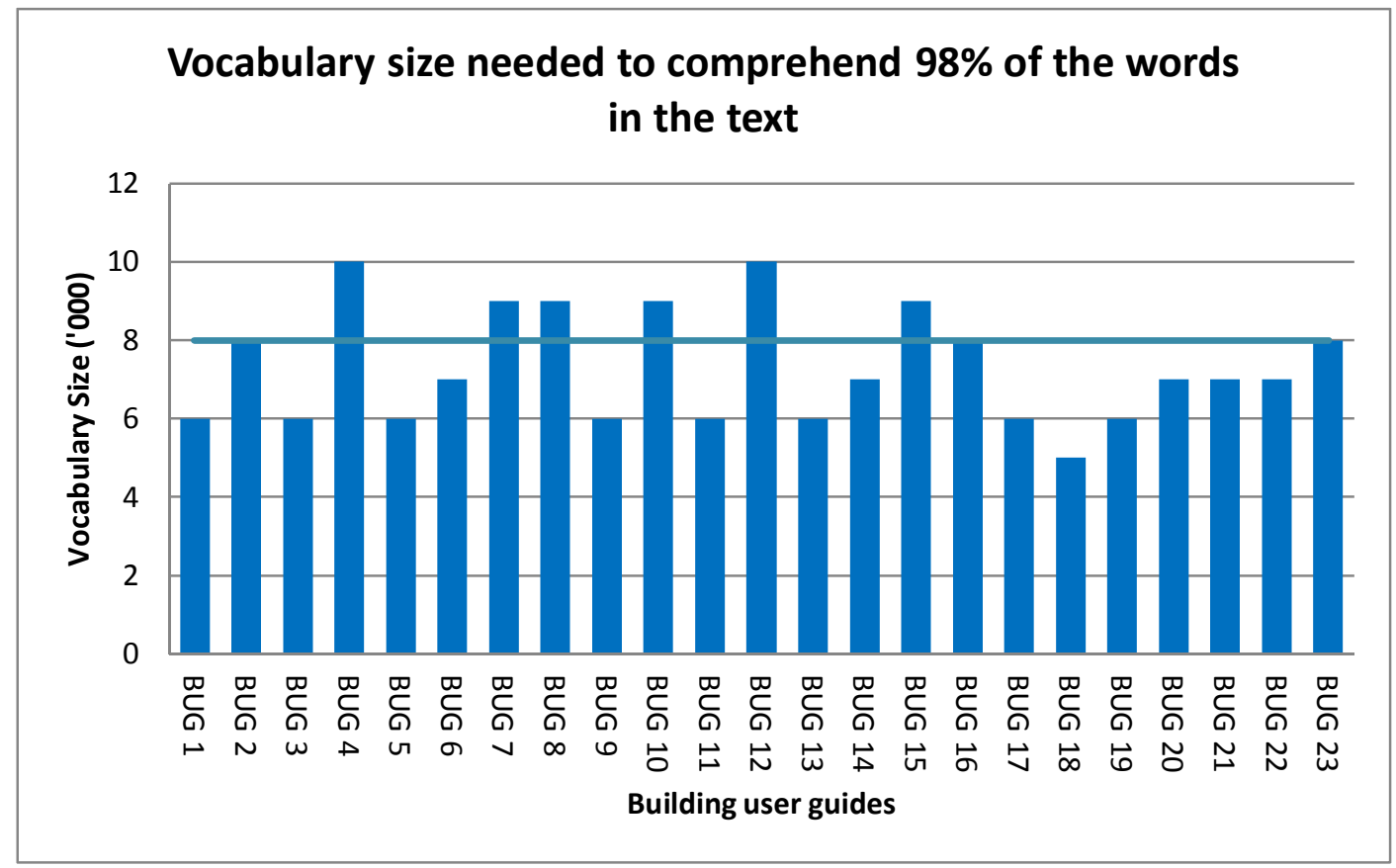

Graph 8 Vocabulary size needed to comprehend $98 \%$ of the words in the text 
Graph 9 displays the number of words in percentage (known as tokens in AntWordProfiler) in all 23 building user guides distributed over the 25 levels. No words from the Building User Guides were present in levels 21-25 therefore they do not show on the graph. Graph 9 indicates that all 23 building user guides follow the same distribution of tokens, with the majority (on average 69.4\%), appearing in the first $1 \mathrm{~K}$ list. The next largest percentage can be found in the $2 \mathrm{~K}$ list, the third largest in the $3 \mathrm{~K}$ list and so on until all the tokens have been distributed. This pattern is consistent with Nation's (2006) findings, however he states that approximate written coverage in the first $1 \mathrm{~K}$ list should be between $77 \%$ and $80 \%$ (without proper nouns). This indicates that there could be more 'harder' ('harder' being represented by words that appear less frequently in all written text) words in the building user guides.

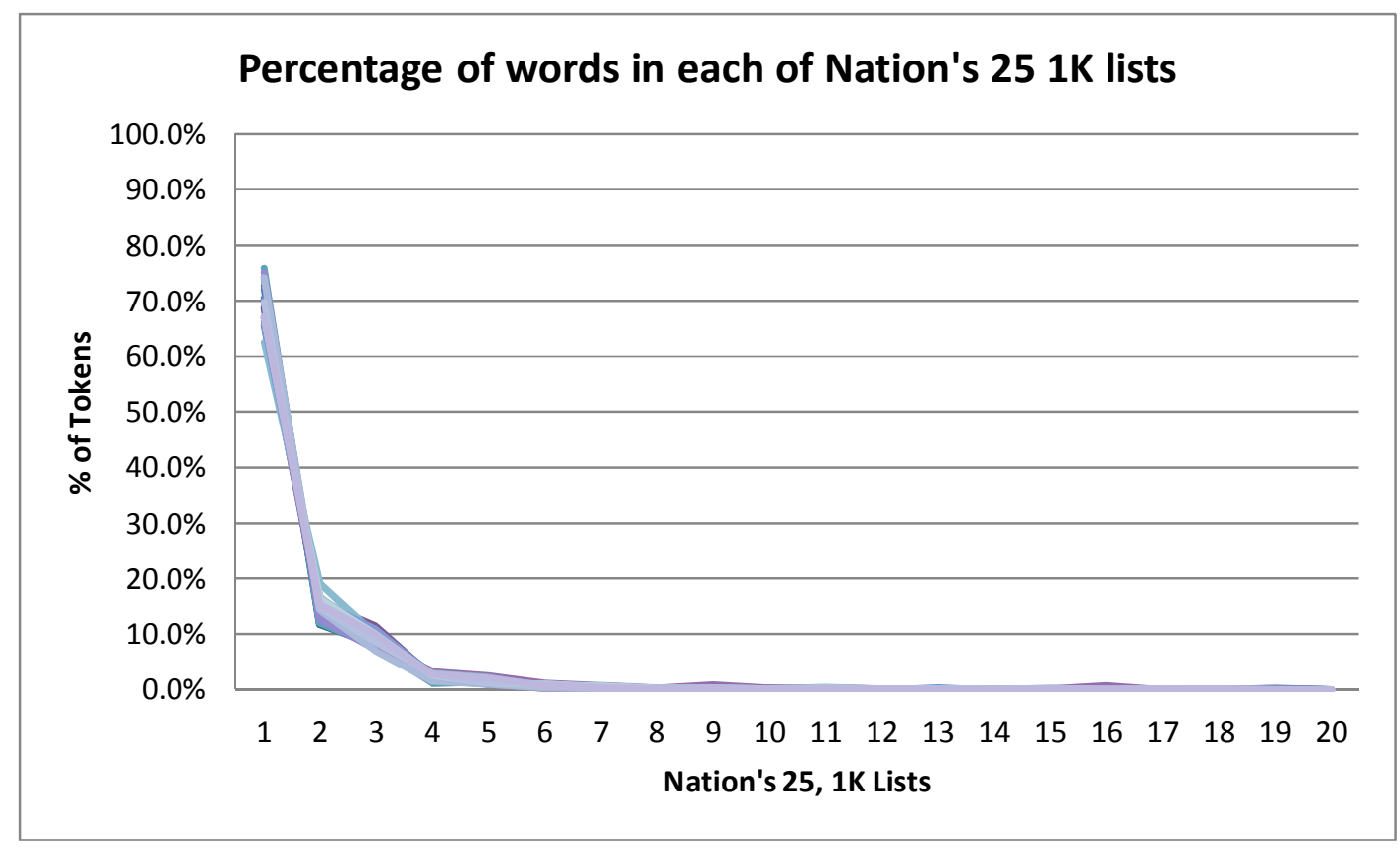

Graph 9 Percentage of words in each of Nation's $25,1 \mathrm{~K}$ lists across all building user guides.

\subsubsection{Comparison Between the two Assessments}

This section will investigate whether there are any correlations between the SMOG assessment and the Word Frequency Profiler assessment. This analysis was similar 


\section{Readability Analysis}

to the process completed on the four SMOG assessments in that a chi-square test was used to indicate if there was any association between the two assessments.

A comparison between the SMOG equation using the whole text (indicated as being the most accurate) and the Word Frequency Profiler assessment was completed. A chi square test $\left(\chi^{2}\right)$ was completed using IBM SPSS to test the null hypothesis that there was no significant difference between the two assessments. The results show an association of $p=0.387$ indicating that there was no association. This means that if a SMOG Equation ranked a BUG as having the highest grade level score; the Word Frequency Profiler would not necessarily rank the same BUG as having the highest word frequency result. This finding can be seen on Graph 10, showing the two results for each BUG, the BUGs are ordered from the highest to lowest based on the SMOG equation results.

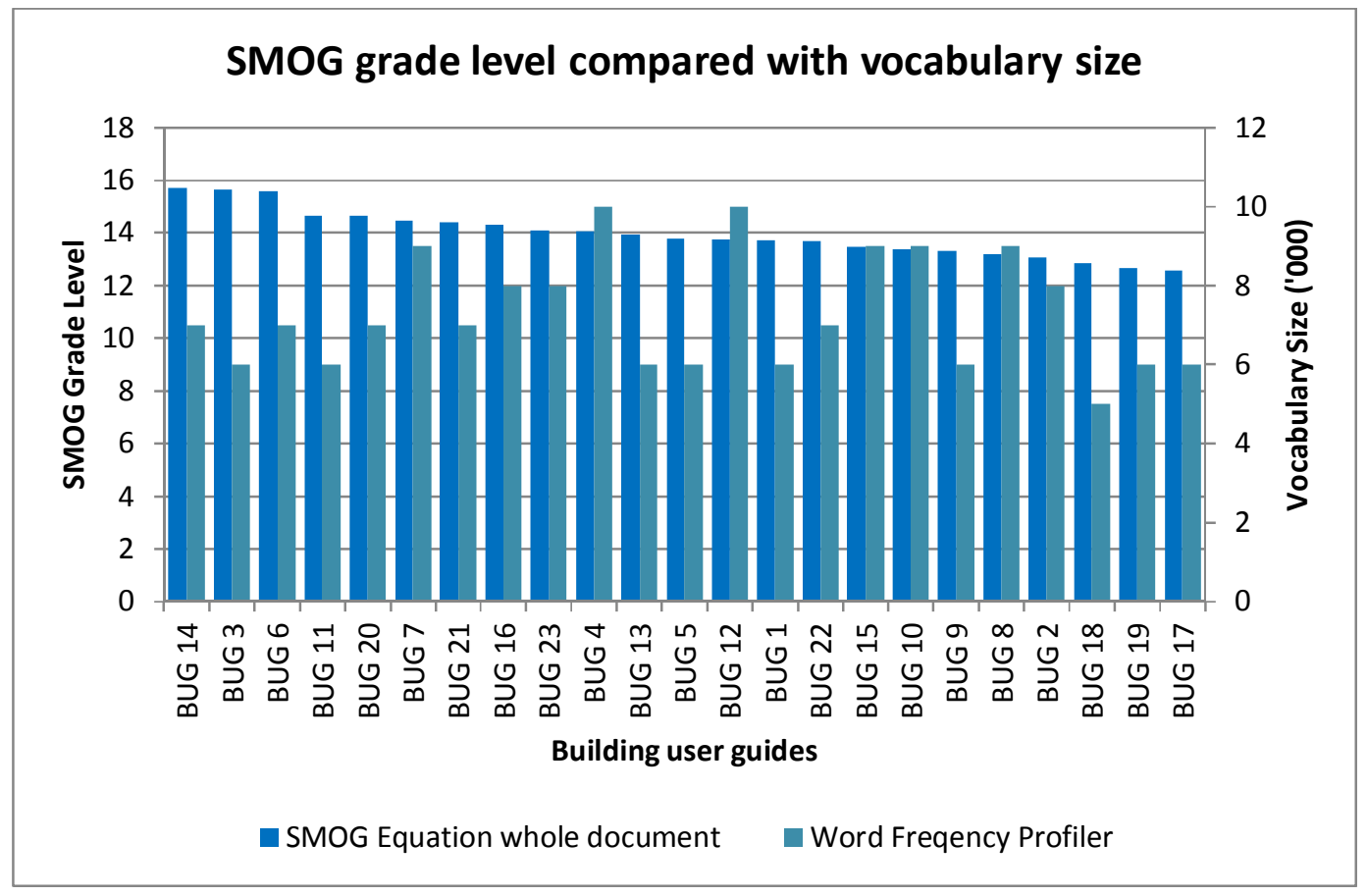

Graph 10 SMOG Grade Level compared with Vocabulary Size 


\subsection{Readability Discussion}

\subsubsection{Range of Readabillity Results}

The readability results from the SMOG assessment ranged from a 12 grade index to 17.3 Grade Level. The minimum was found in BUG 17's grade index score using 30 sentences, and the maximum in BUG 5's grade level score using 30 sentences. The rest of the building user guides' results were evenly distributed between this maximum and the minimum with the mean score of all results being $13.9 \pm 0.4$ (see 3.3).

The SMOG equation that used 30 sentences had the highest overall results across the four equations and the SMOG Index that used the whole document had the lowest overall score. However, it was found in the analysis of results (Section 3.3) that the different SMOG assessment methods closely correlate so that as one's level increases the others also increase.

The SMOG Grade Level that uses the whole document was found to be the most accurate (see Section 3.3) and so was chosen to represent the overall grade level of each of the building user guides. The mean grade level of $13.9 \pm 0.4$ is close to the grade level of 'The New York Times' which has been assessed at a grade level of between 13-15 (Hurst, 2008). As covered in the literature (Section 2.4) the mean grade level of 13.9 illustrates that the building user guides are, on average, beyond the readability of the majority of New Zealanders.

Readability as assessed with the word frequency analysis ranged from a score of $5,000-10,000$. This range means the minimum vocabulary size needed to read the building user guides was 5,000 word lemmas (BUG 18) and at maximum 10,000 word lemmas (BUG 4 and 12). The rest of the building user guides averaged 7,000 word lemmas (full results can be seen in section 3.3.2). In context, a local newspaper requires a reader to have a vocabulary size of 8,000-9,000 word lemmas (Nation, 2006). 


\subsubsection{Comparison with New Zealand Literacy levels}

As found in the literature review (Section 2.4) the average schooling grade for New Zealand was 'Year 10'; this is equivalent to 10 years of schooling or an American School grade of between 8 and 9. This literacy level was found based on two factors: the first was that $76 \%$ of New Zealanders had obtained a secondary school educational qualifications or higher (interpreted as Year 10 or above), and second, that $84 \%$ had obtained a higher secondary school education qualification and had the ability to read and follow basic instructions based on the Adult Literacy and Life Skills Survey (Satherley et al., 2008).

A review of the literature uncovered a limitation in the current assessment of New Zealand literacy levels due to the age of available data. The statistics used are from 2002 and 2006. These statistics are now up to 11 years old which may not represent current figures.

The SMOG results (shown in Section 3.3.1) indicate that all of the building user guides' results are above the literacy level represented by New Zealand's year 10 of schooling. Consequently the average New Zealander would struggle to read and comprehend the text used in most, if not all of the building user guides used in this study. This may lead to the incorrect use of a buildings services, which in turn could affect the efficient use of GreenStar rated buildings and the energy they consume (Baharuddin et al., 2011). Incorrect use of building user guides may also result in decreased user comfort as indicated in (Section 1). The high readability level found may also increase frustration with the building user guides (Lemos, 1983, p. 377). This frustration was identified when a COBOL user manual was found to be written at a high readability level, with users stating that "One should not be forced to refer to a textbook in order to figure out a manual" (Lemos, 1983, p. 377).

A study of Child Safety Seat Installation Instructions (Wegner \& Girasek, 2003), used the SMOG equation to find the readability level of the installation instructions. The results indicated that the readability level was up to 4 grade levels higher than the instructions target market. Wegner and Girasek (2003), stated that among other aspects, the high readability level may have contributed to child seats being 
installed incorrectly up to $94 \%$ of the time, with the incorrect use significantly increasing the chance of injury during an accident. This example of high readability levels is quite extreme, however it does illustrate that there can be significant adverse effects resulting from inappropriate readability levels.

Due to the differences in units and a lack of literature associating word frequency profiles to Grade Level score, there has been no comparison made between the word frequency profiles and New Zealand literacy levels in this research (see Section 3.2.3 for description).

\subsubsection{Comparison of the SMOG results and the Word Frequency Profiler results}

As stated in Section 3.4.2, the Word Frequency Profiler results cannot be converted into a school grade level; this makes the comparison of the two assessment tools difficult.

After reviewing the literature only one document was found that had been compared with both the SMOG Equation, and Nations 25K word list. This was 'The Great Gatsby' written by F. Scott Fitzgerald (1925). The book was assessed by Carapella (2012), for its SMOG Grade Level and Nation (2006), for is vocabulary size. The results showed that 'The Great Gatsby' had a SMOG Grade Level of 12.6 and needed a vocabulary size of 8,000 word lemmas to read and comprehend. This is only one example and so limits the conclusions that can be drawn from it. Both the SMOG assessment and the Word Frequency Profiler were analysed for correlations in results. It was found that there was no association between their results (see Section 3.3.3). This may be due to a two aspects.

The first major aspect is that even though both assess the difficulty of text, based on the 'hardness' of words, the process undertaken is different. The SMOG Equation identifies that on average 'harder' words are longer in syllable length than one or two syllable words. The Word Frequency Profiler identifies 'harder' words as words that readers do not come into contact that often, regardless of syllable length. 
Secondly, the classification of words is different. For example area and energy are both classed as difficult words by the SMOG formula. However, they are a part of Nation's first and second 1,000 word list respectively which means that in Nation's word list, it classes these two words as relatively 'easy'. These two words collectively contribute to $6.6 \%$ of all polysyllabic words found in all of the building user guides. If they were classed as 'easy' words by the SMOG equation the results would be different. For example, if they were taken out of BUG 16 the SMOG Grade Level (using the whole document) would go from 14.3 to 13.9. There are also examples of words that were classified as 'easy' in the SMOG Assessment but 'hard' in the Word Frequency Profiler, for example, egress appears in Nation's Level 16, 1,000 word list.

\subsubsection{Aspects affecting the results of the Assessments}

'Jargon', is technical terminology or characteristic idiom of a special activity or group (Merriam-Webster, 2005). For this research, building user guide jargon is defined as any words that specifically relate to the design, running of, or services of a building. The use of jargon heavily influences the scores of the SMOG equation with the top ten polysyllabic words; energy, area, provided, facilities, management, located, services, conditioning, ventilation and maintenance accounting for $19 \%$ of all polysyllabic words in the SMOG assessment.

Compared with SMOG's top ten jargon words, the Word Frequency Profiler identifies a different set of words as having a greater effect on the understanding of a given building user guide. An analysis of the total number of words used in all building user guides indicates that four completely different words contributed to the higher scores gained; egress (level 16), Celsius (level 15), potable (level 13) and kilowatt (level 9). Words such as refrigerant and luminaires as well as other building user guide jargon also contributed to the scores. These were words grouped in Nation's 'not in lists' classification.

The use of jargon affects a user's comprehension and perceptions of documents (Bucknavage, 2007). A study completed by Bucknavage (2007), assessed two similar psychologist's reports, one with a low level of jargon and the other with a high level. 
The results found that respondents who read the high jargon report had lower comprehension and rated the report negatively. This is a similar view to that found by other studies (Eysenbach G, 2002; Gal \& Prigat, 2005; Harvey, 1997).

A solution to this use of jargon in building user guides by Vallance (2008) suggests that if a word is used multiple times throughout a document, it should be clearly defined. In terms of a building user guide this could refer to the appropriate use of a glossary or an explanation of the term when it is first mentioned.

The introduction (first 10 sentences) was also identified as an aspect that affected the readability of the building user guides analysed. The introductions were found to contain the largest number of 'hard' (polysyllabic) words (shown in Section 3.3.1). The average number of 'hard' words for the introductions was 51.3. This result is significantly higher than the next closest result of a section which was an average of 41.8 for the fifth group of 10 sentences. The large number of 'hard' words in the introduction increases the likelihood of a reader becoming disinterested in the rest of the document as they are discouraged by the level of difficulty (Lemos, 1983; Vallance et al., 2008). Valeriano (1994) found that difficulty in comprehension results would mean readers commonly found other means to answer their questions, which can result in misinformation and disuse of the building user guide.

\subsubsection{Best Readabillity Assessment Method}

The final aim stated in Chapter 1, was to select the most appropriate readability assessment method, for on-going use.

As stated in this discussion, the two readability assessment methods are quite different from one another. They test for readability differently; one is able to be completed without any additional data processing, the second uses a computer program to compare both the building user guide and the word frequency list. As the two assessment tools use a different process, it is concluded that one assessment tool should be chosen, rather than having guidelines on them both. 
The SMOG equation is a well-known readability assessment tool, and has been seen to correlate well with other popular readability equations such as the Flesch Reading Ease, the Fry's Readability Graph and the Flesch-Kincaid Formula (Aleligay et al., 2008). The equation is also very simple to use and is fast to complete. In contrast the Word Frequency Program (Nation's 25K word list using the AntWordProfiler), is not as popular within the literature. It has also been found that the Nation's Word Frequency Profiler can't be correlated with the SMOG equation and the program takes significant time to set up, more than that of the SMOG analysis for a similar result. The SMOG equation, based on the points raised is the better assessment method, to find the readability of building user guides. In particular, the SMOG Equation that uses the whole document as this has been seen to provide the most accurate grade level. However, as all four of the SMOG assessment methods correlate with one another any equation would be appropriate. 


\section{Usability Analysis}

The usability analysis chapter will investigate the overall usability of building user guides. The first section has investigated the most appropriate assessment method to ascertain whether the building user guides are usable. Section 4.2 has detailed the methodology of the usability assessment, followed by the results in Section 4.3. Finally an analysis of the results has been completed in Section 4.4.

\subsection{Usability Assessment Method Selection}

Kostur (1990) states that in order to write documents that are more useable, writers need more information about the users for whom they are writing (p.166).

This chapter identifies the users and how they might use a building user guide, followed by the selection of a usability assessment. As shown in the literature review (section 2.5.5), this represents stages 2-4 of Kostur's (1990) usability methodology.

The usability test will be selected by following de Jong \& Schellens's (1997) usability evaluation selection methodology as outlined in Section 2.5.4. This methodology provides a step-by-step guide to identifying an appropriate usability evaluation method.

\subsubsection{Identifying the target audience}

"Writers of documents often try to identify with the users and consequently write for the only users they know - themselves" (Kostur, 1990, p. 166). For building user guides to be written for the correct users it is important to identify the actual users. The target audience of building user guides, as described by the GreenStar Technical Manual (New Zealand Green Building Council, 2008), are "the building's users, occupants and tenants' representatives". The users that need to be tested during the usability testing are occupants of office buildings or previous occupants of office buildings. 


\subsubsection{The use of Building User Guides by the target audience}

Building user guides can be seen as reference documentation. Kostur (1990), suggests that other than identifying the target audience, you need to learn how and why the users use the document. This information is important as it will determine what the document is used for and goals identified, as seen in the ISO 9241-11 1998 (ISO, 1998) usability framework.

Reference documents are used to look up answers for specific questions, as an example, a user might want to know how the lights work in his or her office space. To find this information, the user would navigate his or her way through the document to find the lighting section of the building user guide and find the answer. This identified 'use' determines the goals that should be targeted by a usability test (Kostur, 1990): the testing of the quality of material (can it be understood) and its efficiency (is it useful). Ganier (2007, p. 309), states that these goals can be addressed by identifying the user guides sub-goals:

- attractive - in order to encourage a large number of users to use it;

- practical - able to be read and used without affecting the running of the building;

- simple - to be able to be read and used by a diverse audience;

- efficient - to encourage learning, as well as to allow easy access to the information required

\subsection{3 de Jong and Schellens Overview of Methods}

As stated in Section 2.5.4.2.2 - Overview of Reader-Focused Text Evaluation. To identify the most appropriate method of usability testing, both the topics and functions of the resultant usability test method need to be addressed. de Jong and Schellen's (1997) usability evaluation selection methodology, require that a selection of topics is chosen from the six identified in Section 2.5.4.2.2 (selection, comprehension, application, acceptance, appreciation, and relevance and completeness). The six topics relate to the different types of usability data that a usability evaluation method can produce (de Jong \& Schellens, 1997). The overall 
function of the usability test needs to be selected from the three identified in section 2.5.4.2.2 (verification, troubleshooting and choice supporting). In what follows, both the topics and functions that are required of the usability evaluation method will be identified.

\subsubsection{Assessing the 6 Topics}

This sub-section will analyse the six topics identified in Sub-Section 2.5.4.2.2 in relation to the four goals identified in section 4.1.2. Each topic will be given a score $(-, x, x x)$. This score relates to the key that is used in Table 4 Overview of Methods in Relation to Functions and Topics) in section 2.5.4.2.1. The scores given will determine the usability evaluation method that will be used. Table 6 describes the scores that are used in Table 7.

Key Explanation

\begin{tabular}{l|l}
- & $\begin{array}{l}\text { The usability data that would be produced from this topic is not } \\
\text { needed in this particular usability study }\end{array}$ \\
$\mathrm{x}$ & $\begin{array}{l}\text { The usability data that would be produced from this topic may not be } \\
\text { specific to the outcome of the usability test, and may be considered } \\
\text { when choosing the usability evaluation method } \\
\text { The usability data that would be produced from this topic is very } \\
\text { specific to the outcome of the usability test, and should be considered } \\
\text { when choosing the usability evaluation method }\end{array}$
\end{tabular}

Table 6 Explanation of scores given in the usability evaluation method

\begin{tabular}{l|l|l|} 
Topic & Evidence & Score \\
\hline Selection & $\begin{array}{l}\text { "Questions about the selective behaviour of readers may be } \\
\text { asked at two levels" (de Jong \& Schellens, 1997, p. 409). The } \\
\text { first level concerns the general appearance and expected } \\
\text { content, and whether or not it is sufficiently attractive and } \\
\text { interesting (de Jong \& Schellens, 1997). The second level } \\
\text { relates to the reading behaviour and if readers can easily find } \\
\text { the information they are looking for (de Jong \& Schellens, } \\
\text { 1997). Assessing users of building user guides to evaluate the } \\
\text { attractiveness and their behaviour will help address the } \\
\text { overall goals required of the usability test. }\end{array}$ & \multicolumn{2}{l}{} \\
\hline
\end{tabular}


Comprehension

Application

Acceptance

Appreciation
"There are several options for addressing the readers' text comprehension" (de Jong \& Schellens, 1997, p. 410). It is important to know if the text can be read and understood by the users. This has already been investigated in the readability section (Section 3 ) of this research.

As stated in the literature review (Section 2.5.4.2), application is an extension of comprehension. The usability data gained from this topic (application) relates to the simplicity and practicality of the information presented in the building user guide.

The usability data found from this topic (acceptance) is information pertaining to the users' acceptance of the content in the building user guide. This information gives insight into the practicality of the building user guide. Data found will identify if the information in the building user guide is realistic and relevant to the users (de Jong \& Schellens, 1997). The significance of this topic is that it will identify if the building user guide contains information that the users want.

The data found in this topic (appreciation) will identify how the users perceive the building user guide aesthetics. The aesthetics relate to how the document looks, the quality of the figures, illustrations and layout, and how the information is presented. Theoretical information around these aspects has been found in the literature review (Section 2.5.4.1). However, actual user information in regards to their appreciation of the building user guides has not been found. This topic will identify if the theoretical information matches the usability results. 


\begin{tabular}{l|l|} 
Topic & Evidence \\
\hline Relevance and & $\begin{array}{l}\text { The data found in this topic will identity if the users perceive } \\
\text { there is anything missing from the building user guides. "The } \\
\text { readers should not be left with any important questions on } \\
\text { the topic" (de Jong \& Schellens, 1997, p. 406). This topic } \\
\text { addresses three out of the four sub-goals presented in } \\
\text { section } 4.1 .2: \\
\text { practicality - the building user guide should be able to } \\
\text { be used whenever it is needed i.e. can be picked up } \\
\text { and used by anyone } \\
\text { simplicity - if the document is not straight to the } \\
\text { point the users will be put off reading the document } \\
\text { in the future } \\
\text { efficiency - if the document is not complete and the } \\
\text { users have to spend time finding extra information } \\
\text { the document is not efficient }\end{array}$ \\
\hline
\end{tabular}

Table 7 The Selection of topics

From the analysis above, 'selection', 'application', 'acceptance' 'appreciation' and 'relevance and completeness' are the topics that have been scored with ' $X X^{\prime}$. The other topic 'comprehension' is not as important. Comprehension has already been investigated in the readability section of this thesis and so will not be addressed again. Table 8 indicates the required topics that need to be evaluated by the usability assessment. 


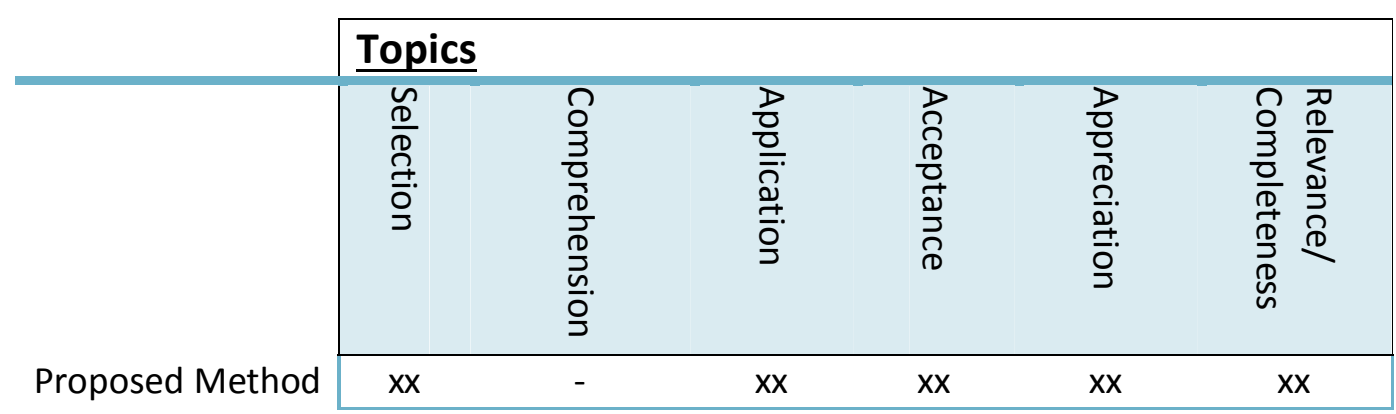

Table 8 the topic's required to be evaluated by the usability assessment

\subsubsection{Assessing the Three Functions}

The function of the usability test needs to be addressed as well as identifying its purpose. "A formative evaluation must have a clear and realistic function in the document design process" (de Jong \& Schellens, 1997, p. 413). The three functions have been identified in Sub-Section 2.5.4.2.2 and will be addressed in the following context:

- Verification - this method is for the general indication of problems, primarily for documents that have been completed (de Jong \& Schellens, 1997). The building user guides collected are all finished products so the verification method would be appropriate.

- Troubleshooting - this method is for locating and diagnosing the problems that readers have with the text (de Jong \& Schellens, 1997). As this is the first time building user guides are being tested, it is be important to find out what the actual problems are, rather than just identifying them. The troubleshooting method is also able to be used at any time during the production of the building user guides.

- Choice Supporting - this function is for when there are multiple documents and the goal is to find which one is better than the rest (de Jong \& Schellens, 1997). In this research multiple building user guides will be assessed. However, the main goal is to investigate how to improve the documents, not choosing which one is better.

'Troubleshooting' has been selected as the function for this usability evaluation. It is being selected as the data produced by a usability evaluation method with a troubleshooting function. It will find specific usability problems rather than just 
identifying them. This is important as the specific problems can be addressed oneby-one.

\subsubsection{Results of de Jong and Schellens' Methodology}

Table 9 contains the topics and functions that relate to usability assessment methods. '**Proposed Method' are the results of the analysis from Sections 4.1.3.1 and 4.1.3.2, compared with the usability evaluation methods found by de Jong and Schellens (1997). Following the table, is the outline of the usability evaluation method selected for this research.

Table 9 indicates the required topics (Section 4.1.3.1) and functions (Section 4.1.3.2) of the usability evaluation method for this research; listed first "**proposed method'. The rest of the table summarises de Jong and Schellens's (1997) research to match the topics and functions with the various usability evaluation methods.

The closet match of both topics and functions with that of the proposed method is the 'Text Evaluation Questionnaire' highlighted in bold.

"A text evaluation questionnaire may be focused on any kind of text characteristic. It assigns to the participants the role of critic: They are asked to judge document quality. In the case of troubleshooting pretests, an interview with relatively open questions might be used. In the case of negative judgements, experimenters and participants may try to explore to what extent these judgements can be attributed to specific text elements" (De Jong \& Schellens, 1997, p. 422)

The majority of the topics match between the two except for the 'application' topic. The 'Text Evaluation Questionnaire' method may provide information on the application, rather than the method explicitly focussing on this topic (de Jong \& Schellens, 1997). The usability data from the 'application' topic has been identified as data that is required for the overall goals of the usability test. 


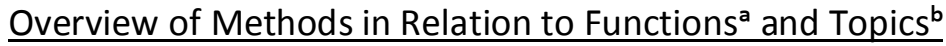

\begin{tabular}{|c|c|c|c|c|c|c|c|}
\hline & Function & & & & opics & & \\
\hline Methods & 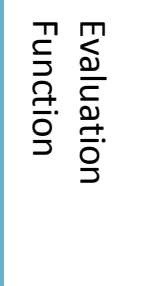 & $\begin{array}{l}\frac{\mathscr{D}}{D} \\
\frac{D}{\stackrel{D}{0}} \\
\frac{0}{J}\end{array}$ & $\begin{array}{l}\frac{0}{0} \\
\frac{3}{3} \\
\frac{0}{1} \\
\frac{1}{0} \\
\frac{1}{0} \\
\frac{\omega}{0} .\end{array}$ & $\begin{array}{l}\frac{D}{0} \\
\frac{0}{\overline{9}} \\
\frac{9}{3} \\
\text { 웅. }\end{array}$ & 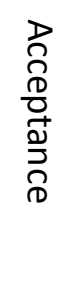 & $\begin{array}{l}\frac{D}{0} \\
\frac{0}{0} \\
\frac{0}{D} \\
\frac{2}{0} . \\
\frac{\bar{I}}{0} . \\
\text { 음 }\end{array}$ & 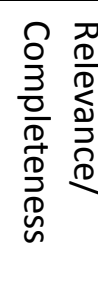 \\
\hline **Proposed Method & $\underline{T}$ & $\underline{x x}$ & & $\underline{x x}$ & $\underline{x x}$ & $\underline{\mathbf{x x}}$ & $\underline{\mathbf{x x}}$ \\
\hline Portfolio method & $\mathrm{V} / \mathrm{T}$ & $x x$ & & & & & \\
\hline Target-plan method & $\mathrm{V} / \mathrm{T}$ & $x x$ & $x$ & & & & \\
\hline $\begin{array}{l}\text { Reading behaviour } \\
\text { registration }\end{array}$ & $\mathrm{V} / \mathrm{T}$ & $x x$ & & & & & \\
\hline Cloze test & V & & $x x$ & & & & \\
\hline Comprehension test & $\mathrm{V} / \mathrm{T}$ & & $x x$ & & & & \\
\hline Performance test & $\underline{\mathbf{v}}$ & $\underline{x x}$ & $\underline{\mathbf{x}}$ & $\underline{x x}$ & & & \\
\hline User protocols & $\mathrm{V} / \mathrm{T}$ & $x x$ & $x$ & $x x$ & & & \\
\hline $\begin{array}{l}\text { Text elevation } \\
\text { questionnaire }\end{array}$ & $\underline{\mathrm{V} / \mathrm{T}}$ & $\underline{x x}$ & $\underline{\mathbf{x}}$ & $\underline{\mathbf{x}}$ & $\underline{x x}$ & $\underline{x x}$ & $\underline{x x}$ \\
\hline Focus groups & $\mathrm{T}$ & $x$ & $x$ & $x$ & $x x$ & $x x$ & $x x$ \\
\hline Attitude questionnaire & V & & & & $x x$ & & \\
\hline $\begin{array}{l}\text { Motivated-choice } \\
\text { technique }\end{array}$ & C & & & & & $x x$ & \\
\hline Plus-minus method & $\mathrm{T}$ & & $x$ & $x$ & $x$ & $x$ & $x$ \\
\hline $\begin{array}{l}\text { Signalled stopping } \\
\text { technique }\end{array}$ & $\mathrm{T}$ & & $x$ & $x$ & $x$ & $x$ & $x$ \\
\hline Reader protocols & $\mathrm{T}$ & & $x$ & $x$ & $x$ & $x$ & $x$ \\
\hline \multicolumn{8}{|c|}{ a. $\mathrm{V}=$ verification; $\mathrm{T}=$ troubleshooting; $\mathrm{C}=$ choice supporting } \\
\hline $\begin{array}{l}\text { b. } x x=\text { the method is ex } \\
\text { information on this top }\end{array}$ & \multicolumn{7}{|c|}{ b. $x x=$ the method is explicitly focused on this topic; $x=$ the method may provide } \\
\hline
\end{tabular}

Table 9 Proposed evaluation method compared to the usability evaluation methods 
As the 'Text Evaluation Questionnaire' may only provide a small amount of information in regards to the application of the building user guides, a second method may be appropriate to use. A 'Performance Test' is a good method to use in conjunction with the 'Text Evaluation Questionnaire' as it:

"Assesses whether participants can accomplish real-world tasks using the document [...] Performance tests can only be used for instructional documents" (de Jong \& Schellens, 1997, p. 420).

As the 'Performance Test' asks the users to perform real-world tasks using the document, it results in the users exploring the document to find information. This is a good method to use in conjunction with the 'Text Evaluation Questionnaire', as the users get a better understanding of how the document works, and use their experience of completing the 'Performance Test' to answer the questionnaire.

Ganier (2007) uses this method to assess user guides of an electrical appliance. The study first used an Information Location Task, which asked the users questions such as "When cooking food which may increase in volume, how full can you fill the pot?", the answers given were then compared to the expected answer (identified before the test was started). The Information Location Task, found results relating to the user guides practicality and efficiently (Selection Topic) and the application (Franck Ganier, 2007). This test was followed by a Preference Test, that was used to evaluate the user guides based on the presentation of the documents (Franck Ganier, 2007). This test evaluated the user guides' acceptance, appreciation and their relevance and completeness. Ganier's (2007) test method of the 'Information Location Task' followed by the 'Preference Test' is very similar to the 'Performance Test' followed by the 'Text Evaluation Questionnaire'.

\subsubsection{Conclusion}

The most appropriate test method for the assessment of usability of Building User Guides is a combination of both; the Performance Test and the Text Evaluation Questionnaire. This has been identified by assessing the information needed by the test with the six topics and three functions set out by de Jong and Schellens (1997). 
Ganier's (2007) study reinforces this choice as he has used these two tests to evaluate the usability of a steam cooker's user guide. 


\subsection{Usability Methodology}

This research used a survey consisting of two methods; a 'Performance Test' and a 'Text Evaluation Questionnaire' as determined in (Section 4.1). These two methods were used to identify any usability problems as well as identifying possible solutions.

This chapter first describes the selection of the building user guides that were used in the usability evaluation. This is followed by the development of questions for the evaluation. In the discussion, a pilot test and the consequent changes made to the initial survey have been detailed. It finishes with how the usability evaluation was administered and who it was sent to.

The usability evaluation survey was used to answer the following research questions as stated in Section 1.2:

- Are the building user guides able to be used by building occupants?

- What made the building user guides easy to use?

- What made the building user guides harder to use?

\subsubsection{The Build ing User Guides that will be assessed}

To demonstrate a cross section of the 23 building user guides collected, a sample of three was assessed. This was because assessing all 23 building user guides would have exceeded the scope of this research. The three building user guides BUG4, BUG5 and BUG 18 (from the readability study) were chosen because:

- All three were written by different companies

- The building user guides had a range of scores based on the SMOG equation - BUG 4 ranked $18^{\text {th }}$, BUG 5 ranked $9^{\text {th }}$ and BUG 18 ranked $1^{\text {st }}$

- The selected building user guides contained a range of page and word quantities

Overall, the building user guides were selected to represent the many different features included in the collected building user guides. For the rest of the usability study BUG4 will be referred to as BUG 1, BUG 18 as BUG 2 and BUG 5 as BUG 3. The 
names of the building user guides have been changed so there is no confusion from the participants of the resultant usability evaluation.

\subsubsection{Assessing the Building User Guides using a survey}

As stated in the test method selection (Section 4.1) a survey was selected as the most appropriate way to administer the usability evaluation. Surveys were found to be the most common form of user-centred evaluation methods (Van Velsen et al., 2008).

\subsubsection{The usability survey}

The survey consists of three parts;

- Part One - Introductory Questions

- Part Two - 'Performance Test' Method

- Part Three - 'Text Evaluation Technique' Method

The following sections will outline the questions used in the three parts of the survey.

\subsubsection{Introductory questions}

The introductory questions had two objectives:

- To ensure a good cross section of participants were surveyed

- To identify if building user guides had actually been used by participants

The first objective has been identified by Axinn, Link and Groves (2011) as important for targeting the correct demographic for the survey. The participants need to be those who were identified in (Section 4.2.4.2) - anybody working or has the potential to work in an office. The following questions were asked to ensure that there was a sufficient range of participants surveyed:

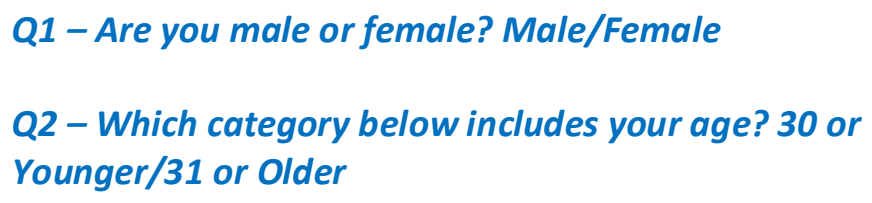




$$
\begin{aligned}
& \text { Q3 - Have you ever used a Building User Guide? Yes/No } \\
& \text { Q4-When were you born? Between January - April/Between } \\
& \text { May-August/Between September - December }
\end{aligned}
$$

\subsubsection{Performance Test Questions}

The first questions relating to the building user guides asked real-world questions that the readers will use the building user guides to answer. The participants were asked to answer one question in all three building user guides (see Table 10, Table 11 and Table 12 for the questions and answers), as a way to undertake the 'Performance Test' outlined in section 4.1.

The questions asked depended on the month of the participant's birthday as found in Q4 in the introductory section; participants with a birthday between JanuaryApril answered question one, May-August - question two and SeptemberDecember - question three. This phase was aimed at evaluating objectively the extent to which each building user guide allowed efficient information access.

The answers to these questions existed in all three building user guides. Asking three separate questions meant that more than one section of the building user guide had to be used to answer the questions, therefore providing insight into more than just one section of the building user guides

The order that the participants were asked to view the BUG's was counterbalanced (meaning they were asked in varying order) to eliminate any possible consequence of the order of the information.

The three questions all followed a simple layout (larossi, 2006), the participants were given a situation, this situation was followed by a question that required the use of a building user guide to answer. An option was given if the participants could not find the information. Those who could not would simply answer the question with 'could not find'. The three question sets are illustrated below in Table 10, Table 11 and Table 12.

\footnotetext{
${ }^{1}$ Q4 was included to separate the participants into three groups so three separate questions could be answered
} 


\subsection{Question One - January to April}

\begin{tabular}{|c|c|c|c|}
\hline Situation & Question & Answer & \\
\hline \multirow{3}{*}{$\begin{array}{l}\text { You are sitting in your } \\
\text { office, have just taken } \\
\text { off your jacket as you } \\
\text { are getting too hot. } \\
\text { However this is not } \\
\text { enough and you are } \\
\text { still too } \\
\text { uncomfortable. You } \\
\text { access your Building's } \\
\text { User Guide (BUG 1), } \\
\text { to find out what you } \\
\text { can do about being } \\
\text { too hot. }\end{array}$} & \multirow[t]{3}{*}{$\begin{array}{l}\text { How does BUG } \\
1 \text { describe what } \\
\text { you should do if } \\
\text { you are too } \\
\text { hot? }\end{array}$} & $\begin{array}{l}\text { Expected } \\
\text { Answer for BUG } \\
1\end{array}$ & $\begin{array}{l}\text { Increase airflow to your } \\
\text { immediate area by } \\
\text { opening the vent in the } \\
\text { nearest floor diffuser. }\end{array}$ \\
\hline & & $\begin{array}{l}\text { Expected } \\
\text { Answer for BUG } \\
2\end{array}$ & $\begin{array}{l}\text { Two possible answers: } \\
\text { Open the window if fresh } \\
\text { air or a cooling breeze is } \\
\text { required and/or speak to } \\
\text { facilities manager to } \\
\text { adjust the heating system } \\
\text { accordingly }\end{array}$ \\
\hline & & $\begin{array}{l}\text { Expected } \\
\text { Answer for BUG } \\
3\end{array}$ & $\begin{array}{l}\text { BMS - This interface can } \\
\text { be used to adjust } \\
\text { temperature set points of } \\
\text { spaces within the } \\
\text { building if desired }\end{array}$ \\
\hline
\end{tabular}

Table 10 Questions and answers for question set one - January to April

\subsection{Question Two - May to August}

\begin{tabular}{|c|c|c|c|}
\hline Situation & Question & Answer & \\
\hline $\begin{array}{l}\text { Your whole office has } \\
\text { been told to reduce } \\
\text { the amount of } \\
\text { electricity use, you } \\
\text { have been trying } \\
\text { different ways over }\end{array}$ & $\begin{array}{l}\text { How does BUG } \\
1 \text { describe how } \\
\text { you find the } \\
\text { total amount of } \\
\text { electricity being } \\
\text { used? }\end{array}$ & $\begin{array}{l}\text { Expected } \\
\text { Answer for BUG } \\
1\end{array}$ & $\begin{array}{l}\text { The revenue meters } \\
\text { identified for } \\
\text { transformers } 1 \& 2 \\
\text { identify the total net } \\
\text { energy usage for the } \\
\text { electricity grid }\end{array}$ \\
\hline $\begin{array}{l}\text { the past month, and } \\
\text { how would you find } \\
\text { out the reduction in }\end{array}$ & & $\begin{array}{l}\text { Expected } \\
\text { Answer for BUG } \\
2\end{array}$ & $\begin{array}{l}\text { Energy monitoring } \\
\text { system accessible by } \\
\text { 'office staff' }\end{array}$ \\
\hline $\begin{array}{l}\text { energy use? You } \\
\text { access your Building's }\end{array}$ & & $\begin{array}{l}\text { Expected } \\
\text { Answer for BUG }\end{array}$ & $\begin{array}{l}\text { By accessing the GDB2 } \\
\text { meter or the individual }\end{array}$ \\
\hline $\begin{array}{l}\text { User Guide (BUG 1) to } \\
\text { find out how much } \\
\text { electricity has been } \\
\text { used. }\end{array}$ & & 3 & office level meters \\
\hline
\end{tabular}

Table 11 Questions and answers for question set two - May to August 


\subsection{Question Three - September to December}

\begin{tabular}{|c|c|c|c|}
\hline Situation & Question & Answer & \\
\hline \multirow[t]{3}{*}{$\begin{array}{l}\text { You have noticed a } \\
\text { slight discolouration } \\
\text { in the water when } \\
\text { you flush the toilet. } \\
\text { You access your } \\
\text { Building's User Guide } \\
\text { (BUG 1); to find out if } \\
\text { there is a problem or } \\
\text { if this is normal? }\end{array}$} & \multirow[t]{3}{*}{$\begin{array}{l}\text { How does BUG } \\
1 \text { explain the } \\
\text { discolouration? } \\
\text { Should anything } \\
\text { be done about } \\
\text { this? }\end{array}$} & $\begin{array}{l}\text { Expected } \\
\text { Answer for BUG } \\
1\end{array}$ & $\begin{array}{l}\text { The building has a water } \\
\text { harvesting facility that } \\
\text { collects rain water from } \\
\text { the roof, stores it in a } \\
\text { tank and uses it to flush } \\
\text { the toilets. Discoloration } \\
\text { may appear but the } \\
\text { water is filtered so is } \\
\text { quite safe for flushing the } \\
\text { toilets. Nothing to be } \\
\text { done about it. }\end{array}$ \\
\hline & & $\begin{array}{l}\text { Expected } \\
\text { Answer for BUG } \\
2\end{array}$ & $\begin{array}{l}\text { Occupants may notice a } \\
\text { different colour in the } \\
\text { water when it has been } \\
\text { flushed - this is due to } \\
\text { using recycled water and } \\
\text { is normal, but it still isn't } \\
\text { potable. Nothing to be } \\
\text { done about it. }\end{array}$ \\
\hline & & $\begin{array}{l}\text { Expected } \\
\text { Answer for BUG } \\
3\end{array}$ & $\begin{array}{l}\text { Explains the discoloration } \\
\text { as being normal due to } \\
\text { use of rain water. Does } \\
\text { not suggest anything be } \\
\text { done about it. }\end{array}$ \\
\hline
\end{tabular}

Table 12 Questions and answers for question set three - September to December

\subsubsection{Text Evaluation Technique Questions}

The third and final phase of the survey used 'the Text Evaluation Technique' method. The main reason for using this method was to ask the participants for their opinion (de Jong \& Schellens, 1997). So it was important to use open ended questions. "Open-ended questions have the possibility of discovering the responses that individuals give spontaneously, and thus avoid the bias that may result from suggesting responses in closed-ended questions" (Reja, Manfreda, Hlebec \& Vehovar, 2003, p. 161). Foddy (1994, p. 127), also states that "closed-ended questions limit the respondent to the set of alternatives being offered, while openended questions allow the respondent to express an opinion without being influenced by the researcher". 
Two questions were asked in the final section; an open-ended question followed by a qualitative multiple-choice question.

Open-ended question: Which Building User Guide did you prefer and why?

Using a simple open ended question meant that this section was not laborious and participants did not get deterred. People are significantly more likely to return a smaller survey (Dillman, Sinclair, \& Clark, 1993, p. 298).

To see if users thought that the aspects of a building user guide identified in Section 2.5 would help in a building user guide, participants were asked to select which aspects they found to be important, as identified in section 2.5 .

Multiple choice question: What aspects would make the Building User Guide easier to follow?

You may select as many or as little options as you like.

1. An Index

2. The use of images

3. Bold headings

4. Highlighting of important information

5. Glossary

6. Contents page

7. Use of diagrams

8. Page numbers

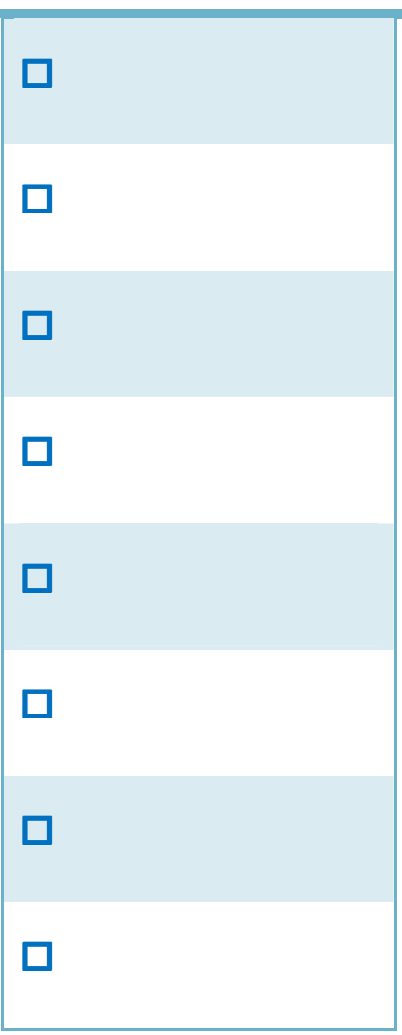




\begin{tabular}{ll|l}
\multicolumn{1}{l|}{ Aspect } & Please Tick \\
\hline 9. Less technical terms & $\square$ \\
10. Other (please specify) & $\square$ \\
\cline { 2 - 2 }
\end{tabular}

Each aspect was identified as being important as follows:

- Index, glossary and a table of contents (Hartley, 1981)

- The use of images, highlighting of important information and the use of diagrams (Young \& Wogalter, 1990)

- Bold headings and highlighting of important information (Priestly, 1991; Wheildon, 1986)

Page numbers were added in because it was found that BUG 1 did not have them. After the aspects were listed, there was also an 'Other' section that would require elaboration by the participant.

\subsubsection{Pillot Test}

A pilot test of the survey was completed to highlight any possible problems with the survey and to determine if the answers to the questions were sufficient to find the usability problems. "Survey questions [...] should mean the same thing to all respondents, as well as to the researcher" (Fowler, 1992, p. 218). "The pilot test represents the only opportunity to verify this and the data collected will ultimately reflect any poorly defined questions or concepts" (Iarossi, 2006, p. 87).

\subsubsection{Pilot Test Process}

The pilot test was administered to three participants. The test raised two issues: a small number of grammatical errors that were corrected; and the inclusion of only a single question in the last section of the survey. The single question led participants to only include positive responses about the building user guides. However, as well as the positive aspects, negative aspects of the building user guides needed to be addressed. 
To ensure a full spectrum of results was collected two questions were added to address the negative aspects of the building user guides. The new revised section included the following three questions:

Q14 The three Building User Guides you were given all used different composition methods.

Please rank the three building user guides in order from 1 to 3 (1 - The easiest Building User Guide to find the information required, to 3 - The hardest Building User Guide to find the information required).

Click and drag into the appropriate order:

- $\quad$ BUG 1

- BUG 2

\subsection{BUG 3}

Q15 What made you choose your top ranked Building User Guide in the above question? Were there certain features of the guide that made it easy to find the information, was the information presented clearly?

Q16 Why weren't the other two guides selected as being the easiest to find the information?

\subsubsection{Administering the Survey}

\subsubsection{The form of the survey}

An electronic version of the survey was deemed the easiest way to administer the survey because an electronic version meant that it was fast to administer, it was cost effective (didn't have to include any postage) and could be administered to a large sample of participants (Vogt, Gardner, \& Haeffele, 2012). The electronic survey also meant that participants could complete the survey at a time that suited them (Vogt et al., 2012).

Survey Monkey (Survey Monkey, 2012) was used for the creation, distribution and collection of results for the survey (see Appendix - B), which was granted ethics 
approval by the Victoria University of Wellington, School of Architecture and Design, Head of School (RM\#19592).

\subsubsection{Participants}

A large national company was used to distribute the survey; the company has a total of 150 employees across five offices throughout New Zealand. These participants were chosen because they were all working in an office at the time of the study. This is important as the participants had to fit the correct demographic that the building user guides are aimed towards (Axinn et al., 2011; ISO, 1998; Kostur, 1990). The survey was also sent to a smaller company near Wellington that had interest in the results, as well as to some personal contacts of the usability tester. The survey was distributed on the $15^{\text {th }}$ of December with reminder messages sent out on the $10^{\text {th }}$ of January and again on the $20^{\text {th }}$. The survey was closed on the $30^{\text {th }}$. The reason for the long duration of survey period was because of the Christmas break.

\subsubsection{Conclusion}

After the pilot test the surveys were distributed to the participants mentioned in Section 4.2.4.2. The final survey can be found in Appendix - B. The results of the survey can be found in Section 4.3. The survey was used to highlight any usability problems with the building user guides. A statistical analysis will be used to establish if the different questions affected the ranking of the building user guides. 


\subsection{Usability Results}

This chapter is split into three sections: first the introductory questions, second the 'Performance Test' and third the 'Text Evaluation Technique'. These sections relate to the three parts of the usability methodology outlined in Section 4.2.

\subsubsection{Introductory Questions - Results}

As stated in the Usability Methodology (Section 4.2) the introductory questions were used to establish if the participants were a fair representation of the target audience. The target audience in this research were those who have worked or are working in an office, as discussed in Section 4.1.1.

Overall a total of 64 participants started the survey with 47 (73.4\%) completing the whole survey. The majority $46(71.8 \%)$ of the surveys were returned within the first week of the survey being administered. A further 10 were returned by January $10^{\text {th }}$, an additional 7 by the $20^{\text {th }}$ and the last returned by January $30^{\text {th }}$. Only the 47 completed surveys have been used in the results. The other 17 surveys were returned incomplete, often stopping after the introductory questions.

As shown in Graph 11 are the percentages of male and female survey respondents overall and to each question. Overall $60 \%$ of the respondents were male and $40 \%$ female; a ratio of 6:4. A similar ratio is seen in all three questions, with Question 3 having a slightly higher ratio of females.

As shown in Graph 12, are the percentages of age groups; 30 year olds and younger and 31 year olds and older. It was found that overall $45 \%$ of participants were aged 30 or younger and $55 \%$ were 31 or older, a ratio of 9:11. The age range across the different questions did not follow the same ratio, with the younger age group being represented more in Question 1. Question 2 and Question 3 were over represented by the older age group, with Question 3 showing a 30\% difference between the two age groups. 
As shown in Graph 13, only 15\% of participants had used a building user guide, showing the majority, (85\%) had not used one before.

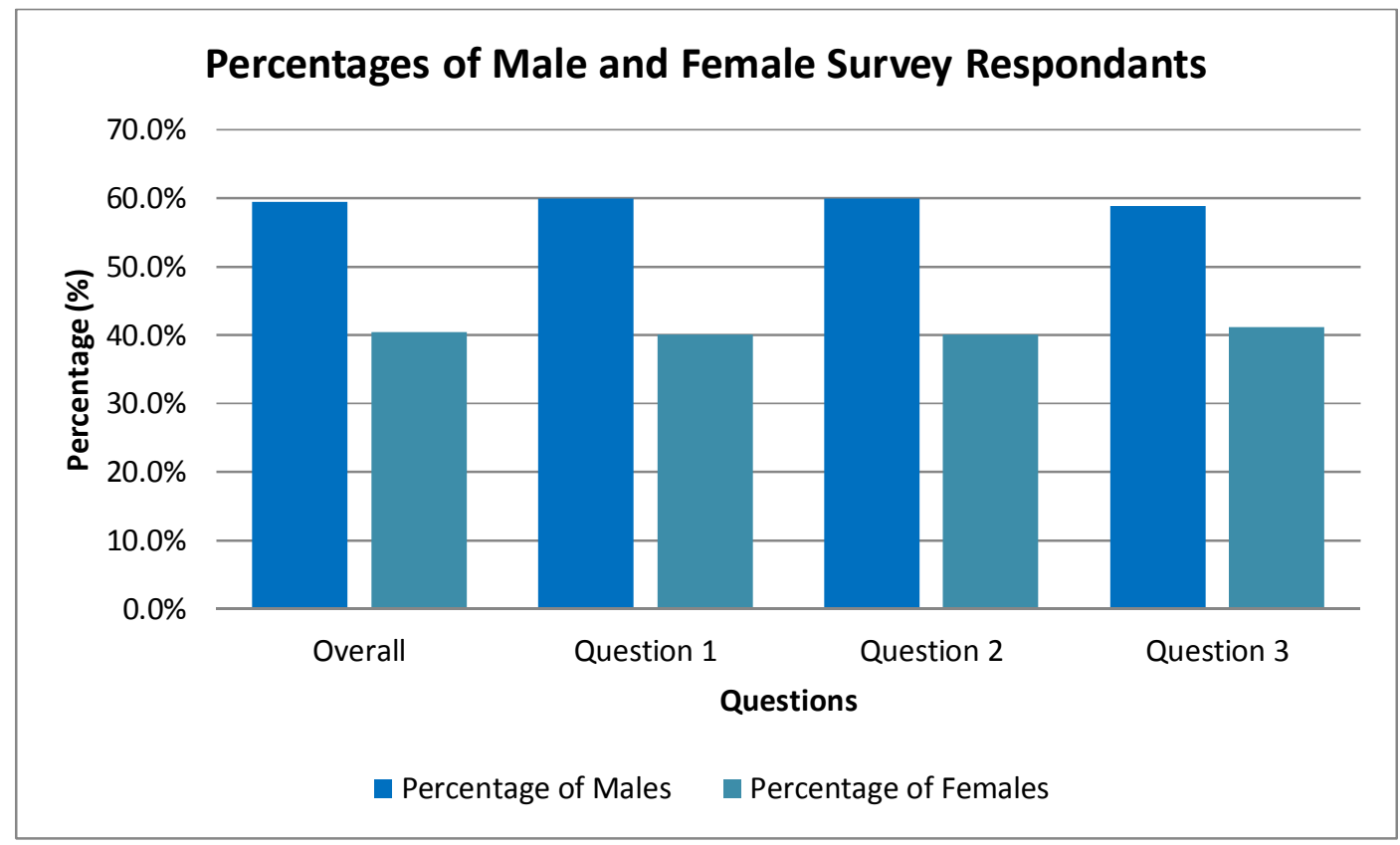

Graph 11 Percentage of Male and Female Survey Respondents, overall and across the three questions

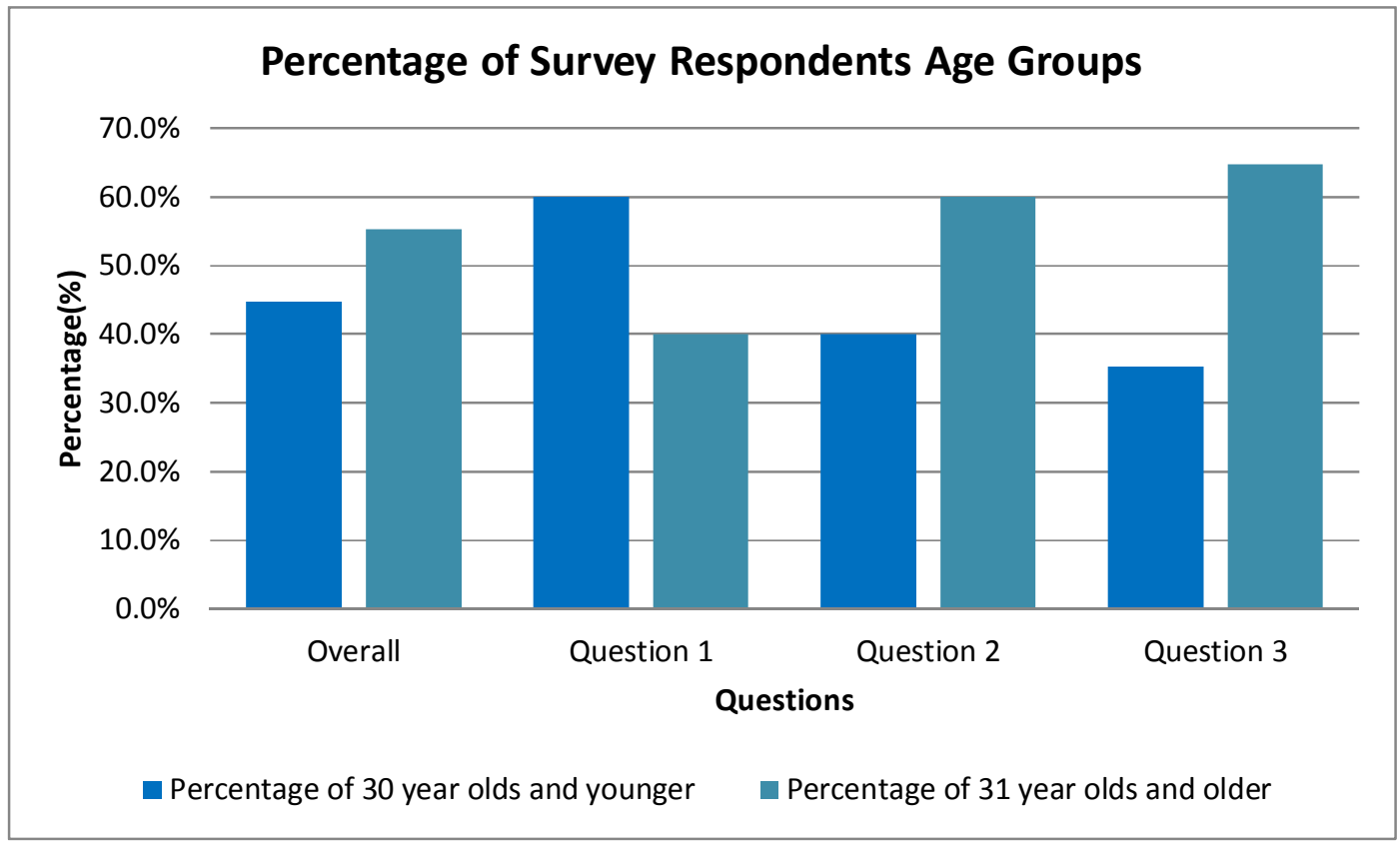

Graph 12 Percentage of the different age groups, overall and across the three questions

Graph 13 Percentage of participants that have used a building user guide, overall 


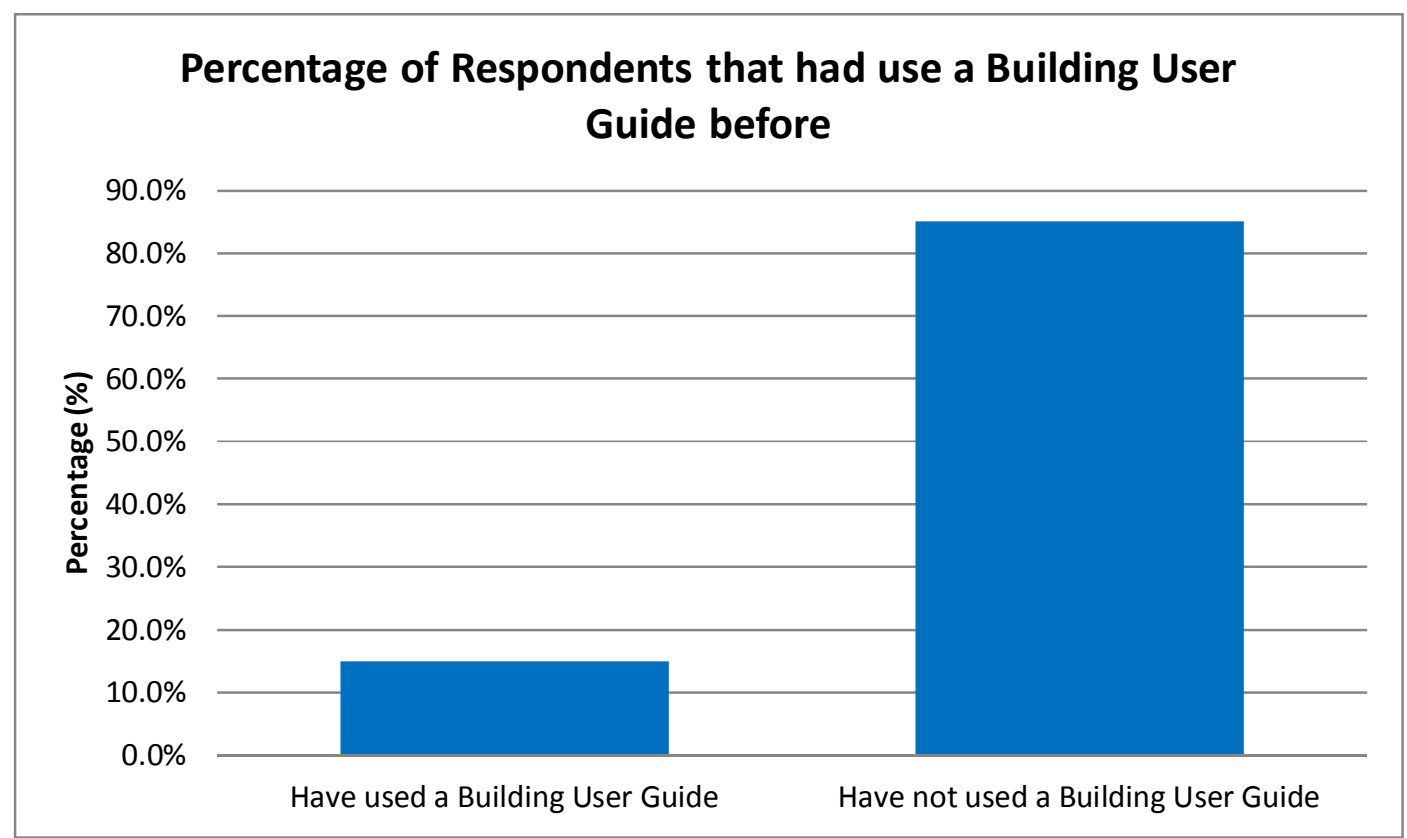

Graph 14 Percentage of participants that have used a building user guide, overall

As shown in Graph 15, almost an equal number of people answered Questions 1, 2 or 3, a description of which can be found in Sub-Section 4.2.2.3. The question answered is a result of the answer give in Q4 that asked about the participant's month born. Question 3 was answered $36 \%$ of the time, rather than $32 \%$ of the time for both Questions 1 and 2. This indicates that there was a good distribution between the questions; no question was over represented.

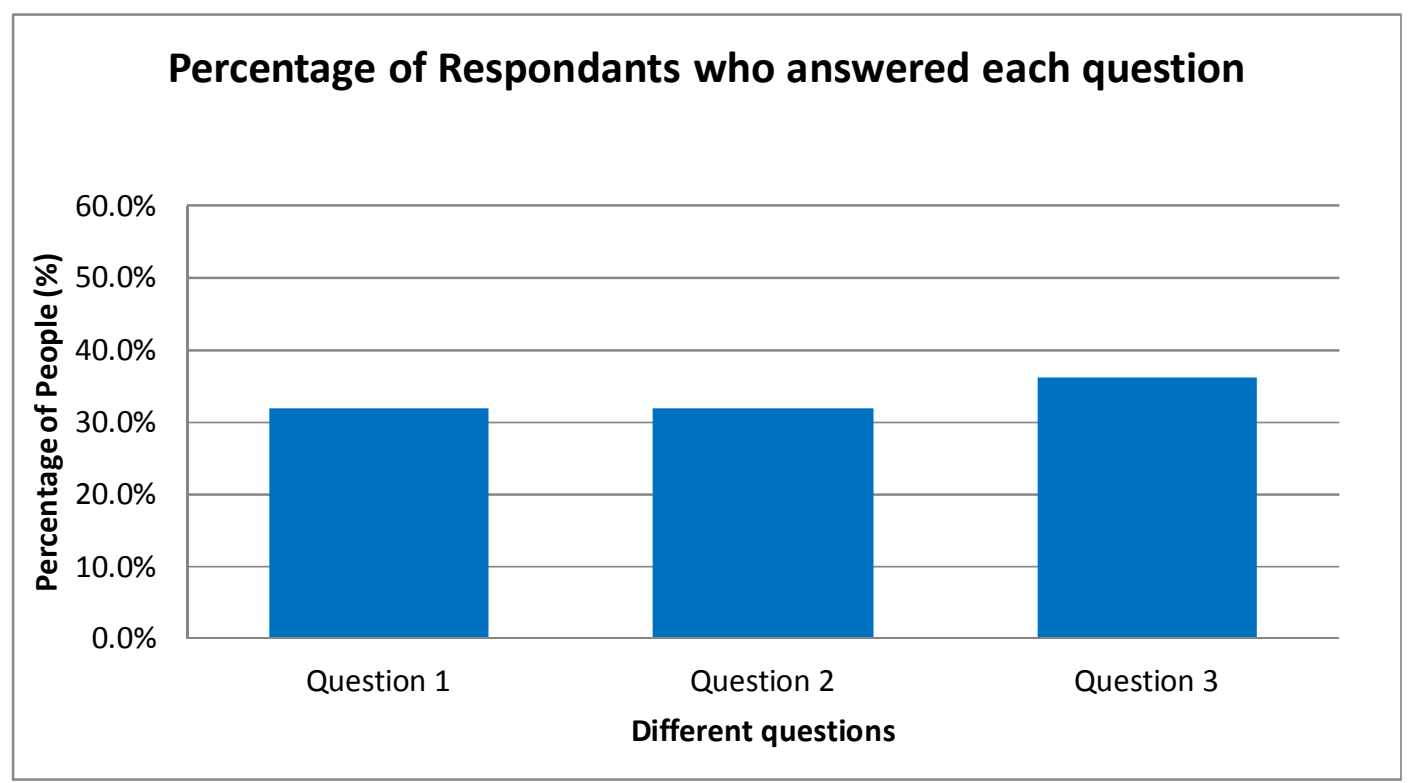

Graph 15 Percentage of participants who answered either question 1, 2 or 3 


\subsubsection{Summary}

From the results of the introductory questions on gender and age, there was a tendency for the respondents to be a male and 31 years or older. This may be due to the nature of the two work places that were chosen, commercial real-estate offices and research facility. The main factor that would influence the results of the usability study was the amount of participants answering each question. Due to the similar percentage of people answering each question it can be said they are all fairly represented. 


\subsubsection{Usability Results 'Performance Test'}

This section identifies the results of the 'Performance Test' or Section 2 from the usability survey. The answers given by the participants in this section were compared to the model answers identified in Section 4.2.2.3. Each answer was either identified as being correct, incorrect or if they didn't know the answer they were given a 'didn't know'. The section is split up into three parts: first the results of Question 1, then Question 2 and finishing with Question 3. In all of the questions the answers were either answered correctly or the participants 'didn't know', no answers were answered incorrectly. As a result there is no 'incorrect' section on Graph 16, Graph 17 or Graph 18.

\subsubsection{Question 1}

The first question was answered correctly $75.6 \%$ of the time and could not be found (indicated by respondents recording 'didn't know' in the answer section) by participants $23.4 \%$ of the time. It was answered correctly $100 \%$ of the time with BUG 2 and $80 \%$ of the time by BUG 1. The building user guide that participants found the most difficult was BUG 3, with participants only answering correctly $46.7 \%$ of time. These results can be seen in Graph 16 and Table 13.

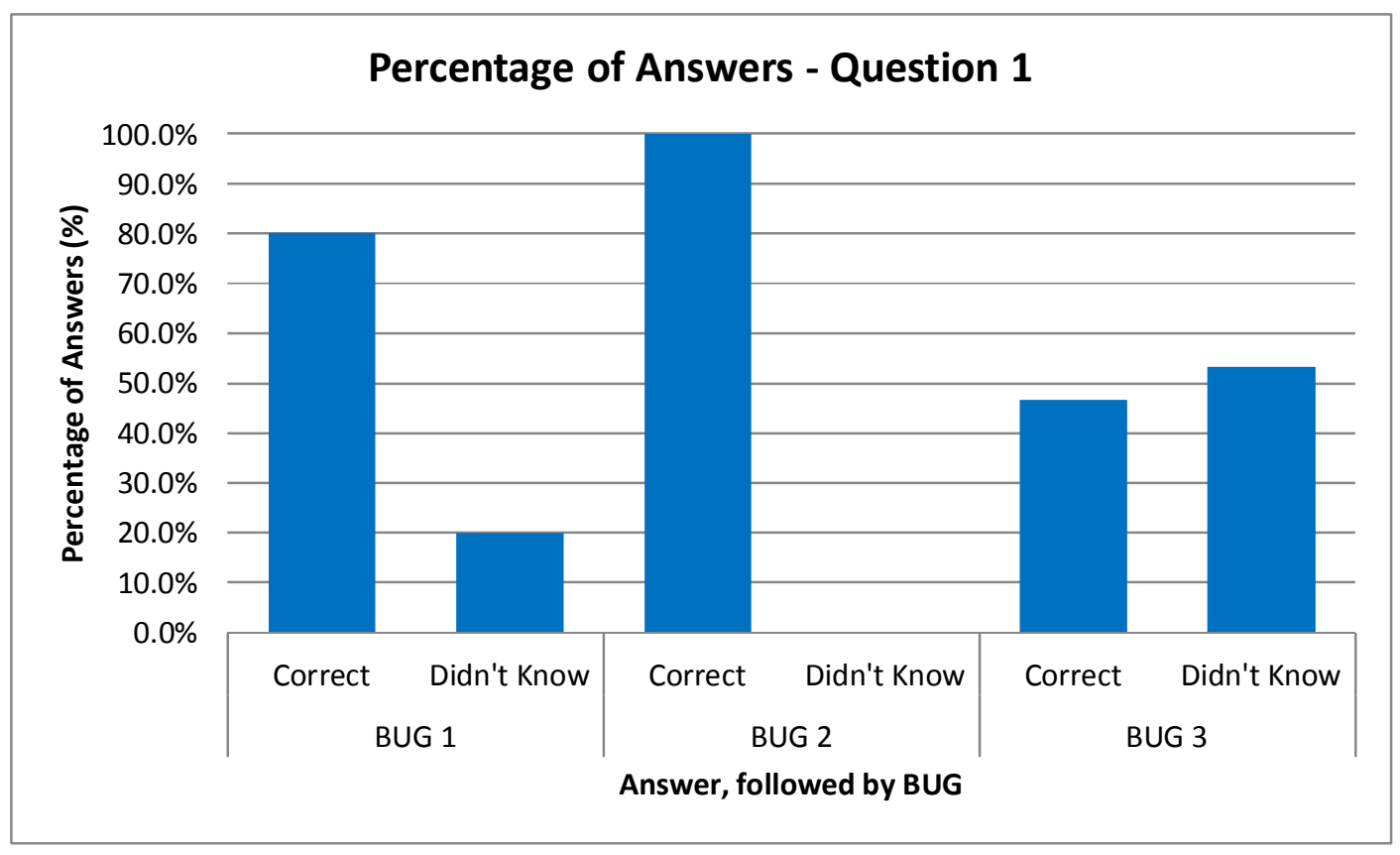

Graph 16 Answers to Question 1 
Usability Analysis

\begin{tabular}{|l|l|l|l|l|l|l|}
\hline \multicolumn{1}{c}{ BUG 1 } & \multicolumn{3}{c}{ BUG 2 } & \multicolumn{2}{c}{ BUG 3 } \\
\hline Answer & $\begin{array}{l}\text { Correc } \\
\mathrm{t}\end{array}$ & $\begin{array}{l}\text { Didn't } \\
\text { Know }\end{array}$ & $\begin{array}{l}\text { Correc } \\
\mathrm{t}\end{array}$ & $\begin{array}{l}\text { Didn't } \\
\text { Know }\end{array}$ & $\begin{array}{l}\text { Correc } \\
\mathrm{t}\end{array}$ & $\begin{array}{l}\text { Didn't } \\
\text { Know }\end{array}$ \\
\hline $\begin{array}{l}\text { Number of } \\
\text { Respondents }\end{array}$ & 12 & 3 & 15 & 0 & 7 & 8 \\
\hline
\end{tabular}

Table 13 Answers to Question 1

\subsubsection{Question 2}

The second question was answered correctly $71.1 \%$ of the time and could not be found by participants $32 \%$ of the time. It was answered correctly $80 \%$ of the time with BUG 3. BUG 1 and BUG 2 were equally as difficult based on the number of correct answers being 66.7\%. These results can be seen in Graph 17 and Table 14 .

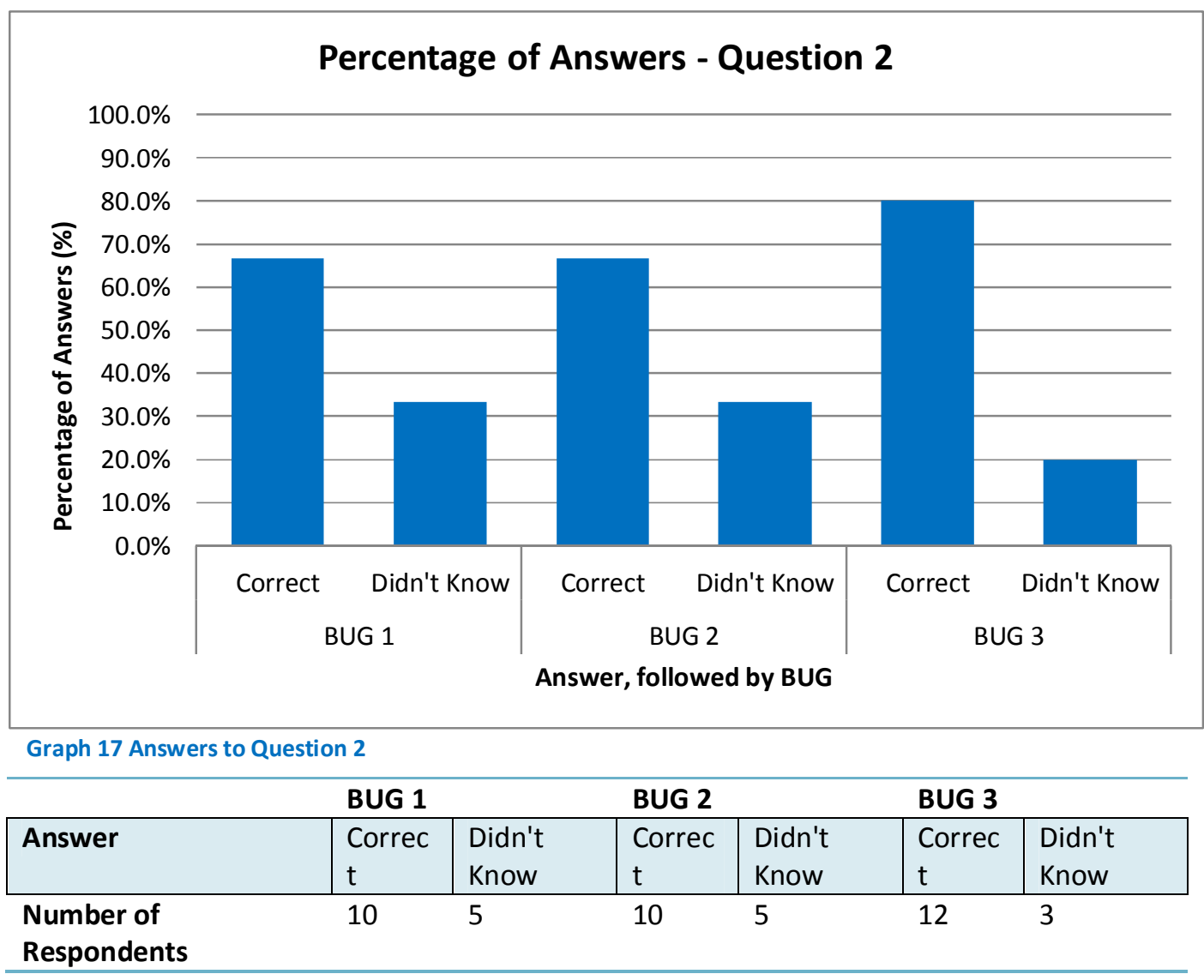

Table 14 Answers to Question 2

\subsubsection{Question 3}


The third question was answered correctly $94.1 \%$ of the time and could not be found by participants $5.9 \%$ of the time. All building user guides had the same results, and these results can be seen in Graph 18 and Table 15.

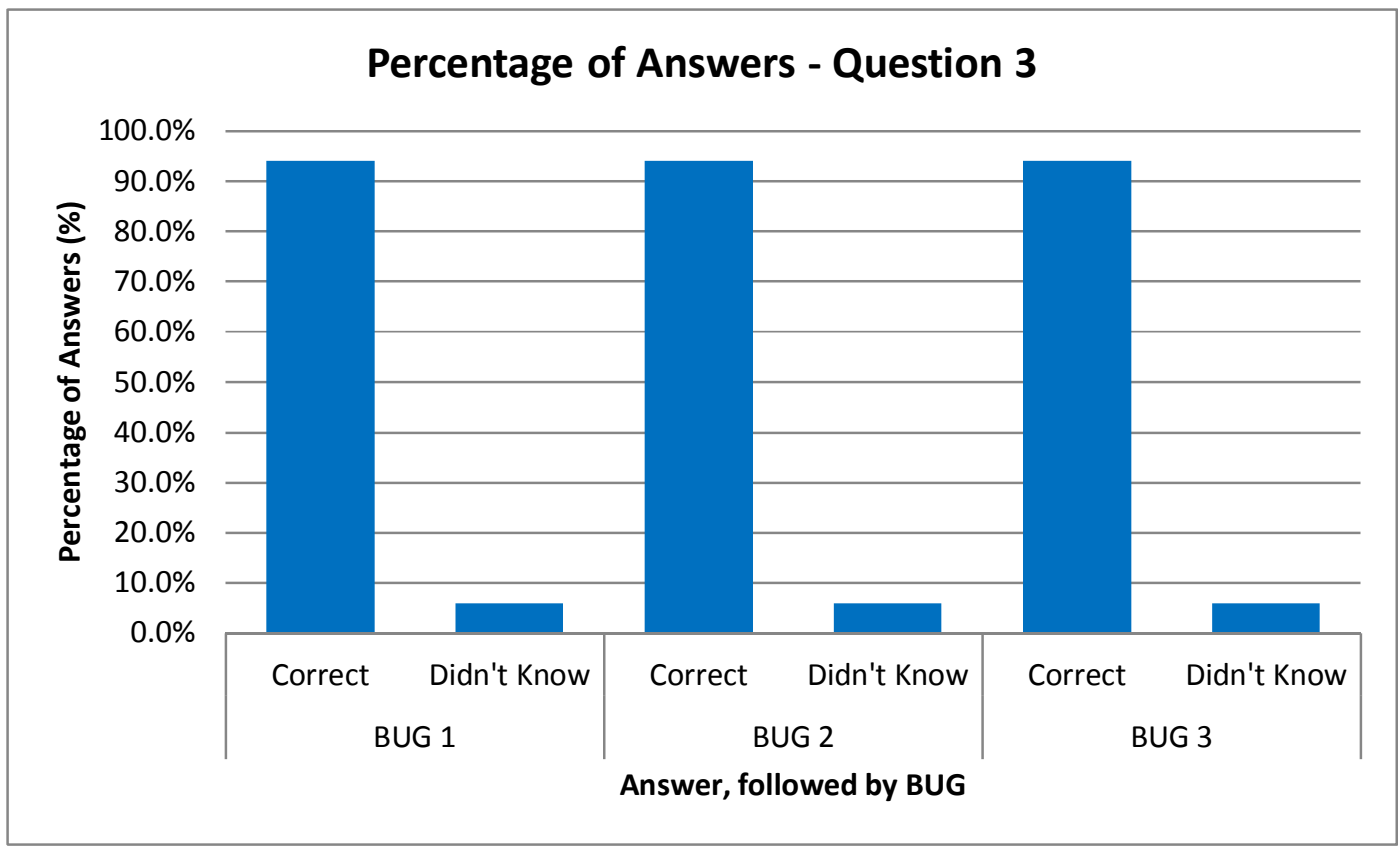

Graph 18 Results of question 3

\begin{tabular}{|l|l|l|l|l|l|l|}
\hline & \multicolumn{3}{c}{ BUG 1 } & \multicolumn{3}{c}{ BUG 2 } \\
\hline Answer & $\begin{array}{l}\text { Correc } \\
\mathrm{t}\end{array}$ & $\begin{array}{l}\text { Didn't } \\
\text { Know }\end{array}$ & $\begin{array}{l}\text { Correc } \\
\mathrm{t}\end{array}$ & $\begin{array}{l}\text { Didn't } \\
\text { Know }\end{array}$ & $\begin{array}{l}\text { Correc } \\
\mathrm{t}\end{array}$ & $\begin{array}{l}\text { Didn't } \\
\text { Know }\end{array}$ \\
\hline $\begin{array}{l}\text { Number of } \\
\text { Respondents }\end{array}$ & 16 & 1 & 16 & 1 & 16 & 1 \\
\hline
\end{tabular}

Table 15 Results of Question 3

\subsubsection{Summary}

From the results of the 'Performance Test' it was found that the number of questions answered correctly was dependent on the question, rather than the building user guide. It can be concluded that participants found BUG 3 the most difficult in terms of finding the correct answer in Question 1. However participants found BUG 3 the easiest in terms of the highest number of correct answers. 


\subsubsection{Usabillity Results 'Text Evaluation Technique'}

This section is split into three sub-sections. The first is a statistical analysis of the ranking of the building user guides (Question 14), followed by an analysis of the open-ended questions (Question 15 and 16), and ending with an analysis of the different aspects participants found useful (Question 17) in building user guides.

\subsubsection{Statistical analysis of Question 14}

A chi square test $\left(\chi^{2}\right)$ was completed using IBM SPSS (IBM, 2012) to test the null hypothesis that there was no significant difference between the three different questions asked (Section 4.2.2.4) and which order the participants ranked the building user guides. It was found that there was an association with BUG 1 with $p=0.001$ and BUG 3 with $p=0.000$, this was not the case with BUG 2 with $p=0.316$.

Using IBM SPSS (IBM, 2012) a Two-Tailed Pearson Correlation test was completed, it was found, like the chi square test had, that there was an association with a significant (2-tailed) of 0.002 for BUG 1 and 0.000 for BUG 3. However, the correlation was not as strong with a result of 0.447 for BUG 1 and -0.556 for BUG 3 . The statistical analysis showed that for BUG 1:

- it was more likely it wouldn't be selected as the third (worst) ranked for Question 1,

- it was less likely again to be chosen as the third (worst) ranked for Question 2 and

- it was more likely to be chosen as the third (worst) ranked in Question 3

The statistical analysis showed that for BUG 3

- it was more likely to be chosen as the third (worst) ranked in Question 1,

- it was less likely that it chosen as the third (worst) ranked for Question 3 and

- it was more likely to be chosen as the second (middle) ranked for Question 3.

The results show that none of the building user guides used in the survey could be considered best overall, with respondents more likely to rank the building user guides differently across the three questions. These results were illustrated by Graph 18. The graph shows the percentage of people that ranked the separate 
building user guides based on the question they answered. For example BUG 3 was ranked third by $87 \%$ of the participants that answered Question 1 .

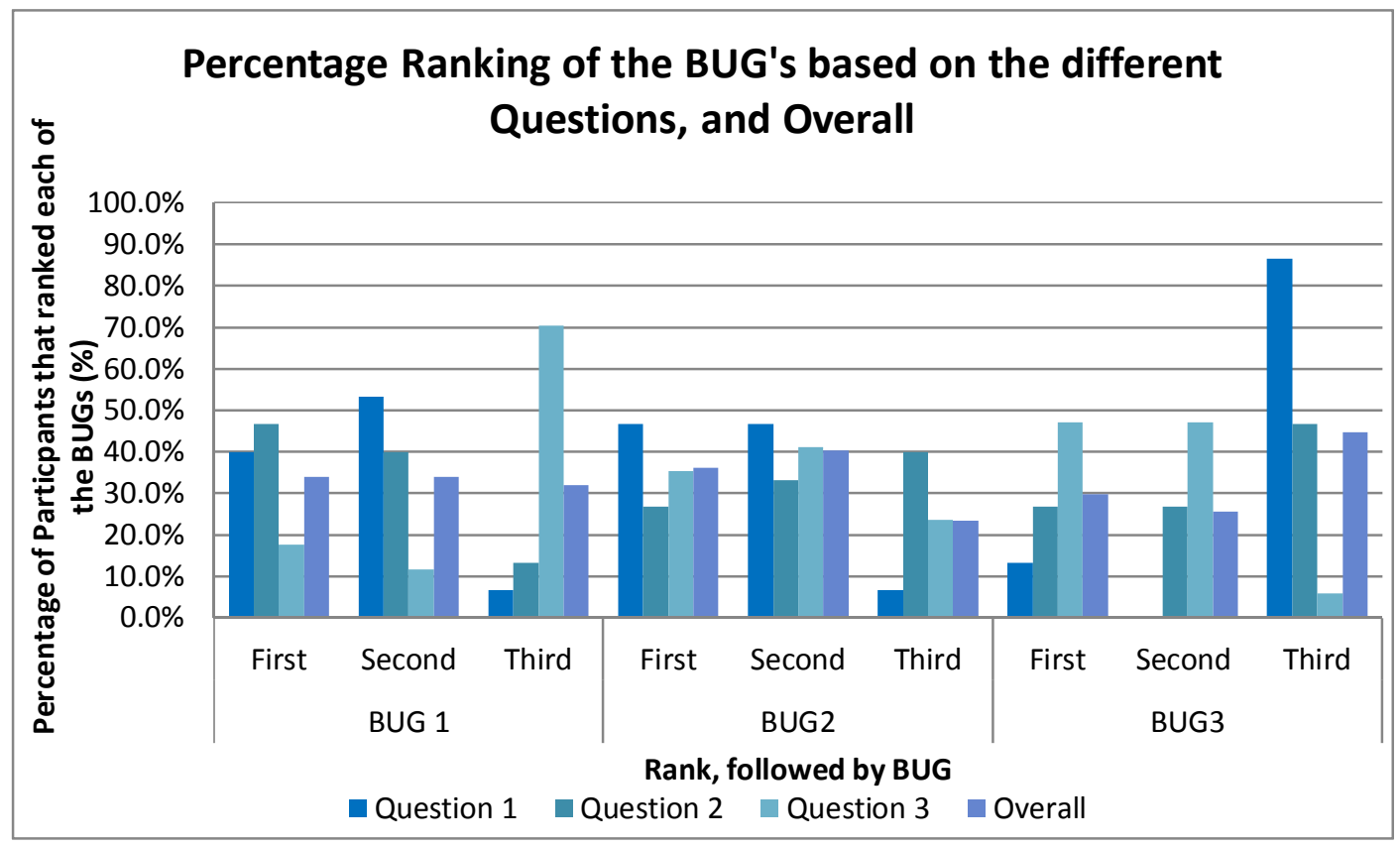

Graph 19 Percentage Ranking of the BUG's based on the different Questions, and Overall

\subsubsection{Analysis of Questions $\mathbf{1 5}$ and $\mathbf{1 6}$}

This sub-section presents the results of Questions 15 and 16.

\section{Question 15 asked:}

What made you choose your top ranked Building User Guide in the above question? Were there certain features of the guide that made it easy to find the information, was the information presented clearly?

\section{Question 16 asked:}

Why weren't the other two guides selected as being the easiest to find the information?

This has been done based on the participants comments that were given for each of the three questions asked. The three questions asked were:

1. You are sitting in your office, have just taken off your jacket as you are getting too hot. However this is not enough and you are still too 
uncomfortable. You access your Building's User Guide (BUG 1), to find out what you can do about being too hot.

2. Your whole office has been told to reduce the amount of electricity use, you have been trying different ways over the past month, and how would you find out the reduction in energy use. You access your Building's User Guide (BUG 1) to find out how much electricity has been used.

3. You have noticed a slight discolouration in the water when you flush the toilet. You access your Building's User Guide (BUG 1), to find out if there is a problem or is this normal?

\subsection{Question 1}

\subsection{BUG 1}

All six responses that indicated BUG 1 was the easiest to use in Question 1 specified that the Frequently Asked Question (FAQ) section located at the end of the building user guide was useful. One respondent also mentioned that the $\mathrm{Ctrl}+\mathrm{F}$ or find function was useful.

From the eight respondents that indicated BUG 1 being the second easiest to use in Question 1, two specified that the contents page was not well thought out. The other six indicated that BUG 1 was a 'close contender' for being ranked first and the majority mentioned that the FAQ section was helpful.

The one respondent that indicated BUG 1 as the hardest to use, stated that there was too much information and it was difficult to find clear instructions. It may be that this respondent didn't find the FAQ section where the answer was located.

\subsection{BUG 2}

All eight respondents that indicated BUG 2 as being the easiest to use in Question 1 specified that the contents page made it easy to locate the information. The headings were found to be 'non-technical' and easy to find on the page.

From the seven respondents that indicated BUG 2 was the second easiest to use in Question 1, two specified the lack of a FAQ section meant that it took more time to find the answer. Two indicated that the information was harder to find because the answer wasn't sufficiently separated from the text enough i.e. wasn't highlighted. The others made mention that it took longer to find the answer than in BUG 1 
The only respondent that specified BUG 2 as being the hardest to use, indicated that there was too much technical language.

\subsection{BUG 3}

The two respondents that indicated that BUG 3 was the easiest to use, stated that the answer was 'easy to find' and 'clearly explained'. However, those two had used a building user guide before.

13 respondents indicated BUG 3 was the hardest to use. Six respondents stated that the guide was 'too technical' and they did not understand the specifics. Others noted that BUG 3 did not have a FAQ section.

\subsection{Question 2}

\subsection{BUG 1}

From the seven respondents that indicated BUG 1 was the easiest to use, four indicated that the use of specific headings made the information easier to find. One mentioning that it could have been easier if there were page numbers. Another respondent stated that it was the "lesser of three evils".

Of the six respondents that indicated that BUG 1 was the second easiest to use, four stated that the lack of a proper contents page made it difficult to find the information. One respondent stated that there was a lack of 'clarity' of index topics.

One respondent out of the two that indicated that BUG 1 was the hardest to use, stated that it had too much writing; the other stated that they did not get a good search result when using the search function (Ctrl+F).

\subsection{BUG 2}

All four respondents that indicated BUG 2 was the easiest to use, made the comment that the information was clearly listed and easiest to find. One respondent made the comment that the use of 'icons' was of some assistance.

All five respondents that indicated BUG 2 was the second easiest to use, made the comment that the information was not laid out in a 'user friendly manner'. One respondent made the comment that the use of unrelated images was distracting. 
From the six respondents that indicated that BUG 2 was the hardest, four indicated that the information was too technical to understand. Others noted that the information was hard to find as the headings were not clear. This is a contradiction from the respondents that ranked BUG 2 the easiest.

\subsection{BUG 3}

All of the respondents that indicated BUG 3 was the easiest stated the contents page and the layout of headings made the information easy to find.

All of the respondents that indicated BUG 3 was the second easiest, indicated the information was easy enough to find but quite hard to interpret.

From the seven respondents that indicated that BUG 3 was the hardest to use, four indicated that the information was non-specific and lacked the information needed. Others stated that information needed to be laid out better.

\subsection{Question 3}

\subsection{BUG 1}

Two out of the three that indicated that BUG 1 was the easiest to use, stated that the use of the CTRL-F or find feature on the PDF meant that the information was easy to find. The other respondent mentioned that the information was clearly presented and the titles and sections were clear.

The two respondents that indicated BUG 1 was the second easiest to use, stated that although the information was easy to find, it was hard to find the right page due to the lack of page numbers.

Out of the 12 respondents that indicated that BUG 1 was the hardest to use, eight mentioned the lack of page numbers. Others mentioned that the information required more searching after finding the relevant section in the contents page.

\subsection{BUG 2}

All six respondents that indicated BUG 2 was the easiest to use, stated that the information was easy on find because the contents page meant that the answer was highlighted in its own section. 
Out of the seven respondents that indicated BUG 2 was the second easiest to use, four indicated that the only reason they did not rank BUG 2 the easiest was because it took them longer to find the answer. One respondent mentioned the use of nonspecific images distracting.

Out of the four respondents that indicated BUG 2 was the hardest to use, two respondents mentioned that the colour and size of the headings was poor. One respondent mentioned it was hard to find the information because a keyword search returned no results.

\subsection{BUG 3}

Out of the eight that indicated BUG 3 was the easiest to use, five stated that the contents page led them straight to the information they required without any hassle. Others stated that the information was easy to understand.

Out of the eight that indicated BUG 3 was the second easiest to use, four mentioned that the information was easy to find, it just took longer than the BUG ranked the easiest. Other respondents mentioned the titles did not direct them to the right place and the spacing between the paragraphs made the text harder to read.

The only respondent that indicated BUG 3 was the hardest to use stated that BUG 1 took the least amount of time to find the information, the others were not bad.

\subsubsection{Summary}

From the participants' comments there are aspects of each of the building user guides that made them easy to use and aspects that made them hard to use. BUG 1 's lack of page numbers made navigating the information hard; the information was quite dense in some places and wasn't specific. However, the use of a FAQ section made some of the information easy to find especially for Question 1. BUG 2 's contents page was considered quite helpful in finding the information. However, the use of non-relevant images was distracting according to some respondents. 
BUG 3 overall was seen as too technical, with the information often being buried in a lot of jargon. However, the contents page was again quite helpful.

\subsubsection{Analysis of Question 17}

The question simply asked the participants to select aspects that they considered to be helpful in using a building user guide see Graph 20 for a breakdown of results.

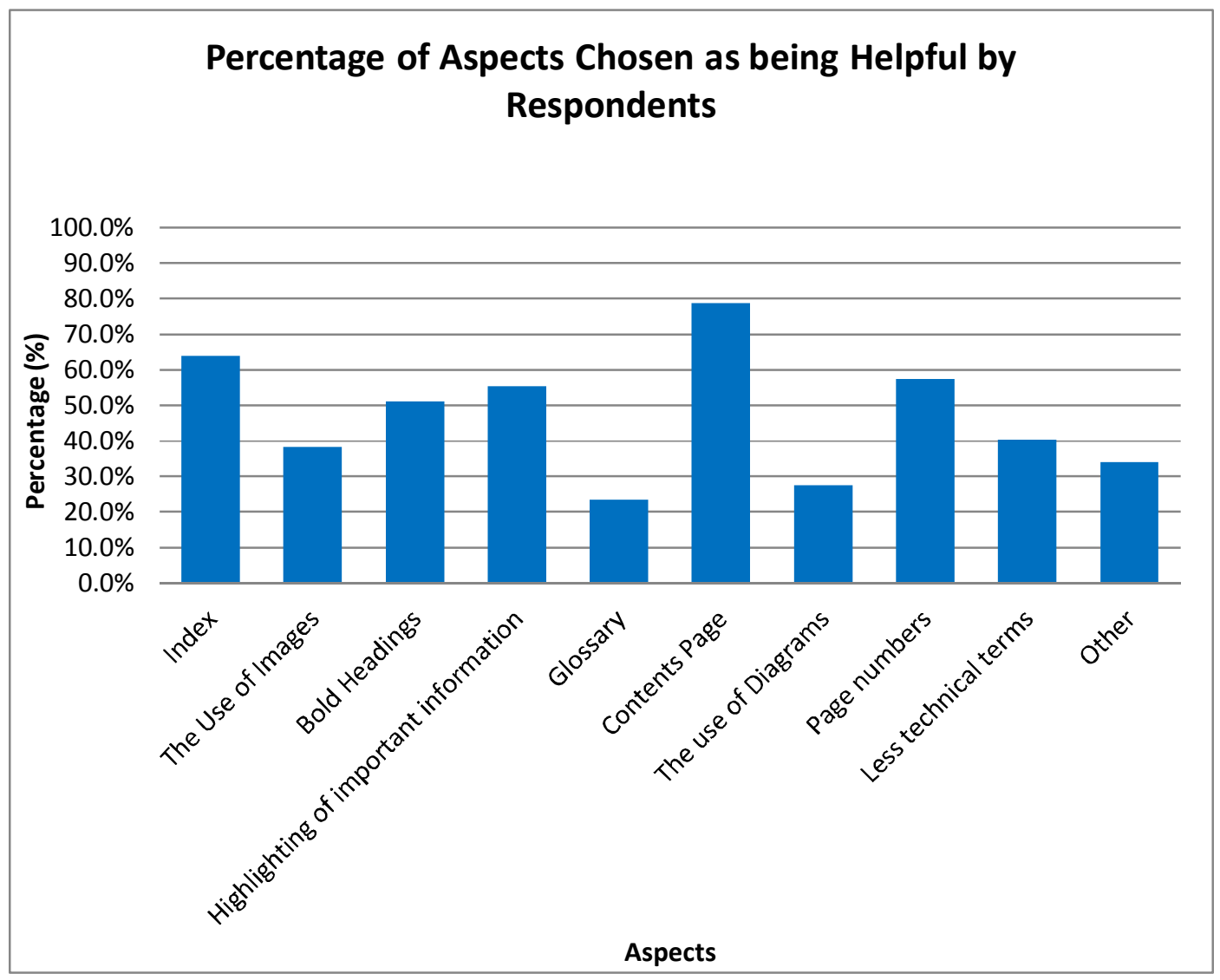

Graph 20 Percentage of Aspects chosen as being Helpful in terms of usability by Respondents

The most helpful aspect of a building user guide in terms of its usability was the contents page ( $79 \%)$, followed by an index $(64 \%)$ and page numbers $(57 \%)$. Other notable aspects were the highlighting of specific information, using bold headings and less technical terminology.

As well as these pre-determined aspects, participants had the opportunity to suggest their own. 16 participants did so. Five participants suggested the inclusion of a FAQ section; four suggested the use of a keyword search (relating to an electronic version of the building user guides). Other suggestions included a better 
layout of the whole document, a troubleshooting section and consistent use of terminology.

\subsection{Usability Discussion}

\subsubsection{Reflections on limitations of the usability survey}

Two main limitations were identified in the data collected from the usability survey distributed to office building users. This section discusses these issues and the methods used to allow analysis.

A contact email address was given to respondents for any comments in regards to the survey. Multiple comments were received from respondents on Q14 (the ranking of building user guides question). The question was found to be confusing in that the software for the survey was hard to work (sections had to be dragged into place).

At least 10 respondents commented on 'frustration' caused by the way the answers moved in order. It was concluded that any further studies would need to resolve this problem. It is suggested that a remedy to this problem might include the use of a Likert-type scale (with an assertion to which respondents have to react on a scale between strongly agree and strongly disagree) (De Jong \& Schellens, 1997).

However, to allow analysis of the results received, some results have been changed to reflect the respondent's proper rank (using Q15 to Q16). For example, an answer to Q15, stated that they choose BUG 3 as the easiest to use, however BUG 3 was ranked as the hardest to read in Q14; only then would their ranking of building user guides be corrected

Whilst analysing the results, it was found that respondents misunderstood the definition of the 'index' aspect asked in the survey. It was found that while none of the building user guides had an 'index' respondents had referred to the index as being 'helpful' in the search of answers The impossibility of this answer means that the index section will be discounted for this research due to the doubt as to whether the respondents had a full understanding of the term. 


\subsubsection{Usability of the building user guides surveyed}

Respondents of the survey answered the three different questions correctly $80.8 \%$ of the time. This value indicates that the building user guides are able to be used for at least some of the information requested. Because $80.8 \%$ of the time the respondents gave the correct answer, this indicates that certain elements of the building user guides have been demonstrated to be useful. Furthermore, the remaining $19.2 \%$ indicate that other elements could be improved upon.

It was found that no one building user guide was ranked above or below the rest consistently. Analysis of the results found that this could be because the building user guides used inconsistent styles, e.g. some sections of the same building user guides could be used well and others not so well. Respondents found that this was the case with questions one and three. The results for this section indicated that BUG 1 performed poorly when answering question 1 and BUG 3 performed poorly on question 3. This shows that while certain elements of the building user guides have been demonstrated to be useful, other responses to the survey identified elements that were not useful and could be improved (specifically for each building user guide, and overall for all building user guides).

\subsection{Easy to use aspects of the building user guides}

Users found a number of aspects increased the usability of a building user guide and identified that if these were not used, or used inappropriately, they decreased the usability. An example of this is respondent comments to 'contents pages'; the contents page of BUG 2 was the reason behind many respondents ranking this guide as being the easiest to use. However, BUG 1's 'poorly constructed' contents page was attributed to the reason BUG 1 was ranked in the middle or the hardest guide to use.

The following section discusses how each aspect was identified by survey respondents and how comments indicated the effect of these aspects on the usability of each building user guide. 


\subsection{Contents page}

As stated in Section 4.4.2.1.1, the design of a contents page effected how users perceived the usability of the building user guides.

Respondent comments were positive for both BUG 2 and BUG 3's contents page, while predominantly negative comments were received for BUG 1's. The differences between the three buildings user guides' contents page can be seen by the different use of the levels of headings. See examples in Figure 7, Figure 8 and Figure 9. As seen in the examples BUG 1 only goes into one level of detail (Figure 7), BUG 2 goes into three levels (Figure 8) and BUG 3 goes into two levels (Figure 9). The extra levels of detail increase the chance of users being able to find the specific piece of information in the table of contents, rather than exploring the whole document.

\section{BUILDING SERVICES SYSTEMS}

Figure 9 Example of the table of contents in BUG 1

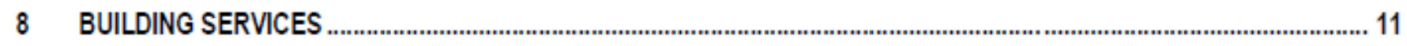

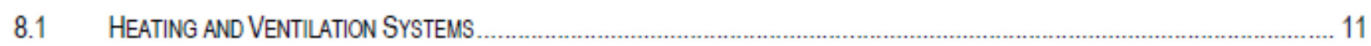

811 Ventilation

Figure 8 Example of the table of contents in BUG 2

6 Heating Ventilation and Air Conditioning .. 7

6.1 Heating and Air Conditioning .

Figure 7 Example of the table of contents in BUG 3

Examples of responses regarding BUG 2 and BUG 3's contents page

- $\quad$ UUG 2 
Usability Analysis

- Easy categories of related information made navigating to right

location in document intuitive

- The contents page was set out better

- Could see where the answer would be in the contents

- $\quad$ BUG 3

- Contents page is better thought out and practical to use

- TOC more clearly directed to issue.

- The TOC was better

While comments on BUG 1's contents pages were predominantly negative:

\section{- $\quad$ BUG 1}

- There wasn't the clarity in the TOC topics

- No table of contents in the case of BUG 1

- BUG 1 did not have a 'heating and ventilation' section in the table of contents

- BUG 1's contents were not arranged as well

The responses around contents pages indicate there should be at least two levels of information to improve the ease of locating information and to optimise usability.

This result is similar to the findings of at least two studies found in existing literature. The first is a study of a user manual that was completed by comparing a before and after of the document (F. Ganier, 2004). During Ganier's (2004) analysis of the original manual, it was found that the contents page needed improving. The results of a user evaluation of both the original and modified user guide, found users evaluation increased from a score of 3.6 to 4.6 (out of 5). The second study was a specific analysis of a contents page for a health brochure (Kools, Ruiter, Van de Wiel, \& Kok, 2007). It found that users' perceptions of its usability were significantly affected by the appropriate inclusion and alteration of its contents page. After more information had been added, the users perception increased from a score of 2.84 to 6.48 (out of 7) when used for the location of information. 


\subsection{Page Numbers}

It was noted in Section 4.2.2.4 that BUG 1 did not contain any page numbers. This aspect was added to the list for respondents to choose from in Q17. Page numbers were seen to be an important aspect to include as part of the layout of a building user guide. $57 \%$ of respondents indicating that page numbers would help the overall usability of the building user guides as per Q17. This was also seen in the open-ended comment boxes:

- a lack of page numbers and incorrectly labelled sections did not help

- BUG 3 didn't have page numbers so even though the table of contents [sic] told me a page number it was hard to find the page

- the lack of page numbers on BUG 1 was very annoying

\subsection{Highlighting Important Information}

The 'highlighting of important information' aspect was chosen by $55 \%$ of the respondents as an aspect that would help the overall usability of the building user guides. This aspect was found as being important in Section 2.5.4.1 of the literature review. In the literature review it was stated that conspicuous print and icons being present enhanced the memory of the content (Young \& Wogalter, 1990).

BUG 2 attempted to do this throughout the document by putting in separate 'Do's and Don'ts' sections. This was noted by at least one respondent who stated that the 'do's and don'ts were 'useful'.

It was discussed in the literature that increasing the visibility of important information would increase the likelihood of this information being remembered by the respondent. This could increase the efficiency of the building user guides as users would not need to repetitively view the guide for the same information. It is noted that this would only be the case when the user of the guide is reading the whole document, not just using it for specific information.

As part of highlighting of important information, it was also suggested that the use of images could help increase the likelihood of information being remembered. It was stated as one of the comments in BUG 2, that the "The assistance of 'icons' 
representing different features was a help". However, there were respondents who disliked the images because they were not relevant, they were not specific to the building the building user guide was created for; "distracted by poorly related images", "images do not appear to relate directly to the information". It has been recommended by Young and Wogalter's (1990) research, however they should relate to the building rather than being 'generic stock' images.

\subsection{Bold Headings}

It was found respondents had a significant number of positive comments for all of the building user guides in terms of the use of bold headings. 'Bold headings' were chosen by $51 \%$ of respondents (a total of 24 people) as an aspect that would help the overall usability of the building user guide. The comments are listed below:

- BUG 1

- Clear use of headings

- Clear headings and no need to search for information

- Very clear titles and sections

\section{- BUG 2}

- Clear headings of the relevant topics

- Presented clearly and easy to understand

- Clearly listed information made it easier to find

- BUG 3

- Information was easy to find

- BUG 3 sets out the required information clearly

- BUG 3 - Although clear titles, the titles are not on the page with the text making it harder to read

In all three building user guides the titles are significantly larger than the main font size, and these are also a different colour than the main text or other sub-headings (a different shade of blue in all three). None of the respondents directly commented that these colours impacted in any way on the building user guides usability. This relates to Hedberg's points about typefaces (Section 2.5.4.1) where he states that all headings should be distinguishable from the body of the text, this can be done by 
increasing the size and/or changing the colour. His study also indicates that the building user guides should not use 'All caps' (for example; HEATING AND

VENTILATION) in headings, which all three building user guides have stayed away from (Hedberg, 1987). He also suggest there should be more space above and below the heading (Hedberg, 1987). Respondents have also found that this spacing has impacted on the usability of building user guides with comments stating: "There was a lack of spacing between headings and paragraphs", "the layout needed to be better it was harder to distinguish the headings from the text" and "text and titles wasn't nicely spaced".

\subsection{The use of Technical Language or Jargon}

It was found that $40 \%$ of the respondents selected 'Less technical terms' as an aspect that would increase the usability of building user guides. This aspect had already been addressed in the readability assessment (Section 3.4). It was found that the building user guides are written with too much jargon or technical terminology for the majority of New Zealand readers. Comments in the usability sections reinforced this:

- BUG 1

- Too much technical language

- The info was in technical language

- $\quad$ BUG 2

- Lots of technical terms

- Technical information was hard to understand

- Too wordy and not direct enough

\section{- BUG 3}

- Lacked any kind of easily understood information

- Too much jargon and wasn't exactly clear on what to do

- Was too technical and did not appear to answer what would be a common question

It was found that respondents commented that when one particular building user guide had less technical language or jargon; for example; "information was easy to 
read and follow", "straightforward, non-technical content", "it was less technical and information was easier to read" and "clear English description. This coincided with the particular building user guide being ranked as the easiest to use. It was found that on 12 separate occasions, the respondents' reasoning for choosing the 'easiest' building user guide was because there was less technical language and jargon.

Both the results from the readability and usability assessment have agreed that the use of technical language or jargon affects the way users read and understand the building user guides. Improving the simplicity of text can increase users perceptions of usability, shown by a study completed by Ganier (2004). This study found scores of user's perception of usability increase from 3.8 to 4.4 , when text was written with less technical language (Ganier, 2004).

It was suggested that a glossary should be included in the readability assessment by Vallance et al, (2008). However, it was only selected by $23 \%$ of respondents in the usability study as being an aspect that would increase the usability of a building user guide. It was deemed by $77 \%$ of people that a glossary was not an element they perceived to increase the usability of a building user guide. Consequently, the inclusion of a glossary will not be suggested in the final recommendations.

\subsection{Frequently Asked Question section and the Ability to Search}

The 'Other' selection, possible in Q17, was where respondents had the chance to suggest their own aspects that would help the usability of the building user guide.

There were two common aspects that were suggested: the first was a 'Frequently Asked Question (FAQ)' section and the second a search function to enable precise location of keywords.

The suggestion of the FAQ section arose because of its use in BUG 1 (see Figure 10). Many comments were made in regards to the FAQ section being helpful in answering the questions, "BUG 1 had a Frequently Asked Question section that was clear and concise", "FAQ section made it easy to find the information" and "Simply 
found in the FAQ section". This section would be a positive addition to a building user guide as identified by the comments in the survey.

\section{Frequently Asked Questions (FAQ's)}

1. I am too hot what can I do?

Increase airflow to your immediate area by opening the vent in the nearest floor diffuser.

2. I am too cold what can I do?

Decrease airflow to your immediate area by partially closing the vent in the nearest floor diffuser.

Figure 10 the example of the FAQ section in BUG 1

The other suggestion was to make the building user guide available electronically so a search using keywords could be completed. This would be an easy step to accomplish as all of the building user guides were given in an electronic form as part of the survey. A simple way to allow this would be to distribute a text-based PDF copy of the building user guide where a search function is accessible.

\subsection{Layout}

Layout is the final aspect that has been identified as having an effect the usability of the building user guides. As identified in the literature review, a simple-to-use layout of the document can be implemented to increase the usability of a user guide (Hartley, 1981, 1985, 2004; Hedberg, 1987; Jonassen, 1980; Priestly, 1991). The respondents illustrated their issues with the layout with negative comments:

\section{- BUG 1}

- Needed to be laid out better

- Headings were hard to identify fast even though a different colour they didn't stand out

- BUG 2

- The text wasn't separated enough from the headings

- Layout was hard to read, irrelevant images were distracting

- BUG 3 
- A lack of correct spacing made it hard to follow the text

- Text not spaced nicely

From the comments, it has been identified there are some issues with the layout that affect the usability of the building user guides. A study completed by Ganier (2004), found that improving the layout increased user perceptions of usability from a score of 3.6 to 4.5 (out of 5). The layout problem identified in this survey was that respondents predominantly highlighted concerns around the separation of headings with regards to the main text. The simple two column page layout presented by Priestly (1991) (see Section 2.5.4.1), may solve this problem. He stated that any headings on the page should start on the far left, while the main text should be indented in. This would mean users could scan the left hand side, and therefore all the headings to find the most relevant information. This would decrease the time it would take for the users to locate specific keywords and headings. 


\section{Conclusion}

\section{Conclusion}

The main aim of this research was to assess the readability usability of building user guides created for the NZGBC rating scheme and recommend guidelines for future building user guides.

\subsubsection{Readability}

It was found that the building user guides analysed, had grade level scores (grades of schooling) that exceeded the grade level of the average New Zealander. The average (American) grade score of the building user guide was found to be $13.9 \pm 0.4$, while the average grade level of a New Zealander has been established to be between (American - as this is the country that the equation was created for) 8 and 9. A Word Frequency Profiler (Nation's 25K List with the AntWordProfiler) was also used as a part of a Word Frequency Profiler assessment. However, results from this analysis were not able to be compared to either a school grade level or the average literacy level of a New Zealander. Therefore, future research would have to be completed to address the lack of comparison.

It was also found that any of the four SMOG assessment equations or indices could be selected to assess the readability of building user guides. However, the SMOG Grade Level using the whole document was found to be the most accurate.

A key finding in the assessment of readability of the building user guides was the significant influence that technical language or jargon had on the readability results. The building user guides often used words that the average New Zealander would find difficult to understand, for example: potable, kilowatt, facilities and ventilation. Respondents of the usability survey found that the use of technical language and jargon meant that they struggled to understand some of the building user guide content. It was found that a decrease or simplification of the use of these words would have a positive effect on the readability by decreasing the grade level of the building user guides. 


\section{Conclusion}

\subsubsection{Usability}

It was found that some elements of the building user guides could be used by building occupants. Respondents were able to correctly answer $80.8 \%$ of the questions posed in the usability survey. The survey did however identify aspects that could be improved to increase the overall usability of the document. These improvements are:

- A contents page should have at least two levels of information; to increase the chance of users locating specific information,

- Page numbers must be included in all building user guides,

- Highlighting is an important aspect to be utilised if the information is deemed to be important as this increases the likelihood of it being remembered. It is suggested that this be done by referencing relevant images and/or distinguishing through the use of different coloured/sized text,

- The use of bold headings, increases the chance of the headings be noticed,

- The introduction of a 'Frequently Asked Question' section was suggested by a number of respondents as a helpful tool to communicate key information,

- The inclusion of a 'search' function in an electronic version of the building user guide could increase the ease in which information is located. This would suggest it would be wise to give building users access electronically,

- Finally, a better layout of the information needs to be utilised. Suggestions were made as to the appropriate use of headings to allow ease of location. This can be seen in the following example Figure 11 and Figure 12.

\subsubsection{Guidelines}

The above aspects have been incorporated into a final set of guidelines for future building user guides to follow, as demonstrated in Figure 11 and Figure 12, on the following pages. 


\section{Conclusion}

| A simple header that would state the name of the building

\section{Contents}

1. A headline that stands out from the rest of the page (24pt) ...............................................

1.1. A section heading that is slightly smaller (18pt) .............................................................

1.1.1. Sub-heading that is smaller, but still stands out from the main body of text (14pt) .....2

1.2. The use of technical language or jargon ............................................................................... 2

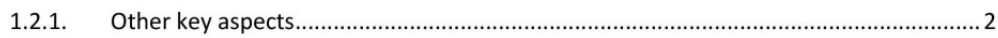

The contents page should go into either 2 or 3 levels of headings, similar to the one above.

Page numbers must be included.

Page 1

Figure 11 Page 1 of the building user guide, guidelines 


\section{A headline that stands out from the rest of the page (24pt)}

\subsection{A section heading that is slightly smaller (18pt)}

The body text of the building user guides should be indented from the headings. (10Pt)

1.1.1. Sub-heading that is smaller, but still stands out from the main body of text (14pt)

The addition of images and tables should also be aligned with the body of text and be relevant to the information it should relate to. For example, if the building user guide mentions a particular type of light switch, the image should be the exact light switch located in the building.

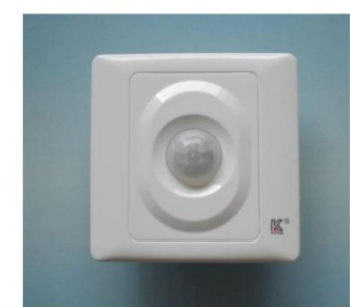

Figure 2 Example of a light sensor found in this building

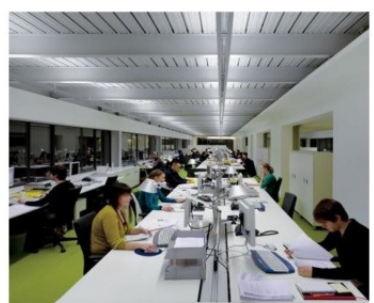

Figure 1 Light sensor controls the main office lights after 7:30 pm

\subsection{The use of technical language or jargon}

Below is an example of a typical sentence from a building user guide, followed by a suggested improvement.

- A 2-pipe inverter split system is provided in the lobby and a 3-pipe heat recovery VRF system in the office to heat and cool the spaces.

- The lobby is heated and cooled by a wall mounted air-conditioning unit. The offices are heated and cooled by a separate air-conditioning system in the ceiling.

\subsubsection{Other key aspects}

- The introduction of a frequently asked questions section was found to increase the ease with which information was found

- The ability for the users to complete a 'search function' of the document would also increase the ease with which information is found. This would mean that the building user guides should be available electronically 
Conclusion

\subsection{Future Works}

- It was the usability survey would need to be updated. The ranking of the building user guides in Q14, did not work well and it has been suggested in this research that a Likert scale should be incorporated instead.

- A comparison usability study would need to be completed to assess how well the new building user guides created with the new format, compare to the older building user guides.

- Due to the differences in units, and a lack of literature associating word frequency profiles to Grade Level score, there has been no comparison made between the word frequency profiles and New Zealand literacy levels in this research. Further research should be undertaken to find a comparison, if one is present.

- A complementary study could be completed to assess the actual usage of building user guides. The low level of participants in this survey stating they have never used a building user guide before was concerning. More research should be completed into the reasons why they have not been used more. 


\section{Works Sited}

\section{Works Sited}

Aleligay, A., Worrall, L. E., \& Rose, T. A. (2008). Readability of written health information provided to people with aphasia. Aphasiology, 22(4), 383-407. doi:10.1080/02687030701415872

Allwood, C. M., \& Kalén, T. (1997). Evaluating and improving the usability of a user manual. Behaviour \& Information Technology, 16(1), 43-57. doi:10.1080/014492997120002

Anagnostou, N. K., \& Weir, G. R. S. (2006). From corpus-based collocation frequencies to readability measure. In ICT in the Analysis, Teaching and Learning of Languages, Preprints of the ICTATLL Workshop 2006 (pp. 33-46).

Armitage, L., Murugan, A., \& Kato, H. (2011). Green offices in Australia: a user perception survey. Journal of Corporate Real Estate, 13(3), 169-180. doi:10.1108/14630011111170454

Axinn, W. G., Link, C. F., \& Groves, R. M. (2011). Responsive survey design, demographic data collection, and models of demographic behavior. Demography, 48(3), 1127-1149. doi:10.1007/s13524-011-0044-1

Babbie, E. R. (2012). The Practice of Social Research. Cengage Learning.

Baharuddin, M., Che-Ani, A., Abdullah, N., Tahir, M., Tawil, N., \& Utaberta, N. (2011). Building User Manual: A Vital Component of the Malaysian Green Building Index (pp. 29-35). Presented at the Recent Researches in Energy, Environment, Devices, Systems, Communications and Computers, Venice, Italy: WSEAS.

Baird, G., \& Lechat, S. (2009). Users' Perceptions of Personal Control of Environmental Conditions in Sustainable Buildings. Architectural Science Review, 52(2), 108-116. doi:10.3763/asre.2009.0013

Barr, R., Kamil, M., Mosenthal, P., \& Pearson, D. (1984). Handbook of Reading Research. Routledge.

Benjamin, R. G. (2012). Reconstructing Readability: Recent Developments and Recommendations in the Analysis of Text Difficulty. Educational Psychology Review, 1-26.

Bevan, N. (1995). Usability is Quality of Use. In K. O. and H. M. Yuichiro Anzai (Ed.), Advances in Human Factors/Ergonomics (Vol. Volume 20, pp. 349-354). 
Works Sited

Elsevier. Retrieved from

http://www.sciencedirect.com/science/article/pii/S0921264706802418

Bevan, N., \& Curson, I. (1999). Planning and implementing user-centred design. In CHI'99 extended abstracts on Human factors in computing systems (pp. 137138). Retrieved from http://dl.acm.org/citation.cfm?id=632800

Bevan, N., \& Macloud, M. (1994). Usability measurement in context. Behaviour \& Information Technology, 13(1-2), 132-145.

doi:10.1080/01449299408914592

Bond, S. (2010). Lessons from the leaders of green designed commercial buildings in Australia. Pacific Rim Property Research Journal, 16(3), 314-338.

Booher, H. R. (1971). Survey of Research on Readability of Technical Publications. DTIC Document. Retrieved from http://oai.dtic.mil/oai/oai?verb=getRecord\&metadataPrefix=html\&identifier $=A D 0725143$

Bordass, B., \& Leaman, A. (1996). Future buildings and their services: Strategic considerations for designers and their clients. In Proceedings of the CIBSE/ASHRAE joint National Conference (Vol. 1).

Bordass, B., Leaman, A., \& Bunn, R. (2007). Controls for End Users: a guide for good design and implementation. $\mathrm{BCIA}$.

Bordass, B., Leaman, A., \& Ruyssevelt, P. (2001). Assessing building performance in use 5: conclusions and implications. Building Research \& Information, 29(2), 144-157. doi:10.1080/09613210010008054

Bormuth, J. R. (1969, March). Development of Readability Analysis. Retrieved from http://www.eric.ed.gov/ERICWebPortal/contentdelivery/servlet/ERICServlet ?accno=ED029166

Brown, Z., \& Cole, R. J. (2009). Influence of occupants' knowledge on comfort expectations and behaviour. Building Research \& Information, 37(3), 227245. doi:10.1080/09613210902794135

Bruce, B., Rubin, A., \& Starr, K. (1981). Why readability formulas fail. IEEE Transactions on Professional Communication, PC-24(50-52).

Bucknavage, L. B. (2007). Psychoeducational Reports: Impact of Jargon and Report Length on Teacher and Parent Recall and Preference. The Pennsylvania State University. Retrieved from https://etda.libraries.psu.edu/paper/7685/2978 


\section{Works Sited}

Burke, V., \& Greenberg, D. (2010). Determining Readability: How to Select and Apply Easy-to-Use Readability Formulas to Assess the Difficulty of Adult Literacy Materials. Adult Basic Education \& Literacy Journal, 4(1), 34-42.

Cain, A. J., \& Benseman, J. (2005). Adult literacy in New Zealand. Review of Adult Learning and Literacy, Volume 5: Connecting Research, Policy, and Practice: A Project of the National Center for the Study of Adult Learning and Literacy, $5,155$.

Carapella, J. (2012, August). Readability of the Common Core Standards 11-CCR Text Exemplars: A Text Sequence Refernce Guide (Masters Thesis). State University of New York, Fredonia, New York.

Carrell, P. L. (1987). Readability in ESL. Reading in a Foreign Language, 4(1), 21-40.

Caylor, J. S., Sticht, T. G., Fox, L. C., \& Ford, J. P. (1973, March). Methodologies for Determining Reading Requirements of Military Occupational Specialties. Retrieved from http://www.eric.ed.gov/ERICWebPortal/contentdelivery/servlet/ERICServlet ?accno=ED074343

Chall, J., \& Dale, E. (1995). Readability revisited: The new Dale-Chall readability formula (Vol. 118). Brookline Books Cambridge, MA. Retrieved from http://www.getcited.org/pub/103286508

Chapman, J. W., Tunmer, W. E., \& Allen, R. (2003). Findings from the International Adult Literacy Survey on the incidence and correlates of learning disabilities in New Zealand: Is something rotten in the state of New Zealand? Dyslexia, 9(2), 75-98. doi:10.1002/dys.238

Cockrell, B. J., \& Jayne, E. A. (2002). How do I find an article? Insights from a web usability study. The Journal of Academic Librarianship, 28(3), 122-132. doi:10.1016/S0099-1333(02)00279-3

Cramer, E. H. (1978). A Quick Guide to Readability Formulas. Curriculum Review, $17(5), 416-17$.

Cunitz, R. J. (1981). Psychologically effective warnings. Hazard Prevention, 17(3), 57.

Cuomo, D. L., \& Bowen, C. D. (1994). Understanding usability issues addressed by three user-system interface evaluation techniques. Interacting with Computers, 6(1), 86-108. 
Works Sited

Dale, E. (1931). A comparison of two word lists. Educational Research Bulletin, 484489.

Dale, E., \& Chall, J. S. (1948). A Formula for Predicting Readability. Educational Research Bulletin, 27(1), 11-28.

Darby, S. (2006). The effectiveness of feedback on energy consumption. A Review for DEFRA of the Literature on Metering, Billing and direct Displays, 486.

De Jong, M., \& Schellens, P. J. (1997). Reader-Focused Text Evaluation An Overview of Goals and Methods. Journal of Business and Technical Communication, 11(4), 402-432. doi:10.1177/1050651997011004003

De Jong, M., \& Schellens, P. J. (2000). Toward a document evaluation methodology: what does research tell us about the validity and reliability of evaluation methods? IEEE Transactions on Professional Communication, 43(3), 242 260. doi:10.1109/47.867941

De Mul, S., \& Van Oostendorp, H. (1996). Learning user interfaces by exploration. Acta Psychologica, 91(3), 325-344.

Department of the Environment and Water Resources. (2007, May). ESD Design Guide - ESD design guide for office and public buildings. Sustainable Built Environments and Centre for Design. Retrieved from http://www.environment.gov.au/sustainability/government/publications/es d-design/index.html

Diaconis, P., \& Efron, B. (1985). Testing for Independence in a Two-Way Table: New Interpretations of the Chi-Square Statistic. The Annals of Statistics, 13(3), 845-874. doi:10.1214/aos/1176349634

Dillman, D. A., Sinclair, M. D., \& Clark, J. R. (1993). Effects of Questionnaire Length, Respondent-Friendly Design, and a Difficult Question on Response Rates for Occupant-Addressed Census Mail Surveys. The Public Opinion Quarterly, 57(3), 289-304. doi:10.2307/2749091

Doak, C. C., Doak, L. G., \& Root, J. H. (1995). Teaching Patients With Low Literacy Skills. J.B. Lippincott.

Drake, C. J. (2008). From conception to the press: considerations for publishing an emergent reader series (Thesis). Master of Publishing Program - Simon Fraser University. Retrieved from http://summit.sfu.ca/item/8775

Dubay, W. (2004). The principles of readability. Impact Information, 1-76. 


\section{Works Sited}

DuBay, W. (2007). Smart language: Readers, readability, and the grading of text [electronic version]. Charleston, SC: BookSurge Publishing.

Duffy, T. M., \& Kabance, P. (1982). Testing a readable writing approach to text revision. Journal of educational psychology, 74(5), 733-748.

Eysenbach G, P. J. (2002). Empirical studies assessing the quality of health information for consumers on the world wide web: A systematic review. JAMA, 287(20), 2691-2700. doi:10.1001/jama.287.20.2691

Fisher, R. A. (1926). The Arrangement of Field Experiments. Journal article. Retrieved February 27, 2013, from http://digital.library.adelaide.edu.au/dspace/handle/2440/15191

Fisher, R. A., \& Yates, F. (1963). Statistical tables for biological, agricultural and medical research, edited by R.A. Fisher and F. Yates. 6th ed. Book. Retrieved February 27, 2013, from http://digital.library.adelaide.edu.au/dspace/handle/2440/10701

Fitzgerald, F. S. (1925). The Great Gatsby. Ch, Scribner's Sons.

Flesch, R. (1948). A new readability yardstick. Journal of applied psychology, 32(3), 221.

Foddy, W. (1994). Constructing questions for interviews and questionnaires: theory and practice in social research. Cambridge university press. Retrieved from http://books.google.co.nz/books?hl=en\&lr=\&id=tok_OKwywQIC\&oi=fnd\&pg $=P R 7 \& d q=$ Constructing+Questions+for+Interviews+and+Questionnaires:+Th eory+and+Practice+in+Social+Research\&ots=Tx9ch7R5KP\&sig=1cSCanOy2eD JCNYeJFpcljyN4qM

Fowler, F. J. (1992). How Unclear Terms Affect Survey Data. Public Opinion Quarterly, 56(2), 218-231. doi:10.1086/269312

Fry, E. B. (1968). A Readability Formula That Saves Time. Journal of Reading, 11(7), 513-578.

Fry, E. B. (1977). Fry's Readability Graph: Clarifications, Validity, and Extension to Level 17. Journal of Reading, 21(3), 242-252.

Fry, E. B. (1986). The Varied Uses of Readability Measurement. Presented at the Annual Meeting of the International Reading Association, Philadelphia, PA. Retrieved from http://www.eric.ed.gov/ERICWebPortal/detail?accno=ED267384 
Fry, E. B., Kress, J. E., \& Fountoukidis, D. (2000). The reading teacher's book of lists. Prentice Hall.

Gal, I., \& Prigat, A. (2005). Why organizations continue to create patient information leaflets with readability and usability problems: an exploratory study. Health Education Research, 20(4), 485-493. doi:10.1093/her/cyh009

Ganier, F. (2004). Factors affecting the processing of procedural instructions: implications for document design. IEEE Transactions on Professional Communication, 47(1), 15 - 26. doi:10.1109/TPC.2004.824289

Ganier, Franck. (2007). Comparative user-focused evaluation of user guides: a case study. Journal of Technical Writing and Communication, 37(3), 305+. doi:Case study

Gilliland, J. (1975). Readability. Hodder and Stoughton for the United Kingdom Reading Association.

Graves, H., Jaggs, M., \& Watson, M. (2003). HOBO protocol Handover of office building operations. Building Research Establishment Digest.

Grice, R. A., \& Ridgway, L. S. (1989). A discussion of modes and motives for usability evaluation. IEEE Transactions on Professional Communication, 32(4), 230 237. doi:10.1109/47.44535

Grundner, T. M. (1981). How to Make Consent Forms More Readable. IRB: Ethics and Human Research, 3(7), 9-10. doi:10.2307/3563861

Guillemette, R. A. (1989). Usability in computer documentation design: Conceptual and methodological considerations. Professional Communication, IEEE Transactions on, 32(4), 217-229.

Gunning, T. G. (2003). The Role of Readability in Today's Classrooms. Topics in Language Disorders, 23(3), 175-189.

Haneef, N. J. (1998). Software documentation and readability: a proposed process improvement. SIGSOFT Softw. Eng. Notes, 23(3), 75-77. doi:10.1145/279437.279470

Hargis, G., Carey, M., Hernandez, A. K., Hughes, P., Longo, D., Rouiller, S., \& Wilde, E. (2004). Developing quality technical information: $A$ handbook for writers and editors. Prentice Hall PTR. 


\section{Works Sited}

Harris, J., Wilson, A., \& Deramchi, S. (2011). Building Manuals and Building User Guides. BSRIA.

Harris, T. L., \& Hodges, R. E. (1995). The Literacy Dictionary: The Vocabulary of Reading and Writing. International Reading Assoc.

Hartley, J. (1981). Eighty ways of improving instructional text. IEEE TRANS. PROFESS. COMMUN., 24(1), 17-27.

Hartley, J. (1985). Designing instructional text (2nd ed.). London: Kogan Page.

Hartley, J. (2004). Designing instructional and informational text. Handbook of research on educational communications and technology, 917-947.

Harvey, V. S. (1997). Improving readability of psychological reports. Professional Psychology: Research and Practice, 28(3), 271-274. doi:10.1037/07357028.28.3.271

Healey, G. (2011). Persuasive Design and Building User Engagement. Environment Design Guide, (66), 1.

Heaton, N. O. (1992). Defining usability. Displays, 13(3), 147-150. doi:10.1016/0141-9382(92)90016-K

Hedberg, J. (1987). Desktop publishing and better design in educational materials. Education, Research and Perspectives, 14(1), 69-87.

Heerwagen, J. (2000). Green buildings, organizational success and occupant productivity. Building Research \& Information, 28(5-6), 353-367. doi:10.1080/096132100418500

Heyneman, J. (2006, January 1). Readability of OT patient education documents for post-stroke home programs. D'Youville College, Buffalo, NY.

Hochhauser, M. (1997). Some Overlooked Aspects of Consent Form Readability. IRB: Ethics and Human Research, 19(5), 5-9. doi:10.2307/3564121

Hochhauser, M. (2008). Consent Comprehension in the 21st Century: What Is Missing? Drug Information Journal, 42(4), 375-384.

Holmes, J., Hudson, G., \& MacDonald, M. (2012). BREEAM Credits - Operational value to the occupier. In Building Performance Assessment. Presented the CIBSE ASHRAE Technical Symposium, Imperical College, London, UK: CIBSE. Retrieved from www.cibse.org/content/cibsesymposium2012/Paper022.pdf 
Works Sited

Hurst, E. (2008). An Assessment of the Readability of Recommended Popular Consumer Health Titles: Implications for Collection Development. Retrieved from http://ils.unc.edu/MSpapers/3377.pdf

Iarossi, G. (2006). The Power of Survey Design A User's Guide for Managing Surveys, Interpreting Results, and Influencing Respondents. Washington, D.C: World Bank. Retrieved from http://helicon.vuw.ac.nz/login ?url=http://www.worldbank.icebox.ingenta.c om/content/wb/2175

IBM. (2012). IBM SPSS Statistics. Somers, NY: IBM Coporation.

Ishikawa, S., Uemura, T., Kaneda, M., Shimizu, S., Sugimori, N., Tono, Y., ... Murata, M. (2003). JACET 8000: JACET List of 8000 basic words. Tokyo: JACET.

ISO, S. (1998). 9241-11. 1998. Ergonomic Requirements for Office Work with Visual Display Terminals (VDTs)-Part II Guidance on Usability.

Jeng, J. (2005). Usability Assessment of Academic Digital Libraries: Effectiveness, Efficiency, Satisfaction, and Learnability. Libri, 55(2-3), 96-121.

Johansson, K., Salanterä, S., Katajisto, J., \& Leino-Kilpi, H. (2004). Written orthopedic patient education materials from the point of view of empowerment by education. Patient Education and Counseling, 52(2), 175-181. doi:10.1016/S0738-3991(03)00036-3

Johansson, S. (1985). Word frequency and text type: Some observations based on the LOB corpus of British English texts. Computers and the Humanities, 19(1), 23-36.

Johnson, W. (1946). People in quandaries: the semantics of personal adjustment. Harper \& Row.

Jokela, T., livari, N., Matero, J., \& Karukka, M. (2003). The standard of user-centered design and the standard definition of usability: analyzing ISO 13407 against ISO 9241-11. In Proceedings of the Latin American conference on Humancomputer interaction (pp. 53-60). Retrieved from http://dl.acm.org/citation.cfm?id=944525

Jonassen, D. (1980). Introduction to the technology of text. NSPI Journal, 19(8), 3-3. doi:10.1002/pfi.4180190804 


\section{Works Sited}

Kahn, A., \& Pannbacker, M. (2000). Readability of Educational Materials for Clients with Cleft Lip /Palate and Their Families. American Journal of SpeechLanguage Pathology, 9(1), 3-9.

Karjalainen, S., \& Koistinen, O. (2007). User problems with individual temperature control in offices. Building and Environment, 42(8), 2880-2887. doi:10.1016/j.buildenv.2006.10.031

Kingston, A. J., \& Weaver, W. W. (1967). Recent Developments in Readability Appraisal. Journal of Reading, 11(1), 44-47.

Kistulentz, A. C. (1975). An Analysis of Two Approaches Used in Teaching Reading and Study Skills Improvement in a Two-Year Community College. University Microfilms, P.O. Box 176, Ann Arbor, Michigan 48106 (Order No. 76-1360, MFilm \$7.50, Xerography \$15.00). Retrieved from http://www.eric.ed.gov/ERICWebPortal/detail?accno=ED117672

Kitson, H. D. (1921). The Mind of the Buyer: A Psychology of Selling. Macmillan.

Klare, G. R. (1963). The measurement of readability. lowa State University Press.

Klare, G. R. (1968). The role of word frequency in readability. Elementary English, $45,12-22$.

Klare, G. R. (1976). A Second look at the Validity of Readability Formulas. Journal of Literacy Research, 8(2), 129-152. doi:10.1080/10862967609547171

Kools, M., Ruiter, R. A. C., Van de Wiel, M. W. J., \& Kok, G. (2007). Testing the usability of access structures in a health education brochure. British Journal of Health Psychology, 12(4), 525-541. doi:10.1348/135910706X132930

Kostur, P. (1990). Incorporating usability into document development. In Professional Communication Conference, 1990. IPCC 90. Communication Across the Sea: North American and European Practices, International (pp. 166-169). Retrieved from http://ieeexplore.ieee.org/xpls/abs_all.jsp?arnumber=111179

Krass, I., Svarstad, B. L., \& Bultman, D. (2002). Using alternative methodologies for evaluating patient medication leaflets. Patient Education and Counseling, 47(1), 29-35. doi:10.1016/S0738-3991(01)00171-9

Kusec, S., Mastilica, M., Pavlekovic, G., \& Kovacic, L. (2002). Readability of patient information on diabetes on the Croatian Web sites. Studies in health technology and informatics, 128-132. 
Lamborn, C., Luther, M., \& Fuller, R. (2013). Environmental design : incorporating a rating tool into the design of commercial buildings. ANZASCA 2004 : Contexts of architecture : proceedings of the 38th Annual Conference of the Architectural Science Association ANZASCA and the International Building Performance Simulation Association - Australasia, 203-209.

Lawrence, A. (2012). AntWordProfiler. Retrieved from http://www.nova.edu/library/dils/lessons/apa/print.htm

Lawson, S. L., \& Adamson, H. M. (1995). Informed Consent Readability: Subject Understanding of 15 Common Consent Form Phrases. IRB: Ethics and Human Research, 17(5/6), 16-19. doi:10.2307/3564569

Leaman, A., \& Bordass, B. (1999). Productivity in buildings: the "killer" variables. Building Research \& Information, 27(1), 4-19. doi:10.1080/096132199369615

Leaman, A., Thomas, L., \& Vandenberg, M. (2007). “Green”buildings: what Australian building users are saying. Ecolibrium, The Journal of Airah, 11, 2230.

Lemos, R. S. (1983). On the readability of COBOL manuals. International Journal of Man-Machine Studies, 19(4), 377-389. doi:10.1016/S0020-7373(83)80060-1

Lentz, L., \& De Jong, M. (1997). The evaluation of text quality: Expert-focused and reader-focused methods compared. Professional Communication, IEEE Transactions on, 40(3), 224-234.

Lim, A. (2010). The Readability of Information Literacy Content on Academic Library Web Sites. The Journal of Academic Librarianship, 36(4), 296-303. doi:10.1016/j.acalib.2010.05.003

Linsley, P. M., \& Lawrence, M. J. (2007). Risk reporting by the largest UK companies: readability and lack of obfuscation. Accounting, Auditing \& Accountability Journal, 20(4), 620-627. doi:10.1108/09513570710762601

Liu, C.-J., Kemper, S., \& Bovaird, J. A. (2009). Comprehension of Health-Related Written Materials by Older Adults. Educational Gerontology, 35(7), 653-668.

Lively, B. A., \& Pressey, S. L. (1923). A method for measuring the vocabulary burden of textbooks. Educational Administration and Supervision, 9(389-398), 73. 


\section{Works Sited}

Lockton, D., Harrison, D., \& Stanton, N. (2008). Making the user more efficient: design for sustainable behaviour. International Journal of Sustainable Engineering, 1(1), 3-8. doi:10.1080/19397030802131068

Lorge, I. (1944). Word lists as background for communication. The Teachers College Record, 45(8), 543-552.

Lorge, I., \& Thorndike, E. L. (1963). The Teacher's Word Book of 30000 Words. Columbia University Press. Retrieved from http://facstaff.bloomu.edu/triley/The\%20Complete\%20Collection/from $\% 20$ The\%20Teacher's\%20Word\%20Book.pdf

Loughran, T., \& McDonald, B. (2010). Measuring readability in financial text. SSRN elibrary.

Luk, A., \& Aslani, P. (2011). Tools Used to Evaluate Written Medicine and Health Information. Health Education \& Behavior, 38(4), 389-403. doi:10.1177/1090198110379576

Mackiewicz, J. (2004). What technical writing students should know about typeface personality. Journal of Technical Writing and Communication, 34(1), 113131. doi:10.2190/NMDQ-XBVH-Q79J-M749

Maginnis, G. H. (1982). Easier, faster, more reliable readability ratings. Journal of Reading, 598-599.

McCall, W. A., \& Schroeder, L. C. (1960). McCall-Crabbs Standard Test Lessons in Reading. Teachers College, Columbia University.

McLaughlin, G. H. (1968). Proposals for British readability measures. In The Third International Reading Symposium (pp. 186-208). Cassell, London.

McLaughlin, G. H. (1969). SMOG grading: A new readability formula. Journal of reading, $12(8), 639-646$.

Meara, P. M., \& Mireaplex, I. (2004). V_Size. Swansea: Lognostics.

Merriam-Webster. (2005). The Merriam-Webster Dictionary. Merriam-Webster, Incorporated.

Ministry Of Education. (2012). ALL (Adult Literacy and Life Skills Survey). Education Counts - Publications. Retrieved September 16, 2012, from http://www.educationcounts.govt.nz/publications/series/ALL 
Works Sited

Molich, R. (2010). A Critique of" How To Specify the Participant Group Size for Usability Studies: A Practitioner's Guide" by Macefield. Journal of Usability Studies, 5(3), 124-128.

Molich, R., \& Dumas, J. S. (2008). Comparative usability evaluation (CUE-4). Behaviour \& Information Technology, 27(3), 263-281.

Mollet, E., Wray, A., Fitzpatrick, T., Wray, N. R., \& Wright, M. J. (2010). Choosing the best tools for comparative analyses of texts. International Journal of Corpus Linguistics, 15(4), 429-473.

Monfared, I. G., \& Sharples, S. (2011). Occupants' perceptions and expectations of a green office building: a longitudinal case study. Architectural Science Review, 54(4), 344-355. doi:10.1080/00038628.2011.613636

Nation, I. S. P. (2006). How large a vocabulary is needed for reading and listening? Canadian Modern Language Review/La Revue canadienne des langues vivantes, 63(1), 59-82.

New Zealand Green Building Council. (2008). Green Star NZ - Office Design \& Built 2008 (including Existing Buildings). New Zealand Green Building Council.

New Zealand Green Building Council. (2012, August 5). Office - Case Studies. Certified Office Projects. Organisation Website. Retrieved May 7, 2012, from http://www.nzgbc.org.nz/index.php?option=com_content\&view=article\&id $=154 \& \mid$ temid $=276$

Ogloff, J. R. P., \& Otto, R. K. (1991). Are Research Participants Truly Informed? Readability of Informed Consent Forms Used in Research. Ethics \& Behavior, 1(4), 239-252. doi:10.1207/s15327019eb0104_2

Osso, A., Walsh, T., Gottfried, D. A., \& Simon, L. N. (1996). Sustainable building technical manual. Public Technology Inc., New York.

Oxford University Computing Services, 13 Banbury Road. (n.d.). About the British National Corpus. Text. Retrieved February 7, 2013, from http://www.natcorp.ox.ac.uk/corpus/

Pander Maat, H., \& Lentz, L. (2010). Improving the usability of patient information leaflets. Patient Education and Counseling, 80(1), 113-119.

doi:10.1016/j.pec.2009.09.030 


\section{Works Sited}

Parker, R. I., Hasbrouck, J. E., \& Weaver, L. (2001). Spanish Readability Formulas for Elementary-Level Texts: A Validation Study. Reading \& Writing Quarterly, $17(4), 307-322$.

Parkkinen, H. (2002). Testing manual usability : a task-based assessment of the usability of two manual versions. Retrieved from https://jyx.jyu.fi/dspace/handle/123456789/7282

Peters, G. A. (1984). A challenge to the safety profession. Professional Safety, 29, 46-50.

Petersen, J. E., Shunturov, V., Janda, K., Platt, G., \& Weinberger, K. (2007). Dormitory residents reduce electricity consumption when exposed to realtime visual feedback and incentives. International Journal of Sustainability in Higher Education, 8(1), 16-33.

Priestly, W. (1991). Instructional typographies using desktop publishing techniques to produce effective learning and training materials. Australian Journal of Educational Technology, 7(2), 153-163.

ReadabilityFormulas.com. (2013, January 18). The Fry Graph Readability Formula. Readability Formulas. Retrieved January 18, 2013, from http://www.readabilityformulas.com/fry-graph-readability-formula.php

Redish, J. (2000). Readability formulas have even more limitations than Klare discusses. ACM J. Comput. Doc., 24(3), 132-137. doi:10.1145/344599.344637

Reja, U., Manfreda, K. L., Hlebec, V., \& Vehovar, V. (2003). Open-ended vs. closeended questions in web questionnaires. Advances in Methodology and Statistics (Metodololvski zvezki), 19, 159-177.

Rosenbaum, S., \& Walters, R. D. (1988). Design requirements for reference documentation usability testing. In Professional Communication Conference, 1988. IPCC'88 Conference Record. On the Edge: A Pacific Rim Conference on Professional Technical Communication., International (pp. 151-155).

Retrieved from http://ieeexplore.ieee.org/xpls/abs_all.jsp?arnumber=24020

Rosenbaum, Stephanie. (1989). Usability evaluations versus usability testing: when and why? IEEE Transactions on Professional Communication, 32(4), 210-216. doi:10.1109/47.44533 
Works Sited

Rude, C. D. (1988). Format in Instruction Manuals: Applications of Existing Research. Journal of Business and Technical Communication, 2(1), 63-77. doi:10.1177/105065198800200105

Rush, R. T. (1985). Assessing Readability: Formulas and Alternatives. The Reading Teacher, 39(3), 274-283.

Satherley, P., Lawes, E., Sok, S., \& Sok, S. (2008). The Adult Literacy and Life Skills (ALL) survey: overview and international comparisons. Comparative Education Research Unit, Research Division, Ministry of Education. Retrieved from http://ala.asn.au/public/docs/report/ALL_Overview_V2.pdf

Schriver, K. (1997). Dynamics in document design: creating text for readers. Wiley New York etc. Retrieved from http://www.lavoisier.fr/livre/notice.asp?id=OKLWR2AOX2XOWE

Schriver, K. (2000). Readability formulas in the new millennium: what's the use? ACM Journal of Computer Documentation (JCD), 24(3), 138-140.

Shaw, D. (1989). Readability of documentation for end user searchers. Online Information Review, 13(1), 3-8.

Sherman, L. A. (1893). Analytics of literature: a manual for the objective study of English prose and poetry. Ginn.

Sienot, M. (1997). Pretesting Web Sites A Comparison between the Plus-Minus Method and the Think-Aloud Method for the World Wide Web. Journal of Business and Technical Communication, 11(4), 469-482.

Smith, J. E., \& Smith, N. P. (1971). Readability: A Measure of the Performance of the Communication Function of Financial Reporting. The Accounting Review, 46(3), 552-561.

Spache, G. D. (1978). Good reading for poor readers. Garrard Pub. Co.

Statistics Canada. (1997). Literacy skills for the knowledge society: further results from the International Adult Literacy Survey. Human Resources Development Canada.

Statistics New Zealand. (2002). Education. New Zealand in the OECD. Retrieved September 16, 2012, from http://www.stats.govt.nz/browse_for_stats/government_finance/central_g overnment/nz-in-the-oecd/education.aspx 


\section{Works Sited}

Survey Monkey. (2012). Survey Monkey. Palo Alto, California, USA:

SurveyMonkey.com, LLC. Retrieved from

http://www.surveymonkey.net/home/

Thorndike, E. L. (1921). The Teacher's Word Book. Teachers College Columbia University.

Thorndike, E. L. (1942). A teacher's word book of the twenty thousand words found most frequently and widely in general reading for children and young people. Teachers college, Columbia university.

Too, L., \& Too, E. G. (2011). Green buildings: a framework for social sustainability. In Proceedings of the Sixth International Conference on Construction in the 21st Century: Construction Challenges in the New Decade.

Tracy, W. (1995). Legibility and Readability. Norton, New York.

Ure, J. (1971). Lexical density and register differentiation. Applications of linguistics, 443-452.

Valeriano, L. L. (1994, December 15). Design: Loved the present. Hated the manual. Wall Street Journal, p. B1. New York, N.Y., United States.

Vallance, J. K., Taylor, L. M., \& Lavallee, C. (2008). Suitability and readability assessment of educational print resources related to physical activity: Implications and recommendations for practice. Patient Education and Counseling, 72(2), 342-349. doi:10.1016/j.pec.2008.03.010

Van Velsen, L., Van Der Geest, T., Klaassen, R., \& Steehouder, M. (2008). Usercentered evaluation of adaptive and adaptable systems: a literature review. Knowledge Engineering Review, 23(3), 261.

Van Waes, L. (2000). Thinking aloud as a method for testing the usability of websites: The influence of task variation on the evaluation of hypertext. Professional Communication, IEEE Transactions on, 43(3), 279-291.

Van Welie, M., Van Der Veer, G. C., \& Eliëns, A. (1999). Breaking down usability. In Proceedings of INTERACT (Vol. 99, pp. 613-620). Retrieved from http://reference.kfupm.edu.sa/content/b/r/breaking_down_usability_8174 3.pdf

Vogt, W. P., Gardner, D. C., \& Haeffele, L. M. (2012). When to Use What Research Design. Guilford Press. 
Works Sited

Waggoner, W. C. (1996). Studying the Readability of Consent Forms. IRB: Ethics and Human Research, 18(3), 11. doi:10.2307/3564043

Wegner, M. V., \& Girasek, D. C. (2003). How readable are child safety seat installation instructions? Pediatrics, 111(3), 588-591.

Wheildon, C. (1986). Communicating? Or Just Making Pretty Shapes. Revised Edition.

Wogalter, M. S., Godfrey, S. S., Fontenelle, G. A., Desaulniers, D. R., Rothstein, P. R., \& Laughery, K. R. (1987). Effectiveness of warnings. Human Factors: The Journal of the Human Factors and Ergonomics Society, 29(5), 599-612.

Wright, P. (1977). Presenting technical information: A survey of research findings. Instructional Science, 6(2), 93-134. doi:10.1007/BF00121082

Wright, P. (1983). Manual dexterity-a user-oriented approach to creating computer documentation. In Proceedings of the SIGCHI Conference on Human Factors in Computing Systems (pp. 11-18). New York, NY, USA: ACM. doi:10.1145/800045.801572

Yamaguchi, T. (2006). Vocabulary Frequency in University Entrance Examination in Japan. In Proceedings of 11th Conference of the Pan-Pacific Association of Applied Linguistics (pp. 318-332). Retrieved from http://paaljapan.org/resources/proceedings/PAAL11/pdfs/26.pdf

Young, S. L., \& Wogalter, M. S. (1990). Comprehension and memory of instruction manual warnings: Conspicuous print and pictorial icons. Human Factors: The Journal of the Human Factors and Ergonomics Society, 32(6), 637-649.

Zeng-Treitler, Q., Kim, H., Goryachev, S., Keselman, A., Slaughter, L., \& Smith, C. (2007). Text characteristics of clinical reports and their implications for the readability of personal health records. Studies in health technology and informatics, 129(2), 1117. 


\section{Appendices}

\subsection{Appendix - A. Information Request}

To Sir or Madam

My name is Michael Anderson; I am currently undertaking a Master of Building Science thesis at Victoria University, School of Architecture under the supervision Prof. George Baird. My objective is to analyse Building User Guides created for the New Zealand Green Building Council's, GreenStar accreditation scheme. This will involve analysing their readability and usability. My ultimate aim is to create a template for future Building User Guides to follow.

I have noted (Building Name) has been accredited with a GreenStar rating, I was enquiring if it were possible to obtain a copy of any building user guides for any GreenStar buildings that you own/manage.

The Guides will only be seen by myself and my supervisor and will be stored in a safe and secure location to ensure confidentiality. Neither they nor their creators will be identified in my thesis.

Once the analysis has been completed I shall be more than happy to provide you with the results for your particular Building User Guides. On completion of my project, you will be provided a link to the finished thesis if you wish.

Fiona Williams of the New Zealand Green Building Council has shown interest in this project and the Green Building Council could potentially use the findings of this research in the future development of Green Star. This should make it easier not only to put together a guide for a building in the future, but also ensure that building occupants are able to use the guide the way it was intended.

If you have any questions, Please do not hesitate to contact me (andersmich3@myvuw.ac.nz or Prof. George Baird (George.Baird@vuw.ac.nz). I look forward to hearing from you.

Kind Regards

Michael Anderson, BBSc

Victoria University Wellington, Architecture and Design School

Masters Student, Building Science

(027) 7788889 


\subsection{Appendix - B. Usability Survey}

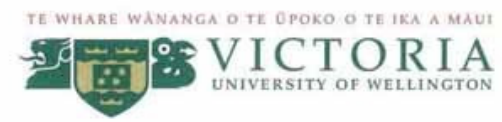

31 October 2012

To The Building User,

Research Proiect: Readability and Usability of a Building User Guide

Project Purpose and Procedure

You have been chosen to complete a survey for the above research project. It is expected to take 10 minutes to complete. The input of building users like yourself is very important if Building User Guides are to be written with you in mind.

Attached in this email is a copy of three different Building User Guides, BUG 1, BUG 2 and BUG 3. A scenario is described that requires the use of these Guides. The objective is to find the answer to a specific question. You will then be asked to describe your experience.

Responses collected will form the basis of the research project, which is to discover the usability of Building User Guides. This information will remain anonymous, and you will not be personally identified. The information will be collated and help form a portion of my thesis. When the thesis is completed, it will be publicly accessible through the library and made available on-line. The raw data from the investigation will only be seen by my supervisor and me and will be destroyed two years after the end of the project.

\section{Contact Information about the Project}

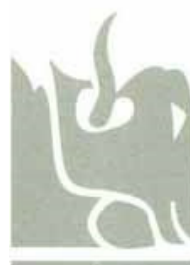

I am currently undertaking the above investigation for a Masters of Building Science at the School of Architecture, Victoria University of Wellington, under the supervision of Prof. George Baird.

If you have any questions or require further information about the project you may contact Michael Anderson at 027-778-8889 or email andersmich3@mvvuw.ac.nz or Prof. George Baird, email george.baird@vuw.ac.nz.

Consent

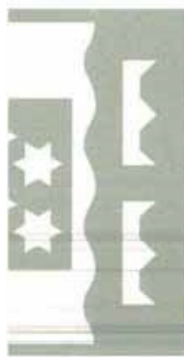

The project has been approved by the Head of School at Victoria University Wellington, School of Architecture. Your consent to participate in this project is assumed once you have completed the scenario questions and the following questionnaire.

Kind Regards,

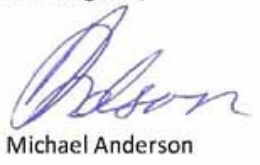


Appendices

\section{Usability of Building User Guides $<b r>$}

1. Are you male or female?

Male

Female

2. Which category below includes your age?

30 or Younger

31 or Older

3. Have you ever used a Building User Guide?

Yes
No

4. When were you born?

Between January-April

Between May-August

Between September-December 


\section{Usability of Building User Guides $<b r>$}

\section{Find the Building User Guide named BUG1.}

Situation: You are sitting in your office, have just taken off your jacket as you are getting too hot. However this is not enough and you are still too uncomfortable. You access your Building's User Guide (BUG 1), to find out what you can do about being to hot.

How does BUG1 describe what you should do if you are too hot? Please describe this below, if you can not find this information please respond with, "can not find".

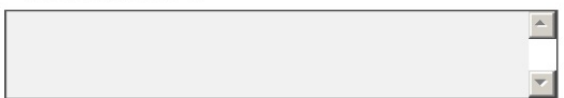

\section{Find the Building User Guide named BUG 2.}

Situation: You are sitting in your office, have just taken off your jacket as you are getting too hot. However this is not enough and you are still too uncomfortable. You access your Building's User Guide (BUG 2), to find out what you can do about being to hot.

How does BUG 2 describe what you should do if you are too hot?

Please describe this below, if you can not find this information please respond with, "can not find". 


\section{Usability of Building User Guides $<$ br $>$}

7. Find the Building User Guide named BUG 3.

Situation: You are sitting in your office, have just taken off your jacket as you are getting too hot. However this is not enough and you are still too uncomfortable. You access your Building's User Guide (BUG 3), to find out what you can do about being to hot.

How does BUG 3 describe what you should do if you are too hot?

Please describe this below, if you can not find this information please respond with, "can not find".

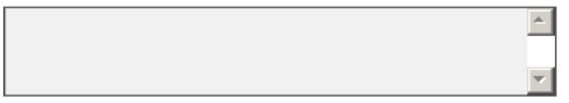




\section{Usability of Building User Guides $<b r>$}

\section{Find the Building User Guide named BUG 1.}

Situation: Your whole office has been told to reduce the amount of electricity use, you have been trying different ways over the past month, how would you find out the reduction in energy use. You access your Building's User Guide (BUG 1), to find out how much electricity has been used.

How does BUG 1 describe how you find the total amount of electricity being used? Please describe this below, if you can not find this information please respond with, "can not find".

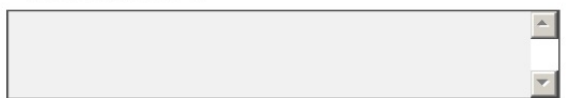

\section{Find the Building User Guide named BUG 2.}

Situation: Your whole office has been told to reduce the amount of electricity use, you have been trying different ways over the past month, how would you find out the reduction in energy use. You access your Building's User Guide (BUG 2), to find out how much electricity has been used.

How does BUG 2 describe how you find the total amount of electricity being used? Please describe this below, if you can not find this information please respond with, "can not find". 


\section{Usability of Building User Guides $<\mathrm{br}>$}

10. Find the Building User Guide named BUG 3.

Situation: Your whole office has been told to reduce the amount of electricity use, you have been trying different ways over the past month, how would you find out the reduction in energy use. You access your Building's User Guide (BUG 3), to find out how much electricity has been used.

How does BUG 3 describe how you find the total amount of electricity being used? Please describe this below, if you can not find this information please respond with, "can not find".

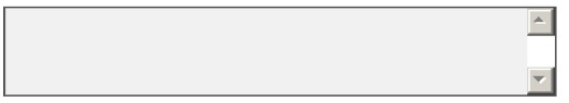




\section{Usability of Building User Guides<br>}

11. Find the Building User Guide named BUG 1.

Situation: You have noticed a slight discolouration in the water when you flush the toilet. You access your Building's User Guide (BUG 1), to find out if there is a problem or is this normal?

How does BUG 1 explain the discolouration? Should anything be done about this? Please describe this below, if you can not find this information please respond with, "can not find".

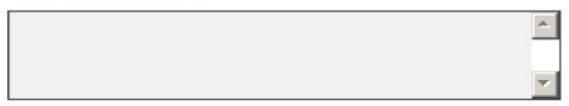

\section{Find the Building User Guide named BUG 2.}

Situation: You have noticed a slight discolouration in the water when you flush the toilet. You access your Building's User Guide (BUG 2), to find out if there is a problem or is this normal?

How does BUG 2 explain the discolouration? Should anything be done about this? Please describe this below, if you can not find this information please respond with, "can not find".

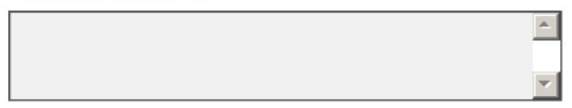

13. Find the Building User Guide named BUG 3.

Situation: You have noticed a slight discolouration in the water when you flush the toilet. You access your Building's User Guide (BUG 3), to find out if there is a problem or is this normal?

How does BUG 3 explain the discolouration? Should anything be done about this? Please describe this below, if you can not find this information please respond with, "can not find". 


\section{Usability of Building User Guides<br>}

The following questions will refer to your experience in answering the previous 3 questions

14. The three Building User Guides you were given all used different composition methods.

Please rank the three building user guides in order from 1 to 3 (1 - The easiest Building User Guide to find the information required, to 3 - The hardest Building User Guide to find the information required).

Click and drag into the appropriate order.

\begin{tabular}{|l|l|}
\hline & BUG 1 \\
\hline & BUg 2 \\
\hline & BUg 3 \\
\hline
\end{tabular}

15. What made you choose your top ranked Building User Guide in Question 4? - were there certain features of the guide that made it easy to find the information, was the information presented clearly?

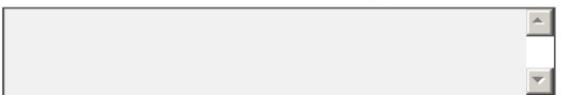

16. Why weren't the other two guides selected as being the easiest to find the information?

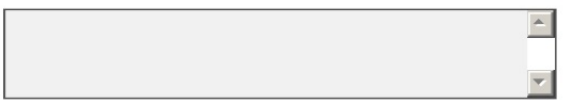

